\title{
WestVirginiaUniversity
}

THE RESEARCH REPOSITORY @ WVU

Graduate Theses, Dissertations, and Problem Reports

2012

\section{Bending, Crushing, and Connector Behavior of Pultruded Glass FRP Tubes}

Denny Wayne Dispennette

West Virginia University

Follow this and additional works at: https://researchrepository.wvu.edu/etd

\section{Recommended Citation}

Dispennette, Denny Wayne, "Bending, Crushing, and Connector Behavior of Pultruded Glass FRP Tubes" (2012). Graduate Theses, Dissertations, and Problem Reports. 4847.

https://researchrepository.wvu.edu/etd/4847

This Thesis is protected by copyright and/or related rights. It has been brought to you by the The Research Repository @ WVU with permission from the rights-holder(s). You are free to use this Thesis in any way that is permitted by the copyright and related rights legislation that applies to your use. For other uses you must obtain permission from the rights-holder(s) directly, unless additional rights are indicated by a Creative Commons license in the record and/ or on the work itself. This Thesis has been accepted for inclusion in WVU Graduate Theses, Dissertations, and Problem Reports collection by an authorized administrator of The Research Repository @ WVU. For more information, please contact researchrepository@mail.wvu.edu. 


\title{
Bending, Crushing, and Connector Behavior of Pultruded Glass FRP Tubes
}

\author{
Denny Wayne Dispennette
}

Thesis submitted to the

\author{
Benjamin M. Statler College of Engineering and Mineral Resources at \\ West Virginia University in \\ partial fulfillment of the requirements \\ for the degree of

\section{Master of Science \\ in \\ Civil Engineering}

\author{
Approved by \\ Hota V. S. GangaRao, PhD, Chair \\ P.V. Vijay, PhD \\ Mark Skidmore, PE
}

\section{Department of Civil and Environmental Engineering}

\author{
Morgantown, West Virginia
}

2012

Keywords: Glass FRP; composites; thin-wall; tube; bending stiffness; failure prediction 


\title{
ABSTRACT \\ Bending, Crushing, and Connector Behavior of Pultruded Glass FRP Tubes
}

\author{
Denny Dispennette \\ West Virginia University
}

Understanding the complex mechanics involved in the behavior of thin-walled fiber reinforced polymer (FRP) composite tubes is essential for optimal structural applications. Flexural, crushing, and connection tests were performed on large-diameter thin-walled (D/t > 20) cylindrical tubes comprised of glass FRP composites manufactured using pultrusion process. The tubes were made of either a vinyl ester or a polyurethane matrix, using high pressure resin infusion during pultrusion.

Full scale bending tests were performed with 16 and 12 inch diameters spanning 320 and 240 inches, respectively. The test data revealed that the tubes possessed superior mechanical properties, with ultimate bending strengths of 50-70 ksi and elastic moduli ranging from 5.5-6.6 Msi. The failure mode from the full scale four point bending tests was determined to be crushing on the compression face coupled with local buckling. In addition, two types of connection tests were executed: a transverse bolt test and a washer test. The transverse bolt test exhibited maximum loads of 18-25 kips. The washer data ranged from 14-27 kips with failure occurring as local cracking. Coupon tests under tension, flexure, and compression were conducted after cutting them from full size tubes, resulting in maximum tensile stresses from 95-107 ksi. Also conducted on full scale specimens were four-point bending fatigue tests up to 200 cycles at $40 \%$ of the ultimate static bending stress and further tested to failure under static load conditions. The results revealed that polyurethane outperformed vinyl ester. The vinyl ester was shown to outperform in the transverse bolt test because of vinyl ester's higher strength and stiffness under localized load conditions.

Investigation of the four-point bending results revealed a bilinear load versus strain response during loading. The bilinear response is shown to be caused by cross section deformation, aka, ovalization. This deformation was captured through video footage of the experiment and confirmed by finite element analysis. Application of classical lamination theory and finite element modeling was performed and found to under-predict the full scale bending stiffness in relation to experimental results. A failure prediction technique for the full scale four point bending is proposed that includes local buckling effect. A more direct approach proposed herein modifies the typical bending stress calculations by accounting for a local compression stress. Good agreement is found between the proposed technique and experimental data with errors ranging from 4-8\%. This proposed technique is compared with the standard bending stress formulation and is shown to be more accurate, thus confirming the proposed approach's ability to account for the local effects. 


\section{ACKNOWLEDGEMENTS}

I would like to first acknowledge my Lord and Savior Jesus Christ for extending to me great mercy and grace that I am able to know Him and attempt to bring glory to Him through this work. For laying down His life for me and redeeming me I am eternally grateful.

I also must thank my research advisor, Dr. Hota GangaRao who invited me to come to WVU to pursue a Master’s degree program. Over the past two years, Dr. Hota has been available at all times, and he has pushed me and instructed me with much wisdom and encouragement. I will always be thankful for him being so patient and helpful with me.

I would like to thank Dr. Liang for guiding me through my previous research endeavor which is not mentioned in this work, but which helped form the foundation for my research skills. Also, I would like to thank Dr. Vijay for serving on my review committee.

I am also grateful for Dustin Troutman, director of product development at Creative Pultrusions, who supported me with information and feedback regarding results.

I also thank Mark Skidmore for guiding me through all the mechanical testing and Jerry Nestor for preparing testing fixtures and operating the equipment. Because the tubes tested were so large and so many, I have to thank Bill Causey, Ken Donald, and Praveen Majjigapu for providing assistance with testing. I am also grateful for David Dittenber for lending me books, technical report advice, and for thinking through ideas with me.

Finally, I am appreciative of my family and friends, especially my local Church family for being so encouraging during this time.

Financial support for this work has been provided by Creative Pultrusions, Inc. 


\section{TABLE OF CONTENTS}

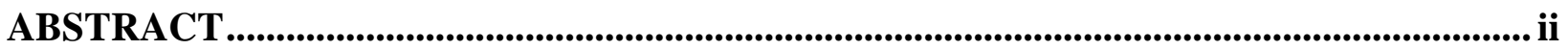

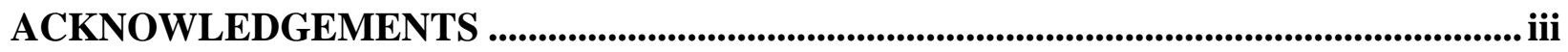

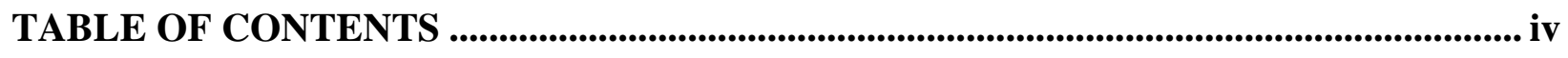

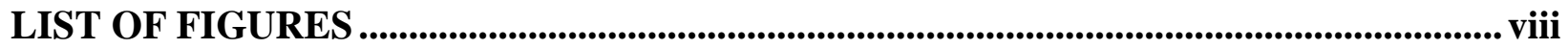

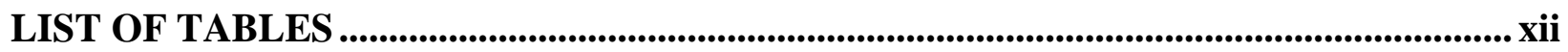

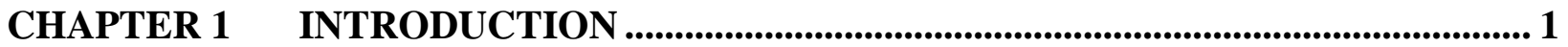

$1.1 \quad$ Background ….......................................................................................................................... 1

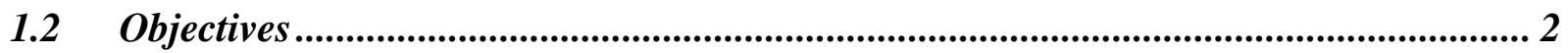

1.3 Organization of Thesis ........................................................................................................ 3

CHAPTER 2 LITERATURE REVIEW ..................................................................... 5

2.1 Bending Behavior of Thin-Wall Tubes ................................................................ 5

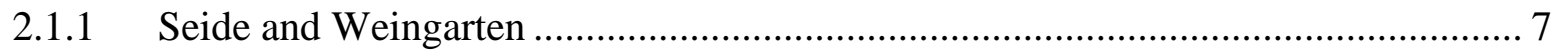

2.2 Plastic Bending Collapse of Metal Cylindrical Sections .......................................... 8

2.3 Prebuckling Response of Cylindrical Composite Tubes.......................................... 11

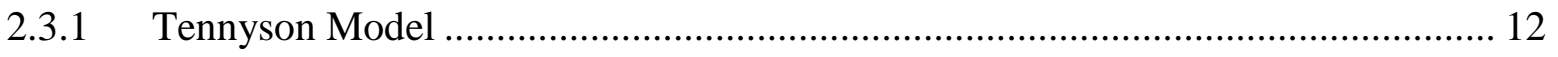

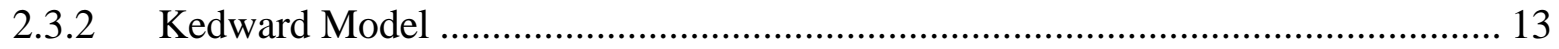

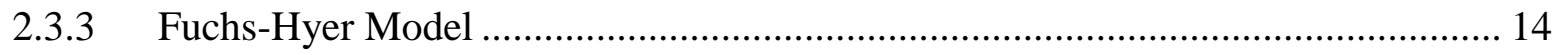

2.3.4 Ibrahim-Polyzois Model ........................................................................ 16 
2.4 Bending Stiffness Prediction of Composite Tubes............................................................ 20

2.4.1 Stiffness Replacement Comparison ........................................................................ 21

2.4.2 Shadmehri-Derisi-Hoa Stiffness Model................................................................ 24

2.4.3 Silvestre Generalized Beam Theory …………………………………………... 27

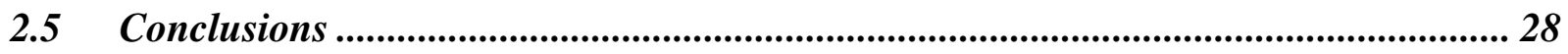

CHAPTER 3 TESTING OF TUBE MEMBERS …............................................................... 30

3.1 Materials Tested .......................................................................................................................... 30

$3.2 \quad$ Instrumentation.............................................................................................................. 31

$3.3 \quad$ Four-Point Bending .............................................................................................................. 32

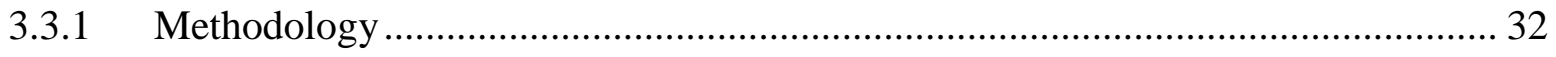

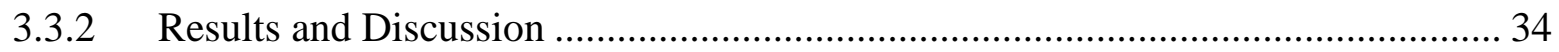

3.4 Crush Testing .................................................................................................................... 50

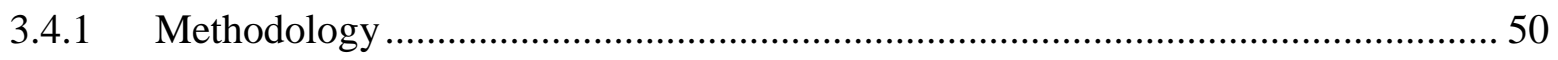

3.4.2 Results and Discussion ............................................................................... 52

3.5 Connection Testing A.......................................................................................................... 61

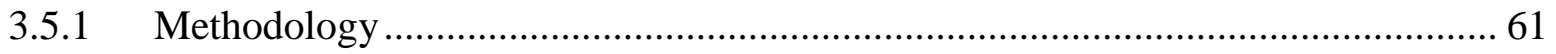

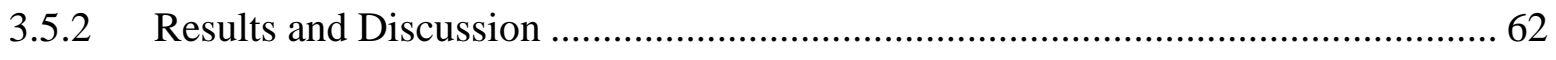

3.6 Connection Testing B........................................................................................................ 66

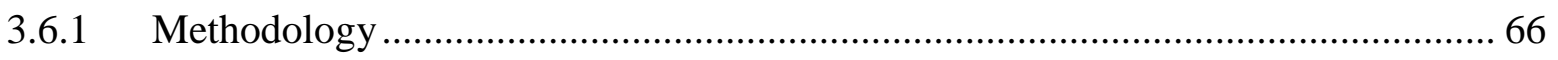

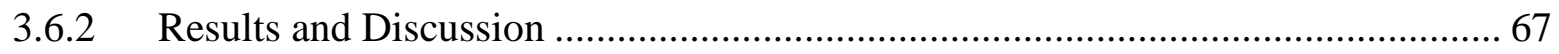


3.7 Coupon Tests ................................................................................................................... 70

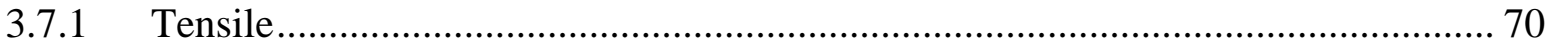

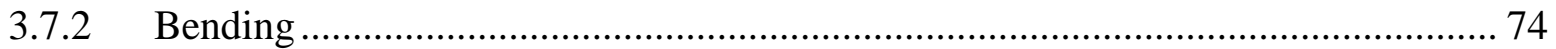

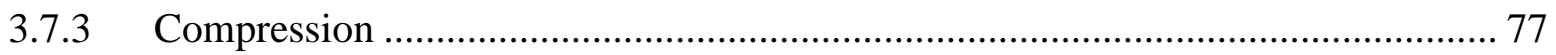

3.8 Four-Point Bending Fatigue ........................................................................................ 80

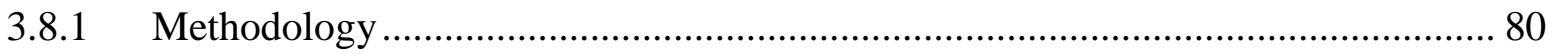

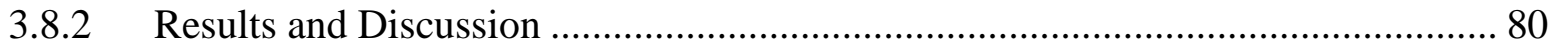

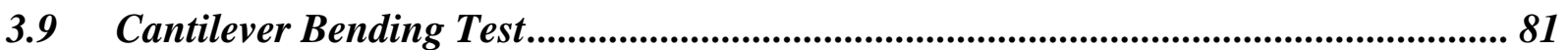

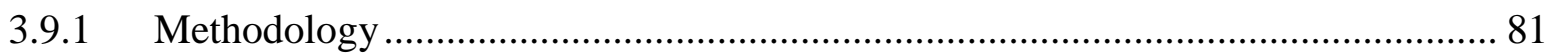

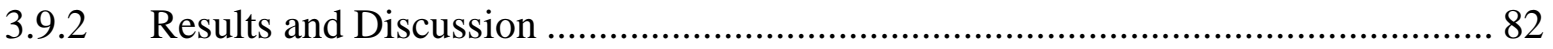

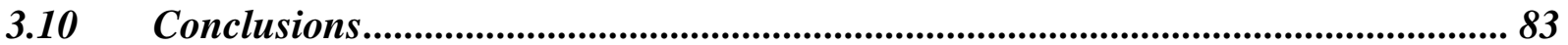

CHAPTER 4 BENDING BEHAVIOR PREDICTION OF GFRP TUBES....................... 86

4.1 Introduction and Scope.................................................................................................. 86

4.2 Analysis Methodology …................................................................................................. 86

4.3 Bending Stiffness Replacement - Laminated Plate Approach ....................................... 95

4.4 Failure Load Prediction............................................................................................................. 98

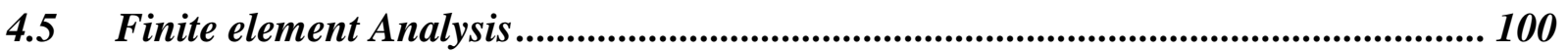

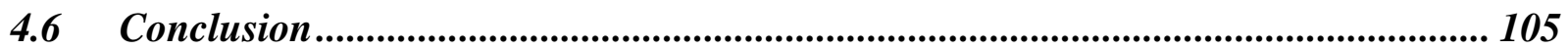

CHAPTER 5 CONCLUSIONS AND RECOMMENDATIONS ...................................... 108

5.1 Mechanical Testing of Glass FRP Tubes................................................................. 108 
5.1.1 Four-Point Bending Response ............................................................... 108

5.1.2 Connection and Coupon Response ............................................................. 109

5.1.3 Comparison of Polyurethane vs. Vinyl Ester................................................... 110

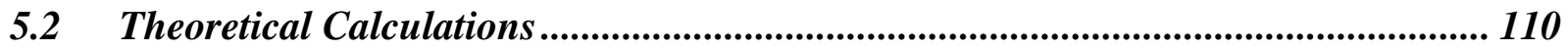

5.2.1 Theoretical vs. Experimental Data Comparison ........................................... 110

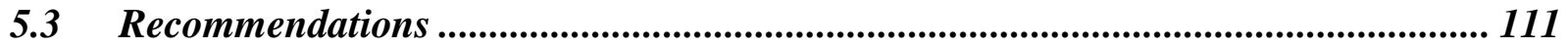

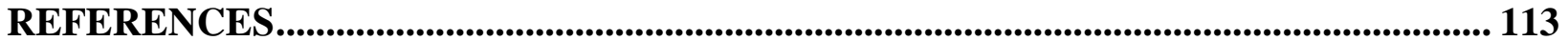




\section{LIST OF FIGURES}

Figure 2-1 Bifurcation Point for a Beam in Bending (Brazier, 1927) ..................................... 6

Figure 2-2 Curves showing moment-curvature characteristics of celluloid tubes (Brazier, 1927) 7

Figure 2-3 Ovalization of Tube due to Bending (Poonaya, Teeboonma, \& Thinvongpituk, 2009)

Figure 2-4 Buckling Prediction Comparison (Fuchs \& Hyer, 1996) ........................................ 16

Figure 2-5 Load-Deflection Relationship (Exp vs. FE) for Full-Scale Specimens (Ibrahim,

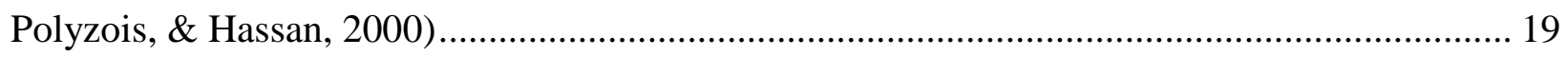

Figure 2-6 Load-Ovalization Relationship (Exp vs. FE) for Full-Scale Specimens (Ibrahim,

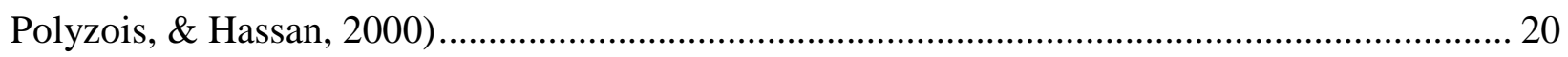

Figure 2-7 Plate Section of a Composite Tube Laminate (Chan \& Demirhan, 2000)................ 22

Figure 2-8 Shell Section of a Composite Tube Laminate...................................................... 23

Figure 2-9 Applied Load vs. Axial Strain (mid-length bottom) of Tube 1 (Shadmehri, Derisi, \&

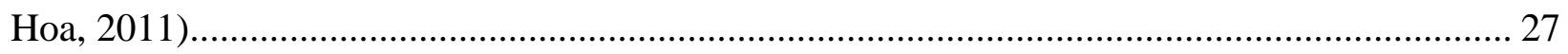

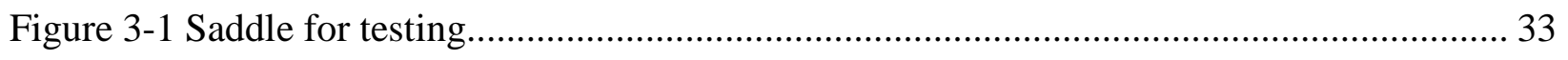

Figure 3-2 Four-Point Bending Test (Section PU-16x0.5) .................................................. 33

Figure 3-3 Strain Gage Diagram for Four-Point Bending Tests ............................................ 34

Figure 3-4 Failed Four-Point Bending Sample - Section PU-16x0.5 …................................... 36

Figure 3-5 Stress vs. Strain for Sample 2 of Section PU-16x0.5 .......................................... 37

Figure 3-6 Stress vs. Strain for Sample 6 - Section PU-16x0.5.............................................. 39

Figure 3-7 Stress vs. Strain for Sample 1 of Section VE-16x0.5 ......................................... 41

Figure 3-8 Stress vs. Strain for Sample 6 - Section VE-16x0.5 ........................................... 43

Figure 3-9 Failed Four-Point Bending Failure - Section PU-12x0.5..................................... 44 
Figure 3-10 Stress vs. Strain for Sample 2 of Section PU-12x0.5 ............................................... 45

Figure 3-11 Stress vs. Strain for Sample 6 - Section PU-12x0.5 ................................................... 47

Figure 3-12 Failed Four-Point Bending Sample - Section PU-12x0.375 ..................................... 49

Figure 3-13 Stress vs. Strain for Sample 4 - Section PU-12x0.375................................................ 50

Figure 3-14 Crush Test Being Performed - Section PU-12x0.5 ................................................... 52

Figure 3-15 Crush Test Load vs. Deflection Response - Section PU-16x0.5................................ 54

Figure 3-16 Crush Test at Failure Load - Section PU-16x0.5 ...................................................... 55

Figure 3-17 Crust Test after Load was Released - Section PU-16x0.5 ………………................. 55

Figure 3-18 Crush Test Load vs. Deflection Response - Section VE-16x0.5 ………................... 57

Figure 3-19 Crush Test Load vs. Deflection Response - Section PU-12x0.5................................ 58

Figure 3-20 Crush Test Load vs. Deflection Response - Section PU-12x0.375............................ 60

Figure 3-21 Crust Test at Failure Load - Section PU-12x0.375 ................................................... 61

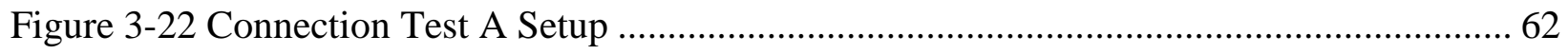

Figure 3-23 Connection Testing A at Failure - Section PU-16x0.5 ……................................ 63

Figure 3-24 Load/Deflection Plot of Connection Test A - Section PU-16x0.5............................. 64

Figure 3-25 Load/Deflection Plot of Connection Test A - Section VE-16x0.5............................. 65

Figure 3-26 Load/Deflection Plot of Connection Test A - Section PU-12x0.5 .............................. 66

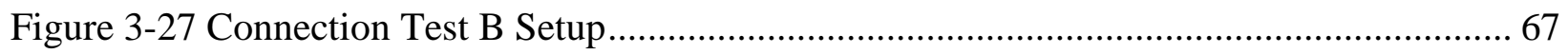

Figure 3-28 Connection Test B Sample with 6-in Washer at 21 kip (failure) Load - Section PU-

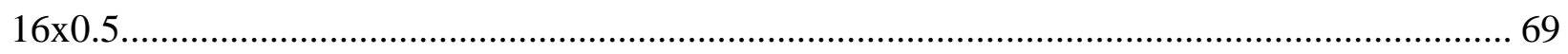

Figure 3-29 Connection Test B Sample with 4-in Washer during Loading - Section PU-12x0.5 69

Figure 3-30 Tension Test Sample in Instron Machine................................................................. 71

Figure 3-31 Failed Samples from Tensile Coupon Test ........................................................ 73 
Figure 3-32 Coupon Tension Failed with Grips (Sample 16-4)

Figure 3-33 Load/Deflection Response for Coupon Bending Tests - Section PU-12x0.375 ....... 76

Figure 3-34 Typical Failure for Coupon Bending Tests - Section PU-12x0.375 ...................... 77

Figure 3-35 Typical Failure for Coupon Compression Tests - Section PU-12x0.375................ 79

Figure 3-36 Cantilever Bending Test Setup................................................................... 82

Figure 4-1 Change in Stiffness Curve from Four-Point Bend Sample 6 (Tension Face) - Section

VE-16x0.5 87

Figure 4-2 Change in Stiffness Curve from Four-Point Bend Sample 6 (Compression Face) Section VE-16x0.5. 88

Figure 4-3 Change in Stiffness Curve from Four-Point Bend Sample 5 (Compression Face) Section PU-16x0.5. 89

Figure 4-4 Change in Stiffness Curve from Four-Point Bend Sample 5 (Tension Face) - Section PU-16x0.5 89

Figure 4-5 Change in Stiffness Curve from Four-Point Bend Sample 2 (Compression Face) -

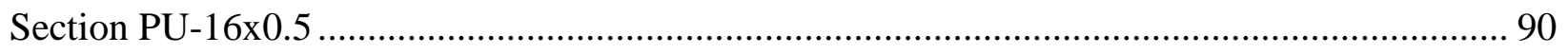

Figure 4-6 Change in Stiffness Curve from Four-Point Bend Sample 3 (Compression Face) -

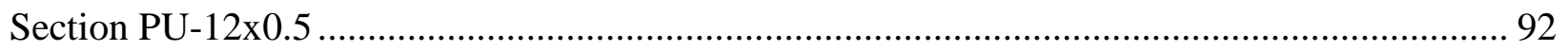

Figure 4-7 Change in Stiffness Curve from Four-Point Bend Sample 2 (Tension Face) - Section PU-12x0.5 92

Figure 4-8 Change in Stiffness Curve from Four-Point Bend Sample 4 (Compression Face) -

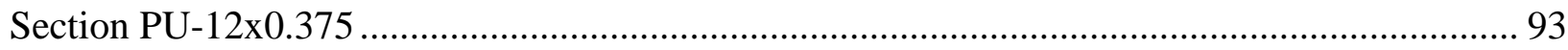

Figure 4-9 Change in Stiffness Curve from Four-Point Bend Sample 4 (Tension Face) - Section PU-12x0.375 94 
Figure 4-10 Discretized Tube Modeled in ANSYS with External Loads and Boundary Conditions 101

Figure 4-11 Load-Deflection Curve Comparison for Exp vs. FEM vs. CLT - Section PU-16x0.5 102

Figure 4-12 Load-Deflection Curve Comparison for Exp vs. FEM vs. CLT - Section VE-16x0.5 102

Figure 4-13 Load-Deflection Curve Comparison for Exp vs. FEM vs. CLT - Section PU-12x0.5 103

Figure 4-14 Load-Deflection Curve Comparison for Exp vs. FEM vs. CLT - Section PU$12 \times 0.375$ 103

Figure 4-15 Ovalization Comparison of Finite Results vs. Experimental Results 105 


\section{LIST OF TABLES}

Table 2-1 Comparison of Ultimate Moments Predicted form Simplified Model and Test Results

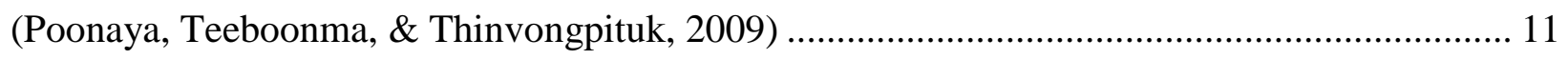

Table 2-2 Curvature Effect on Bending Stiffness of Composite Tube with Ply Sequence of

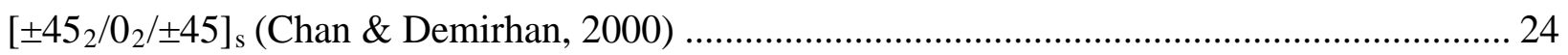

Table 2-3 Comparison of the Equivalent Bending Stiffness of the Composite Tube <EI>

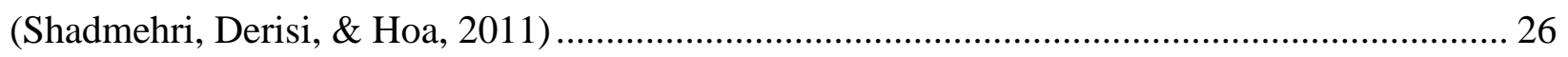

Table 3-1 Material Sections Tested and Reported on ........................................................ 31

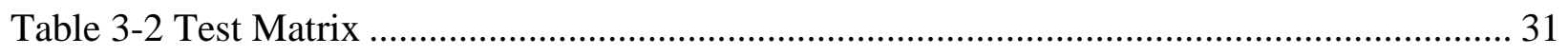

Table 3-3 Four-Point Bending Results - Section PU-16x0.5............................................... 36

Table 3-4 Four-Point Bending Results for Post-Fatigue Sample 6 - Section PU-16x0.5............ 38

Table 3-5 Four-Point Bending Results - Section VE-16x0.5 …........................................ 40

Table 3-6 Four-Point Bending Results for Post-Fatigue Sample 6 - Section VE-16x0.5............ 42

Table 3-7 Four-Point Bending Results - Section PU-12x0.5................................................ 44

Table 3-8 Four-Point Bending Results for Post-Fatigued Samples ........................................ 46

Table 3-9 Four-Point Bending Results - Section PU-12x0.375........................................... 48

Table 3-10 Crust Test Results - Section PU-16x0.5 ........................................................ 53

Table 3-11 Crush Test Results - Section VE-16x0.5........................................................ 56

Table 3-12 Crush Test Results - Section PU-12x0.5 ......................................................... 58

Table 3-13 Crush Test Results - Section PU-12x0.375 .................................................... 59

Table 3-14 Connection Test B Results - All Sections ....................................................... 68

Table 3-15 Coupon Static Tension Test Results - Section PU-16x0.5 .................................... 71 
Table 3-16 Coupon Static Tension Test Results - Section PU-12x0.5 .................................... 72

Table 3-17 Coupon Static Tension Test Results - Section PU-12x0.375 ................................ 72

Table 3-18 Coupon Bending Test Results - Section PU-12x0.375 ........................................ 76

Table 3-19 Coupon Compression Test Results - Section PU-12x0.375 ................................... 78

Table 3-20 Four-Point Bending Fatigue Results .......................................................... 81

Table 3-21 Cantilever Bending Test Results - Section PU-12x0.375 ..................................... 82

Table 4-1 Summary of Stiffness Change Points ................................................................. 95

Table 4-2 Raw Material Properties used in Tube Sections.................................................. 96

Table 4-3 Bending Stiffness Comparison, CLT vs. Experiment ............................................ 97

Table 4-4 Failure Load Prediction Compared to Experiment.................................................. 99 


\section{CHAPTER 1 INTRODUCTION}

\subsection{Background}

Over the past several years, fiber reinforced polymer (FRP) composites (two or more constituents) have been proven to be a superior material when it comes to the aerospace, automobile, and marine industries. An FRP composite is a material in which fibers and resin bond together to form one solid material combining the properties of the constituent materials. Fibers, typically glass or carbon, are the load carriers while the resin holds the fibers together and transfers loads to the fiber network. The popularity of composites is due to a variety of reasons including but not limited to: high strength to weight ratio, high energy absorption, and corrosion resistance. For implementation into civil infrastructure, the ability of FRP to resist corrosion and in turn have a long service life is paramount. Composite materials are being applied in a limited manner as bridge decks, electrical transmission poles, and even bridge beams (Liang \& GangaRao, 2004). Cost per unit performance (i.e., bending load or deflection) of FRP composites has decreased. As they have become more common, well established mass manufacturing methods have been improved. Therefore, FRP composites are becoming viable replacements for steel, concrete, or timber in many areas of civil application.

Composite materials are manufactured by different methods one of which is called pultrusion. Pultrusion is a continuous composite manufacturing process that pulls fibers through a resin bath. It is a low cost continuous mass manufacturing process because it quickly converts fibers and resin into a finished composite (Barbero, 2011). Also, most pultrusion lines can run 24 hours a day. Appealing to civil applications, pultrusion offers the ability to produce many 
different shapes of constant cross section with unlimited lengths. These shapes, for example, are square/rectangular tubes, hollow cylindrical sections, and wide flanged beams.

As FRP sections come in with different dimensions, fiber architectures, and fiber-resin combinations; hence their strength and stiffness limits must be tested experimentally. Large open sections with relatively small wall thicknesses are known to fail under instability before reaching their full strength capacity. Recognizing that engineers must be careful when designing and predicting buckling behavior for isotropic materials, the problem becomes even more complex in anisotropic materials. To properly design an anisotropic material based structural component, experimental testing is absolutely necessary, especially for large diameter thin walled sections.

FRP composite members, such as cylindrical tubes, are not as well understood as their equivalent metal sections. Because FRP composites have proven to be an advantageous option when compared to conventional materials (e.g. steel) due to their higher strength to weight ratio and corrosion resistance, extensive mechanical testing is necessary to exploit these benefits. The bending stiffness and ultimate strength of composite tubes will be utilized extensively provided they have designer friendly prediction equations for strength, stability, and stiffness. Understanding crushing strength and connection behavior are essential to allowing for composites to be used in a plethora of applications. Also the comparison of fiber-resin systems is important in terms of their volume percent and determining the optimal fiber architecture and geometric cross section.

\subsection{Objectives}

The objectives of this study for large diameter thin walled orthotropic tubular sections are: 
- To review current theories for characterizing the failure mode of thin walled glass FRP (GFRP) tubes in bending

- To determine bending, lateral crushing, and connection behavior in terms of stress versus strain, deflection limits, crushing limits, and joint integrity of glass FRP tubes

- To evaluate abilities of current prediction theories to match experimental results

\subsection{Organization of Thesis}

Chapter 2 provides a review of published literature on topics related to the experimental objectives of this research. A brief review of the bending behavior of thin-walled structures is presented. Then, aspects of composite materials are discussed, particularly bending behavior, prebuckling response, and stiffness prediction of composite tubes.

Chapter 3 introduces the sections to be mechanically tested, and describes the differences of each section. The experimental methodologies are covered in detail, and the results are reported and analyzed. The tests conducted include full scale four-point bending tests, crush tests, two types of connection tests, a variety of coupon tests, full scale four-point bending fatigue, and a cantilever bending test of glass FRP composites. Direct comparisons are drawn between two different resin systems.

Chapter 4 discusses in detail the bending behavior of the tubes tested in four-point bending from Chapter 3. Further analysis reveals the change in bending stiffness throughout loading. A standard prediction method is presented and the results are compared to experiment and finite element analysis. Also presented is a method for determining the ultimate strength of the tubes in bending. Comparisons to experimental results are presented. 
Chapter 5 summarizes the results found in the previous chapters, draws general conclusions, and provides recommendations for further work in this area of research. 


\section{CHAPTER 2 LITERATURE REVIEW}

\subsection{Bending Behavior of Thin-Wall Tubes}

The study of the behavior of thin walled tubes of isotropic materials under bending has been a concern for many years. Brazier's work (1927) included higher order terms to account for elastic stability and also to accurately describe the flexure problem for hollow specimens with high moments of inertia. Brazier illustrated the principle of elastic stability of thin circular tubes as a one dimensional cross section of a beam of small diameter $(\mathrm{l} / \mathrm{d}=\infty)$. In this case, the traditional methods of ignoring higher order terms in the bending problem, thus forming a linear equation will not be accurate. Brazier (1927) notes, that in the case of pure bending, a maximum moment is reached at a bifurcation point at which collapse is imminent. This is shown in Figure 2-1, where point $\mathrm{A}$ is the point of maximum moment. After this maximum moment the beam can no longer resist higher moments and must collapse. 


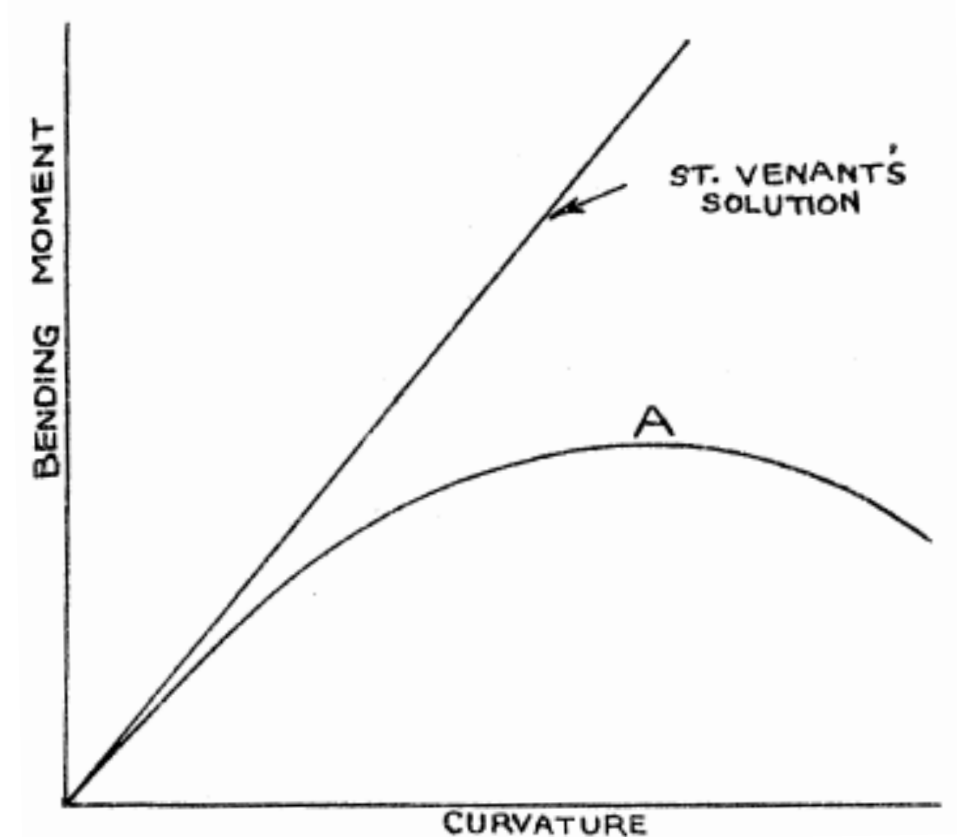

Figure 2-1 Bifurcation Point for a Beam in Bending (Brazier, 1927)

Introducing second order terms into St. Venant's principle, Brazier derived the equation curvature at which the maximum moment occurs for a thin cylindrical shell

$$
c^{2}=\frac{2}{9} \frac{t}{R^{4}\left(1-\sigma^{2}\right)}
$$

at which point the maximum moment is

$$
\bar{M}=\frac{2 \sqrt{2}}{9} \frac{E \pi R t^{2}}{\sqrt{1-\sigma^{2}}}
$$

In Equations 2-1 and 2-2, $\mathrm{c}$ is the curvature, $\mathrm{R}$ is the radius, $\mathrm{t}$ is the wall thickness, $\sigma$ is the allowable stress, and $\mathrm{E}$ is Young's modulus. Once the critical moment, $\bar{M}$, is reached, the element of the tube in compression begins to deform leading to buckling. Brazier experimentally 
confirmed his results in Figure 2-2 for long thin tubular beams made of celluloid and subjected to pure end moments.

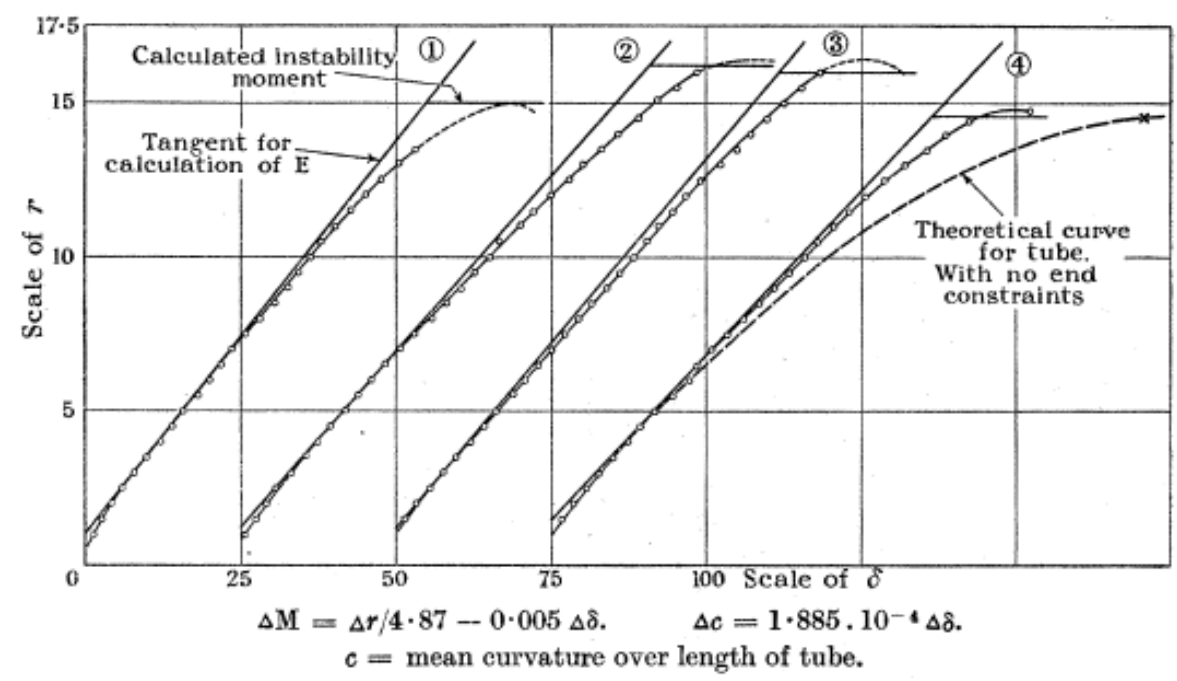

Figure 2-2 Curves showing moment-curvature characteristics of celluloid tubes (Brazier, 1927)

His theory matches well with the experimental data and has served as the foundation for determining the mechanical behavior in thin-walled structures. It is important to remember when looking at Brazier's formulation that thin cylindrical tubes in consideration are infinitely long so that end effects are not taken into account.

\subsubsection{Seide and Weingarten}

The relationship of critical bending stress and critical compressive stress was also studied by Seide and Weingarten (1964). For several years prior to this study, the theoretical maximum bending stress for buckling of a circular cylindrical shell was generally accepted as 1.3 times the compressive buckling stress. Seide and Weingarten (1964) applied theoretical calculations using Batdorf's modification of Donnell's equation for determining buckling loads of circular cylinders. They considered combined compression and bending loading for shells with varying 
$\mathrm{R} / \mathrm{t}$ ratios and wave length. The results showed a ratio of critical bending stress to critical compressive stress that varied widely with respect to R/t ratio. However, by minimizing the wave length parameter the ratio of critical bending stress for buckling to compression buckling stress is 1 for all practical purposes in metals (Seide \& Weingarten, 1964). Therefore the critical buckling stress in bending is found from Equation 2-3

$$
\sigma_{\text {crit }}=\frac{-2 \sqrt{D_{11} E_{0} t}}{\rho t}
$$

where $t$ is the wall thickness, $E_{0}$ is the Young's modulus in the circumferential direction, and $\rho$ is the local radius of the cylinder (from center to top of cylinder). This equation is for orthotropic materials. Local buckling occurs when the maximum compressive stress reaches this value (Seide \& Weingarten, 1964).

\subsection{Plastic Bending Collapse of Metal Cylindrical Sections}

There have been many efforts to analyze the collapse behavior of thin walled circular tubes in bending. Poonaya et al. (2009) presents a closed form solution for predicting the collapse behavior for steel tubes subjected to pure bending. The collapse is divided into three phases: 1) elastic phase, 2) ovalization phase, 3) structural collapse. The elastic phase was described as the stage in which the material exhibits a linear stress-strain behavior. In the second phase (nonlinear stress-strain), the cross section of the tube begins to deform into an oval shape, or ovalize. It is assumed that the bending moment in this phase is constant and reached its ultimate value (Poonaya, Teeboonma, \& Thinvongpituk, 2009). The third phase is explained as the stage where the load carrying capacity decreases rapidly due to local or global collapse in the section. Collapse in this phase results in plastic hinge lines forming. 
Understanding the behavior of the tubes in the second phase is paramount to predicting the ultimate moment. Poonaya et al. (2009) reviewed two straightforward methods for determining this ultimate bending moment as well as present their own method. The first method for finding the ultimate bending moment, derived by Ueda (1985), is obtained by integrating the stress over the cross section. His ultimate bending moment is:

$$
M_{u}=\sigma_{y} Z_{p}+\left(\sigma_{u}-\sigma_{y}\right) Z_{e}
$$

where $\sigma_{\mathrm{y}}$ is the yield stress, $\sigma_{\mathrm{u}}$ is the ultimate tensile stress, $\mathrm{Z}_{\mathrm{p}}=(4 / 3)\left(\mathrm{R}_{\mathrm{o}}{ }^{3}-\mathrm{R}_{\mathrm{i}}{ }^{3}\right)$ is the plastic bending section modulus, $\mathrm{Z}_{\mathrm{e}}=\left(\pi / 4 \mathrm{R}_{0}\right)\left(\mathrm{R}_{0}{ }^{4}-\mathrm{R}_{\mathrm{i}}{ }^{4}\right)$ is the elastic bending section modulus, $\mathrm{R}_{\mathrm{o}}$ is the outer radius of tube, and $\mathrm{R}_{\mathrm{i}}$ is the inner radius of tube.

By approximating the ovalized section as an elliptical shape, Elchalakani (2002) produced an ultimate bending moment expression. From experimentation, it was displayed that ovalization started once the major axis reached 1.10D and the minor axis reached 0.9D. Their resulting expression is shown in the following equation:

$$
\begin{gathered}
M_{u}=S_{\text {ovalized }} \sigma_{y}=\frac{4}{3}\left(R_{v}^{2} R_{h}-R_{v i}^{2} R_{h i}\right) \sigma_{y} \\
R_{h}=\frac{D_{h}}{2}=.55 D_{0} \\
R_{v}=\frac{D_{v}}{2}=.45 D_{0}
\end{gathered}
$$

where $S_{\text {ovalized }}$ is the plastic section modulus of an ovalized tube, $\sigma_{\mathrm{y}}$ is the measured yield stress of an ovalized tube. $\mathrm{R}_{\mathrm{h}}$ and $\mathrm{R}_{\mathrm{v}}$ are the external horizontal and vertical radii of an ovalized tube, respectively. The internal horizontal and vertical radii are $R_{h i}=\left(R_{h-} t\right)$ and $R_{v i}=\left(R_{v}-t\right)$, respectively, and $t$ is the thickness of tube (Elchalakani, Zhao, \& Grzebieta, 2002). 
Poonaya et al (2009) developed the two models described above into one method. This ovalization model is shown in Figure 2-3.

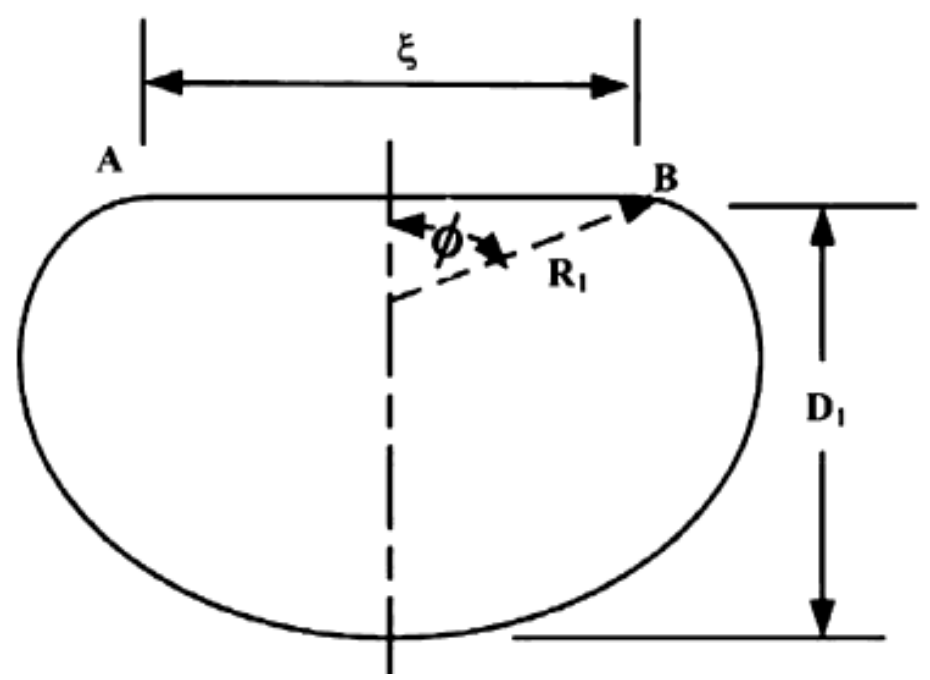

Figure 2-3 Ovalization of Tube due to Bending (Poonaya, Teeboonma, \& Thinvongpituk, 2009)

Using the radius of curvature $\mathrm{R}_{1}$, formed at the flattening ends of the cross section, and assuming constant bending moment throughout the ovalization phase, and ignoring the rolling hinge of the cross section, the ultimate moment of an ovalized tube can be found by integrating the stress over the cross section. Assuming the geometry of the cross section to be inextensible, the bending moment is expressed as

$$
M=\int_{A} \sigma z d A
$$

where $\mathrm{dA}=\mathrm{t}$ ds is the cross-sectional area of an element of the tube, $\mathrm{t}$ is the thickness of the tube, $\mathrm{z}$ is the distance from the neutral axis of a sectional ovalization to the circumferential area and ds is the length of the circumferential cross section. After integrating Equation 2-6, and then minimizing with respect to the deformation angle, $\varphi$, the ultimate bending moment is finally obtained as 


$$
M_{u}=3 \sigma_{0} t R^{2}
$$

where $\sigma_{0}$ is the ultimate stress of material, $\mathrm{t}$ is the thickness of the tube, and $\mathrm{R}$ is the outside radius of the tube.

Poonaya et al. (2009) sought to verify this formula by comparison with experimental tests. Using steel specimens with known material properties and varying D/t ratios (21 to 43), they set up an experiment that applied end moments to the specimen. The authors then compared the results of their method, Ueda's method, and Elchalakani's method to the experimental results. As shown in Table 2-1, the ultimate moment predicted by Poonaya et al. to correlate well to experiment with slight overestimations for specimens with high D/t ratios.

Table 2-1 Comparison of Ultimate Moments Predicted form Simplified Model and Test Results (Poonaya, Teeboonma, \& Thinvongpituk, 2009)

\begin{tabular}{|c|c|c|c|c|c|c|c|c|}
\hline \multirow[t]{2}{*}{$\begin{array}{l}\text { Specimen } \\
\text { no. }\end{array}$} & \multirow[t]{2}{*}{$D / t$} & \multirow{2}{*}{$\begin{array}{l}\text { Experimental ultimate } \\
\text { moment } \\
M_{E x p}(\mathrm{kN} \mathrm{m})\end{array}$} & \multicolumn{2}{|c|}{$\begin{array}{l}\text { Predicted ultimate moment, } \\
\text { Eq. (8) }\end{array}$} & \multicolumn{2}{|c|}{$\begin{array}{l}\text { Elchalakani's ultimate moment, } \\
\text { Eq. (4) }\end{array}$} & \multicolumn{2}{|c|}{$\begin{array}{l}\text { Ueda's ultimate moment, } \\
\text { Eq. (3) }\end{array}$} \\
\hline & & & $\mathrm{M}_{u}(\mathrm{kNm})$ & $M_{u} / M_{E x p}$ & $M_{u}(\mathrm{kN} \mathrm{m})$ & $M_{u} / M_{E x p}$ & $\begin{array}{l}M_{u} \\
(\mathrm{kN} \mathrm{m})\end{array}$ & $M_{u} / M_{E x p}$ \\
\hline UB1 & 21.16 & 3.20 & 2.83 & 0.88 & 3.02 & 0.94 & 2.93 & 0.92 \\
\hline UB2 & 25.65 & 1.85 & 1.87 & 1.01 & 2.12 & 1.15 & 2.10 & 1.13 \\
\hline UB3 & 26.03 & 1.12 & 1.05 & 0.94 & 1.18 & 1.05 & 1.17 & 1.04 \\
\hline UBA & 32.97 & 1.76 & 1.76 & 1.00 & 2.09 & 1.19 & 2.11 & 1.20 \\
\hline UB5 & 36.59 & 1.09 & 1.22 & 1.11 & 1.13 & 1.04 & 1.34 & 1.23 \\
\hline UB6 & 42.57 & 2.38 & 2.76 & 1.16 & 2.76 & 1.16 & 2.84 & 1.19 \\
\hline \multirow{2}{*}{\multicolumn{2}{|c|}{$\begin{array}{l}\text { Average } \\
\text { Coefficient of variation }\end{array}$}} & & & 1.017 & & 1.088 & & 1.118 \\
\hline & & & & 0.093 & & 0.080 & & 0.096 \\
\hline
\end{tabular}

Poonaya et al.'s work presents a straightforward method for determining when ovalization begins to occur in an isotropic cylindrical shell. The relation of this work to laminated composites will be discussed later (Section 2.5) in this chapter.

\subsection{Prebuckling Response of Cylindrical Composite Tubes}

Ovalization describes the deformation of cylindrical cross sections subject to bending, and is most notable in thin-walled structures. As described by Poonaya (2009) for isotropic materials 
under bending, a cylinder goes through three phases: 1) linear elastic phase, 2) ovalization or prebuckling state, and 3) a structural collapse phase. These three phases also occur in FRP composite tubes. However due to the fibers typically used in composite materials, there is little to no plastic region; therefore, the third phase isn't marked by yield failure, but often abrupt material failure. There are many factors that affect the local buckling of FRP composite tubes such as: fiber type, matrix type, and fiber architecture/layup to name a few. The following papers illustrated analyses performed on composite tubes that take into account these factors.

\subsubsection{Tennyson Model}

Tennyson (1971) found the critical moment for laminated anisotropic circular shells based on the cylinder geometry and the material properties. The classical collapse moment can be estimated from the theoretical axial compression buckling load for cylinders and is given as

$$
M_{\text {crit }}=\pi R^{2} N_{c r}=2 \pi R \sqrt{E_{\mathrm{y}} t D_{11}}
$$

where $\mathrm{E}_{\mathrm{y}}$ is the Young's modulus in the circumferential direction of the laminate, $\mathrm{R}$ is the radius of the tube, and $t$ is the wall thickness. Tennyson studied, furthermore, the effect of shape imperfections on the buckling load for laminated composites. He concludes that the effects of initial imperfection on the buckling load of composite cylindrical shells are similar to isotropic shells. This research assumed a sufficient span length and therefore end effects were completely ignored in this formulation.

Tennyson (1975) also conducted an extensive literature of the buckling of laminated composite cylinders. For the cases of bending he cites a nonlinear prebuckling analysis for various end constraints. Also, he cites the work of Cheng Ho (1963) in which bending critical loads were found to be essentially equal to axial compression values; agreement with theory was 
within $67 \%-90 \%$. Tennyson also points out a work done by Jones (1969) that considers the difference in elastic moduli for tension and compression. The assumption of constant elastic moduli is generally made by designers; however, in the cases studied by Jones, one should be aware of the difficulties associated with moduli differences in tension and compression (Tennyson, 1975).

\subsubsection{Kedward Model}

Equations that are equivalent to Brazier's work are deduced by Kedward (1978) for laminated composites of any type of fiber and resin. He reviewed the assumptions made by Brazier as 1) the shell is infinitely long, which removes the effects of end boundary conditions, 2) the deformation of the cross section with respect to the circumference is inextensional, and 3) displacements in the tangential to circumference direction and then radial direction are always small compared to the radius of the shell. He presented a collapse moment formula, $\mathbf{M}_{\text {crit }}$, a moment-curvature relationship, $\mathrm{M} / \mathrm{E}_{\mathrm{x}} \mathrm{I}$, and an equation for the reduction in vertical diameter, $\Delta$. Also, he presents these equations for the special case of the orthotropic shell:

$$
\begin{gathered}
M_{c r i t}=\frac{2 \sqrt{2}}{9} \frac{E_{x} \pi R t^{2}}{\sqrt{1-v_{x y} v_{y x}}} \sqrt{\frac{E_{y}}{E_{x}}} \\
\frac{M}{E_{x} I}=\frac{1}{\rho}\left[1-\frac{3}{2} \frac{R^{4}}{\rho^{2} t^{2}} \frac{E_{x}}{E_{y}}\left(1-v_{x y} v_{y x}\right)\right] \\
\frac{\Delta}{2 r}=\frac{R^{4}}{\rho^{2} t^{2}}\left(1-v_{x y} v_{y x}\right) \frac{E_{x}}{E_{y}}
\end{gathered}
$$

where $E_{x}$ is the Young's modulus in the axial direction, $E_{y}$ is the Young's modulus in the circumferential direction, $\mathrm{R}$ is the radius of the tube, $\mathrm{t}$ is the wall thickness, $v_{\mathrm{xy}}$ and $v_{\mathrm{yx}}$ are Poission's ratios, $\rho$ is the radius of curvature of the tube axis, $I$ is the moment of inertia of the tube. Like the equation developed by Brazier, Equation 2-9 dictates when the tube will 
experience collapse. It is at this point that the tube can no longer resist loading. Kedward also notes that these equations are only concerned with local instability and the designer should always be aware of general buckling when dealing with thin walled tubes (Kedward, 1978).

\subsubsection{Fuchs-Hyer Model}

Fuchs et al (1996) expanded Braziers work in order to determine the critical prebuckling moment for short thin-walled composite cylinders in bending. Similar to Seide and Weingarten mentioned above, Fuchs et al. employed Donnell's shell theory to capture the geometric nonlinearity. They outline a solution in which the applied end rotation is computed by integrating $\mathrm{N}_{\mathrm{x}}$ around the circumference at the end of the cylinder. This approach took into account boundary condition effects, geometrically nonlinear deformations, and if desired, can include initial imperfections and non-ideal boundary conditions (Fuchs \& Hyer, 1996).

Fuchs et al. compared their predictions to the predictions found from the classical method shown above in Equation 2-8 and the classical prediction found by Kedward (1978) shown in Equation 2-12. Equation 2-12 is the precursor to Equation 2-8 which is for the special case of orthotropy. This formula is an extension of the classical Brazier analysis to include constitutive relations for balanced symmetric laminates. Their equation for the collapse moment results in

$$
M_{c r i t}=2 \pi R \sqrt{\frac{8}{27} E_{x} t D_{22}}
$$

where $E_{x}$ is the Young's modulus in the longitudinal direction of the laminate, $\mathrm{R}$ is the radius of the tube, and $\mathrm{t}$ is the thickness. End effects are completely ignored in this formulation. In both classical equations shown above, the critical end rotation, $\Omega_{\text {crit }}$, can be determined as 


$$
\Omega_{c r i t}=\frac{M_{c r i t} L}{2 E_{x} I}
$$

where $\mathrm{L}$ is the span length, and I is the moment of inertia of the tube. Fuchs et al. test three different layups and specimens of two different $\mathrm{L} / \mathrm{R}$ ratios. Their results can be seen in Figure 2-4. 


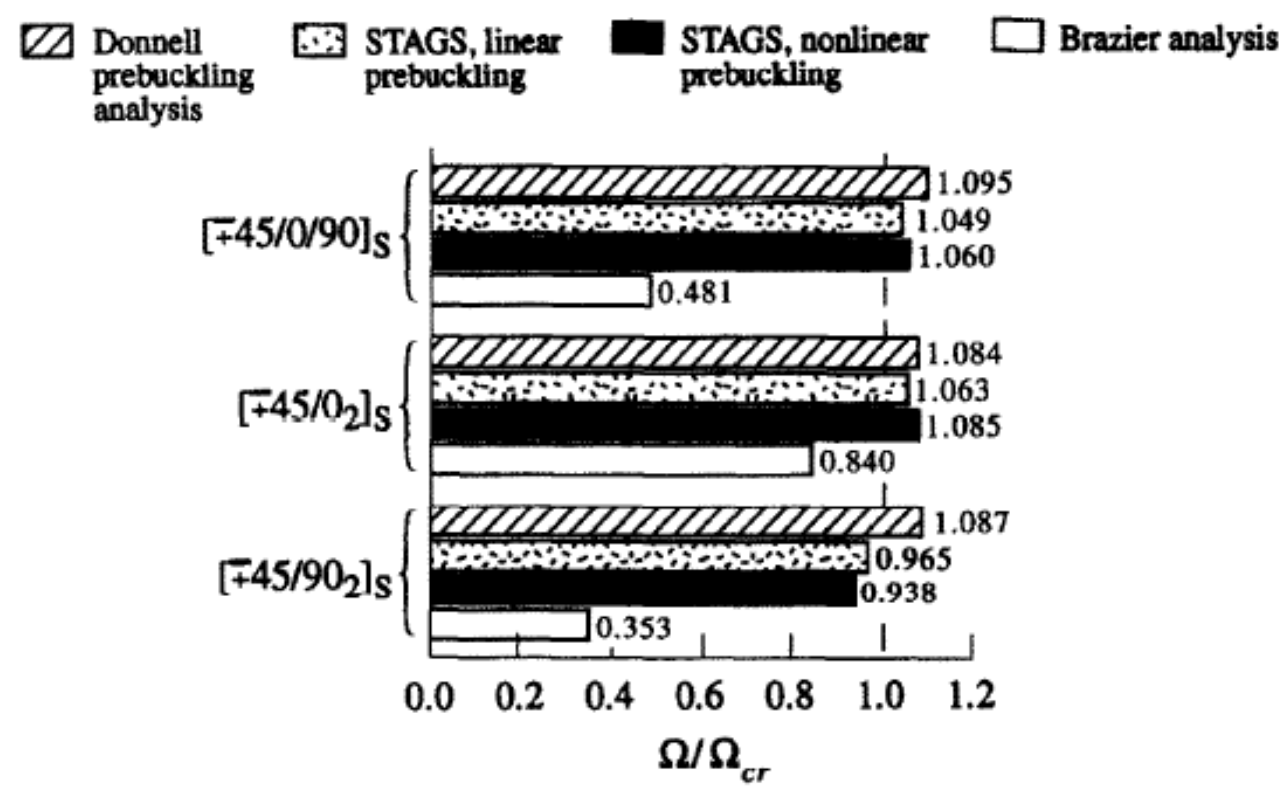

(a) $L R=2$

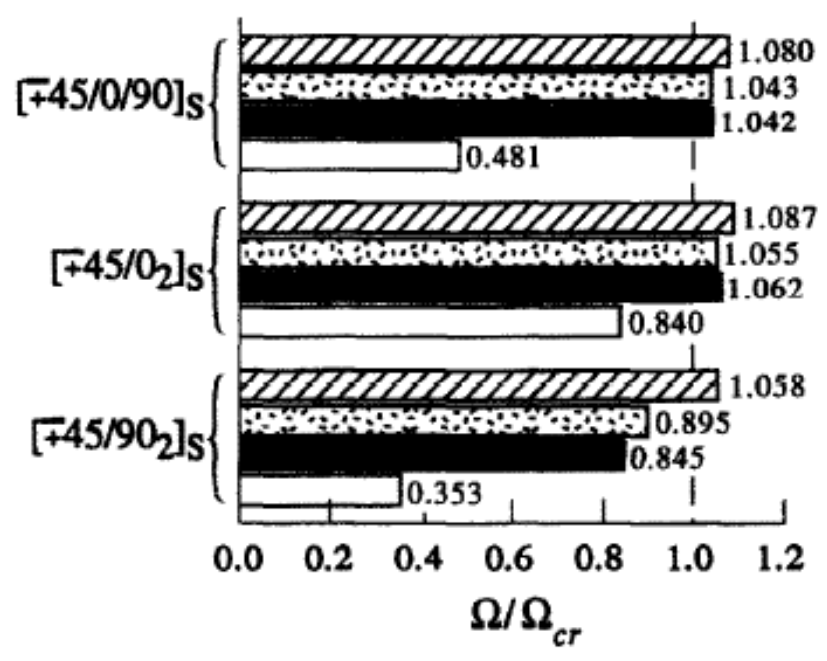

(b) $L / R=5$

Figure 2-4 Buckling Prediction Comparison (Fuchs \& Hyer, 1996)

\subsubsection{Ibrahim-Polyzois Model}

The principles of critical buckling loads of thin-walled orthotropic cylinders were applied by Ibrahim and Polyzois (1999) to characterize the prebuckling state, known as ovalization, of FRP poles subjected to cantilever bending. The glass FRP poles studied in this work are to be used as utility poles and they are tapered, decreasing in diameter from bottom to top, and are 
manufactured by filament winding. Using finite element analysis and parametric full scale mechanical testing, Ibrahim and Polyzois studied critical buckling in orthotropic members. Their goal was to determine the effects of varying fiber layup on ovalization and to propose a prediction equation based on Brazier's work for the critical moments of thin-walled cylindrical tubes. They proposed a design model for computing the critical ovalization load for FRP utility poles. It includes the critical moment that can be carried by the pole and position where the maximum ovalization occurs. The critical load applied in transverse direction to longitudinal pole axis at the top of the pole for cantilever bending can be found by the following equation:

$$
P_{\text {crit }}=\frac{M_{\text {crit }}}{(L-Y)}
$$

where $\mathrm{L}$ is the height of the pole measured from the loading position to the base. $\mathrm{M}_{\text {crit }}$ and $\mathrm{Y}$ can be found from the following expressions:

$$
\begin{gathered}
M_{\text {crit }}=\frac{2 \sqrt{2}}{9} \frac{\pi E_{x} R t^{2}}{\sqrt{1-\mu_{x y}^{2}}}\left[2.1 \frac{E_{y}}{E_{x}}-.84\left(\frac{E_{y}}{E_{x}}\right)^{2}\right] \\
Y=\left[.13-.04 \frac{E_{y}}{E_{x}}\right]^{3} \sqrt{\frac{R}{t}} L
\end{gathered}
$$

where $E_{x}$ is the elastic modulus in the axial direction, $E_{y}$ is the elastic modulus in the circumferential direction, $\mu_{\mathrm{xy}}$ is the poisons ratio of the laminate, $\mathrm{R}$ is the average radius of the pole and $\mathrm{t}$ is the wall thickness.

Their results showed that increasing the number of circumferential layers increased the critical ovalization load of FRP poles, and their proposed equation to determine critical ovalization load matches well with their finite element results (Ibrahim \& Polyzois, 1999). Ibrahim and Polyzois's equation for buckling cannot be taken as a broad stroke because 
cantilever bending behavior does not encompass all of the same phenomena as pure bending behavior. However, their findings can be adapted to further study the nonlinear ovalization behavior of orthotropic beams in bending.

In a continuation of the previous study, Ibrahim et al. (2000) further discussed the behavior of the composite tubes. The authors tested a variety of different layups in order to optimize the most efficient fiber architecture and overall geometric dimensions for use as utility poles. The researchers attempted to provide an ultimate strength prediction of the glass composite utility poles using finite element methods. Their experimental setup was able to capture the change in diameter of their specimens (tending to ovalize) under cantilever loading. In the finite element model, the researchers employ an eight node quadrilateral shell element. They also use a geometrical nonlinear model which uses the Newton-Rhapson iterative method to incorporate shape changes into the stiffness equations during stepped loading. The researchers predict failure in the model using the Tsai-Wu failure criteria unless local buckling was reached before stress rupture (Ibrahim, Polyzois, \& Hassan, 2000). A comparison of the load-deflection results from experiment and finite element analysis is shown in Figure 2-5. 


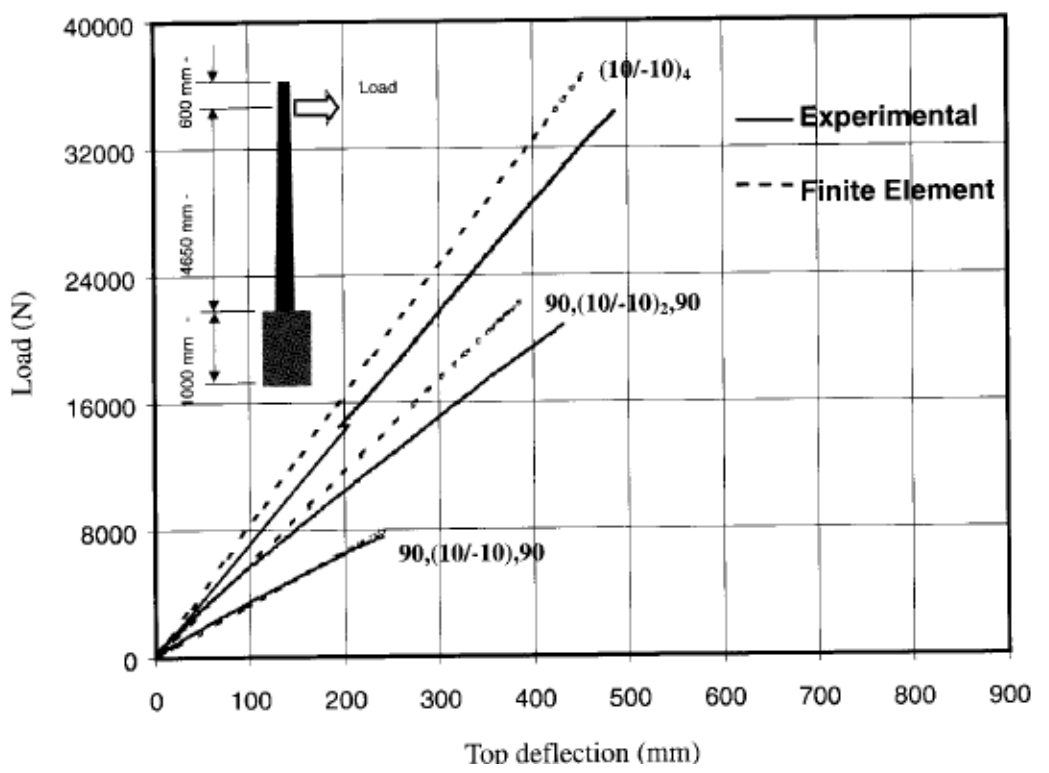

Figure 2-5 Load-Deflection Relationship (Exp vs. FE) for Full-Scale Specimens (Ibrahim, Polyzois, \& Hassan, 2000)

It is also interesting to note the ovalization phenomenon under loading as well as the ability of the finite element model to predict this phenomenon. These results are illustrated in Figure 2-6. 


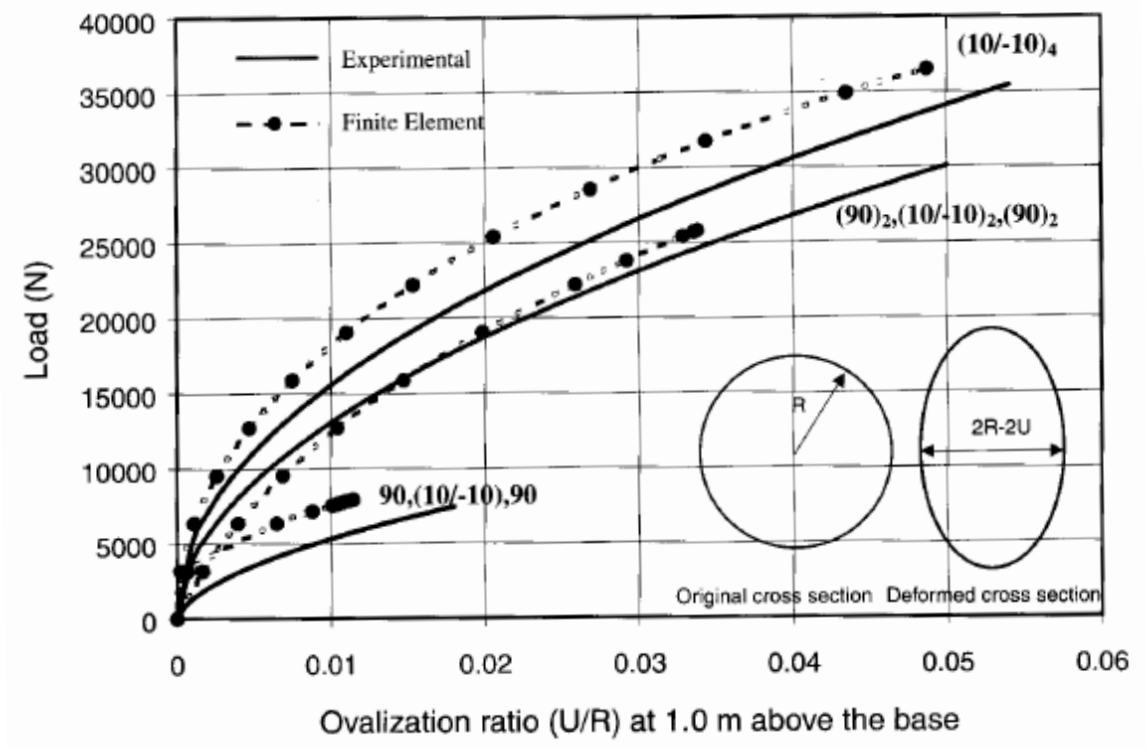

Figure 2-6 Load-Ovalization Relationship (Exp vs. FE) for Full-Scale Specimens (Ibrahim, Polyzois, \& Hassan, 2000)

The authors go on to state that local buckling is the primary mode of failure for all the tubes tested. Only one of the several tubes tested failed due to material failure and not local buckling and this was due to that particular layup having no fibers in the circumferential direction. The authors state that the presence of circumferential layers helps reducing ovalization (Ibrahim, Polyzois, \& Hassan, 2000). It should also be noted that a very similar work with regards to finite element analysis of tapered composite utility poles having a service opening is presented by Masmoudi et al. (2008). Their objective was to present an optimized GFRP section to meet the design requires of utility poles (Masmoudi, Mohamed, \& Metiche, 2008).

\subsection{Bending Stiffness Prediction of Composite Tubes}

The desire of many designers is to predict the overall bending stiffness of a laminated composite section in order to analyze beams simply. This would be accomplished by using an equivalent bending stiffness in formulas such as Euler-Bernoulli's beam theory to predict 
deflections and behavior of a composite section. The designer must always be aware that a laminated composite cannot always be analyzed in the same fashion of an isotropic homogenous material, and that any simplified equivalent stiffness does have the influence of many assumptions.

The classical method of obtaining a bending stiffness for a composite tube involves calculating the product of Young's Modulus and moment of inertia of a FRP composite laminate and assembling various laminates into a lamina over the circumference of a circular cross section. This method is described by Kollár and Springer (2003) and presented in section 4.3.

To account for the many assumptions neglected by classical methods, non-classical methods have been derived and are presented below as well.

\subsubsection{Stiffness Replacement Comparison}

There are a few different ways to predict the bending stiffness of a laminated composite beam section. The most straightforward methods are classical approaches. The classical lamination approach analyzes each ply layer individually and brings them together into an overall stiffness matrix. When it comes to tube sections with a circular cross section, Chan et al. (2000) present three approaches to determining the bending stiffness, EI.

The first is a smeared modulus approach. This approach uses the effective axial modulus

of the laminate and simply multiplies it by the moment of inertia of the tube section. The expression is given as:

$$
E I=E_{x} \frac{\pi}{4}\left(R_{o}^{4}-R_{i}^{4}\right)
$$


where $E_{x}$ is the smeared modulus of the laminate obtained by lamination theory, and $R_{0}$ and $R_{i}$ are the outer radius and inner radius of the tube, respectively.

The second approach is the laminated plate approach which considers an infinitesimal plate section of tube laminate inclined at angle (see Figure 2-7).

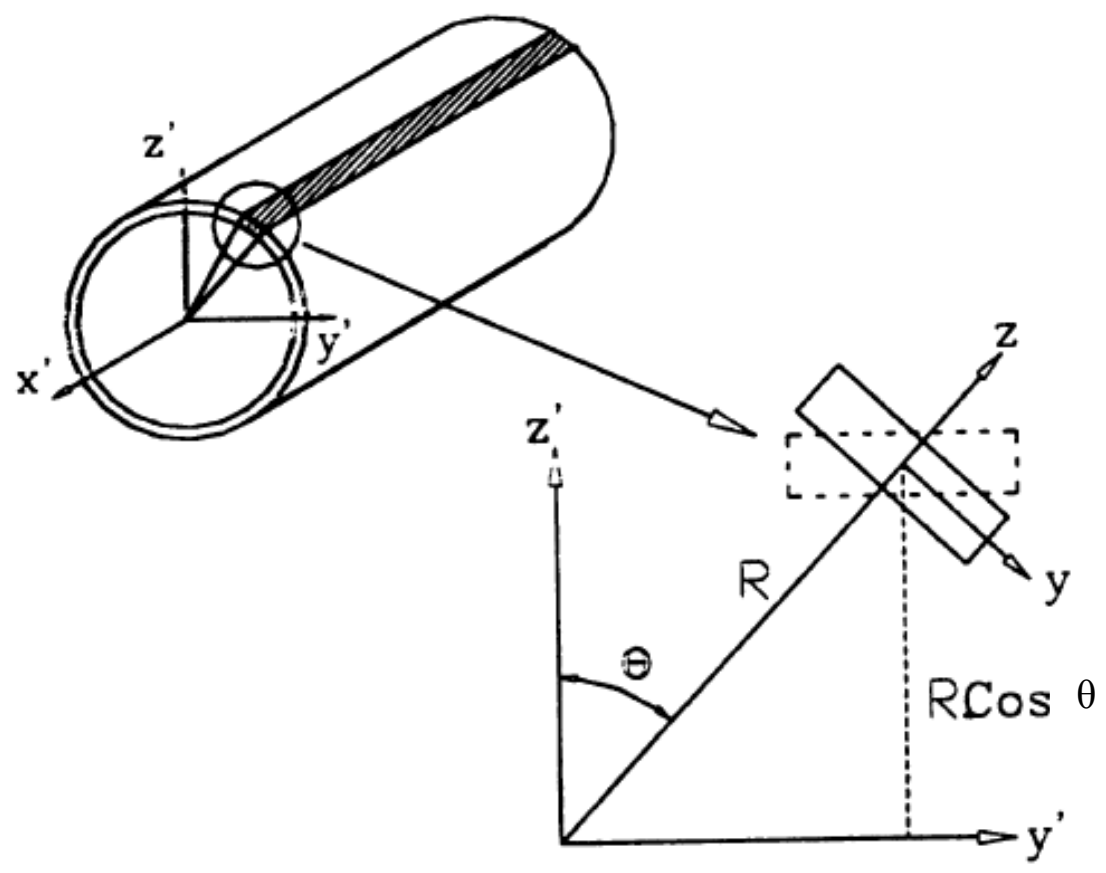

Figure 2-7 Plate Section of a Composite Tube Laminate (Chan \& Demirhan, 2000)

The overall stiffness matrices, [A] [B] [D], are computed as functions of angle $\theta$, and are then integrated accordingly. The affecting bending stiffness is then found expressed as

$$
D_{x}=\frac{1}{\bar{d}_{11}}
$$

where $\bar{d}_{11}$ is the $(4,4)$ element of the inverse matrix of $[\bar{A} \bar{B} \bar{D}]$ matrix (Chan \& Demirhan, 2000). 
The third approach is the laminated shell approach which is similar to the laminated plate approach; however, an infinitesimally small curved shell is considered instead of a plate (see Figure 2-8).

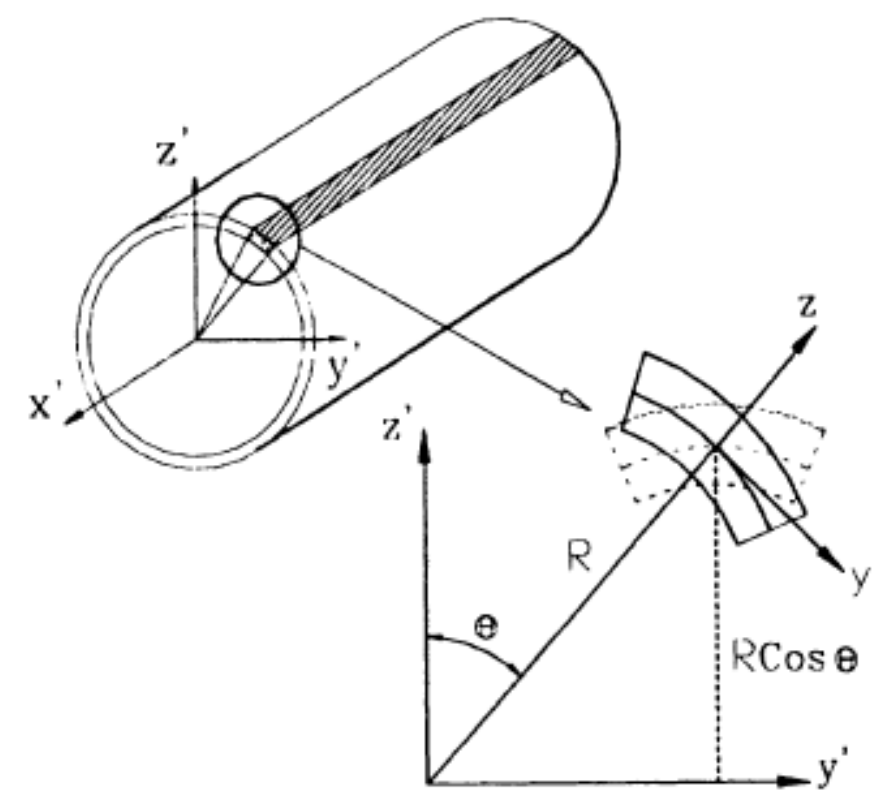

Figure 2-8 Shell Section of a Composite Tube Laminate

Due to the curvature the derivation of the overall stiffness matrices is more complex, but it follows the same fundamental procedure as used in the laminated plate approach.

Chan et al. (2000) use all three approaches for several tubes with a range of radii. They compared each result to a finite element model based results, which they validated prior by comparing to aluminum experimentation. The results of the stiffness prediction for the composite tube are shown in Table 2-2. The percentage difference from the FEM solution is in parentheses next to each stiffness value. 
Table 2-2 Curvature Effect on Bending Stiffness of Composite Tube with Ply Sequence of $\left[ \pm 45_{2} / 0_{2} / \pm 45\right]_{\mathrm{s}}(\mathrm{Chan} \&$ Demirhan, 2000)

\begin{tabular}{lcccc}
\hline & \multicolumn{4}{c}{ Bending Stiffness (Ib-in $\mathbf{2}^{2}$} \\
\cline { 2 - 4 } Radius & \multicolumn{3}{c}{ Analytical Solution } \\
(in) & $\begin{array}{c}\text { FEM } \\
\text { Solution }\end{array}$ & $\begin{array}{c}\text { Smear Property } \\
\text { Approach }\end{array}$ & Plate Approach & Shell Approach \\
\cline { 2 - 5 } & $3.764 E+07$ & $3.79 E+07(-0.58 \%)$ & $3.71 E+07(1.39 \%)$ & $3.73 E+07(0.96 \%)$ \\
2.6 & $2.289 E+07$ & $2.27 E+07(0.68 \%)$ & $2.25 E+07(1.73 \%$ & $2.27 E+07(0.99 \%)$ \\
2.2 & $1.261 E+07$ & $1.23 E+07(2.50 \%)$ & $1.23 E+07(2.28 \%)$ & $1.25 E+07(1.02 \%)$ \\
1.8 & $5.976 E+06$ & $5.67 E+06(5.11 \%)$ & $5.80 E+06(3.00 \%)$ & $5.91 E+06(1.04 \%)$ \\
1.4 & $2.190 E+06$ & $1.99 E+06(8.98 \%)$ & $2.11 E+06(3.50 \%)$ & $2.17 E+06(1.08 \%)$ \\
1.0 & $1.140 E+06$ & $9.89 E+05(13.26 \%)$ & $1.08 E+06(5.09 \%)$ & $1.13 E+06(1.14 \%)$ \\
0.8 & $4.859 E+05$ & $3.96 E+05(18.56 \%)$ & $4.57 E+05(5.95 \%)$ & $4.80 E+05(1.22 \%)$ \\
0.6 & $1.483 E+05$ & $1.05 E+05(28.89 \%)$ & $1.36 E+05(8.50 \%)$ & $1.46 E+05(1.28 \%)$ \\
0.4 & $1.939 E+04$ & $9.60 E+03(50.48 \%)$ & $1.72 E+04(11.54 \%)$ & $1.91 E+04(1.31 \%)$ \\
0.2 & & &
\end{tabular}

As shown in Table 2-2, the shell approach yields the most accurate results, because the shell approach considers a curved shell that is most similar to the tube. It's also important to note that the errors in results from each method increase as the radius of the tube decreases. This is because the amount of curvature in the wall increases, and the smear approach and plate approach suffer greatly as they do not take curvature into account in their derivation. It is the shell approach that is comparable to the approach used in this paper (section 4.3) that is taken from Kollár (2003).

\subsubsection{Shadmehri-Derisi-Hoa Stiffness Model}

Shadmehri et al. (2011) presented a non-classical formula for calculating the bending stiffness of composite tubes. Their method was derived from a three-dimensional theory and accounts for transverse shear deformation, non-uniform twist, and warping inhibition. The equivalent stiffness is shown in their paper and the resulting equation involves laminate stiffness coefficients from a three-dimensional [ABD] matrix which is too long to show here. This equation is simplified for isotropic materials in the equation 


$$
\langle E I\rangle=R \pi\left\{\frac{R^{2} E t}{(1+v)(2 v-1)}\left[\frac{9 v^{3}+3 v^{2}-12 v+4}{4(2 v-1)}\right]+\frac{t^{3} E(v-1)}{12(1+v)(2 v-1)}\right\}
$$

where $\mathrm{R}$ is the radius of the tube, $\mathrm{E}$ is the Young's Modulus, $\mathrm{t}$ is the thickness of the tube wall, and $v$ is the Poisson's ratio. The authors even provided a more simplified version by assuming $v$ $=0.3$ which is shown as

$$
\langle E I\rangle=E * R^{3} * t * \pi\left(.102\left(\frac{t}{R}\right)^{2}+1\right)
$$

The resulting stiffness is compared to a simplified moment of inertia approach which is expressed as

$$
\begin{gathered}
\langle E I\rangle=\sum_{n=1}^{N} \frac{\pi\left[\left(R_{o}^{n}\right)^{4}-\left(R_{i}^{4}\right)^{4}\right]}{4} E_{n} \\
E_{n}=\frac{A_{11} A_{12}-A_{12}^{2}}{A_{22} h_{n}}
\end{gathered}
$$

where $h_{n}$ is the thickness of the particular layer group, $n$. This approach assumes symmetry. A comparison of the non-classical method and the moment of inertia approach for varying layups is presented in Table 2-3. The moment of inertia approach is calculated using Equation 2-20 and the non-classical theory is found by the equation involving several terms containing laminate stiffness coefficients which is not shown in this paper (Shadmehri, Derisi, \& Hoa, 2011). 
Table 2-3 Comparison of the Equivalent Bending Stiffness of the Composite Tube <EI $>$ (Shadmehri, Derisi, \& Hoa, 2011)

\begin{tabular}{|c|c|c|c|c|}
\hline $\begin{array}{l}\text { Tube } \\
\#\end{array}$ & Lay-up ${ }^{\mathrm{a}}$ & $\begin{array}{l}\text { 1st } \\
\text { approach }\end{array}$ & $\begin{array}{l}\text { 2nd } \\
\text { approach }^{c}\end{array}$ & $\begin{array}{l}\text { Difference } \\
\%\end{array}$ \\
\hline 1 & {$\left[90^{\circ}{ }_{20} / 0^{\circ}{ }_{20}\right]$} & 26,817 & 27,464 & -2.4 \\
\hline 2 & {$\left[\left(90^{\circ}{ }_{10} / 0^{\circ}{ }_{10}\right)_{3} / \pm 45^{\circ}{ }_{25}\right]$} & 71,038 & 58,737 & 17.3 \\
\hline 3 & $\begin{array}{l}{\left[90^{\circ}{ }_{10} / \pm 25^{\circ}{ }_{45} / 90^{\circ} / \pm 30^{\circ}{ }_{20} / 90^{\circ} /\right.} \\
\left. \pm 45^{\circ}{ }_{20}\right]\end{array}$ & 222,853 & 169,607 & 23.9 \\
\hline 4 & $\begin{array}{l}{\left[90^{\circ}{ }_{20} / \pm 25^{\circ}{ }_{20} / 90^{\circ} / \pm 30^{\circ}{ }_{25} / 90^{\circ} /\right.} \\
\left. \pm 45^{\circ}{ }_{10}\right]\end{array}$ & 84,071 & 62,142 & 26.1 \\
\hline
\end{tabular}

${ }^{a}$ Fiber angle is defined with respect to axial direction of the tube ( $z$-coordinate). Lay-up starts from the inside of the tube.

${ }^{b}$ Non-classical composite beam theory.

${ }^{c}$ Moment of inertia approach.

The researchers also compared their results to four experimental tests consisting of three point bending and four point bending. Good agreement was found between the non-classical prediction and experimental results, and the agreement is better than that of the moment of inertia approach and experiment. A comparison of the non-classical theory and experiment for tube 1 under three point bending is seen in Figure 2-9. 


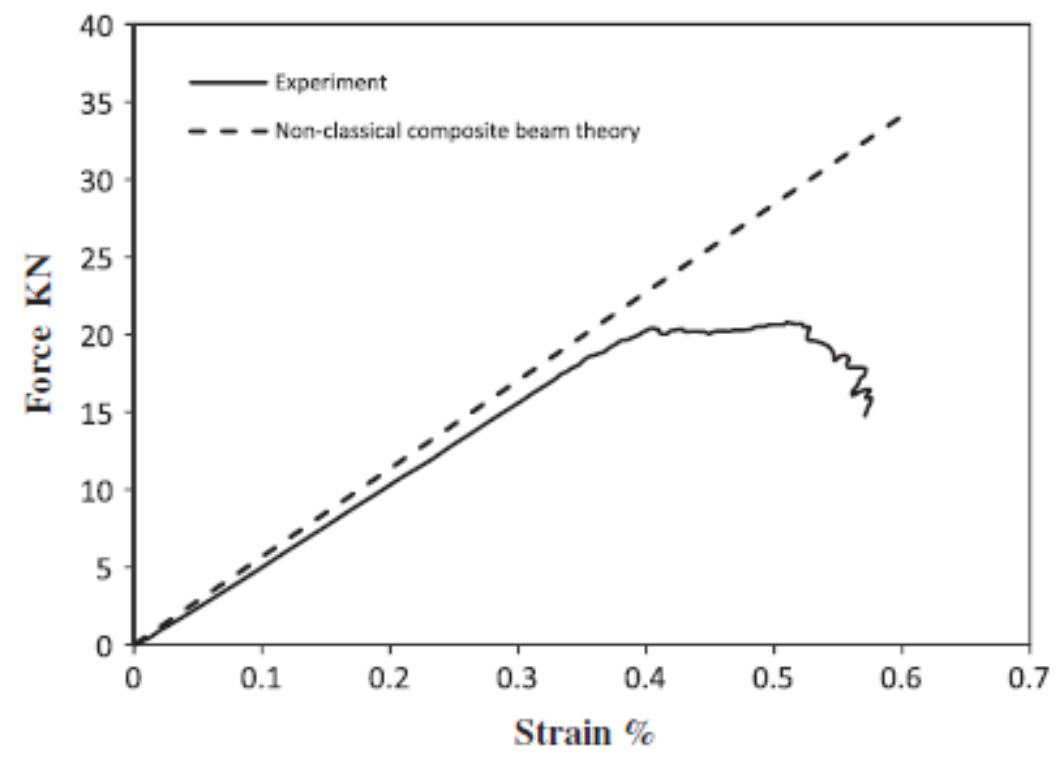

Figure 2-9 Applied Load vs. Axial Strain (mid-length bottom) of Tube 1 (Shadmehri, Derisi, \& Hoa, 2011)

The results for all the tubes showed that good agreement is reached (Shadmehri, Derisi, \& Hoa, 2011). They also show that the moment of inertia approach works well only in the case of cross ply tubes and not when fibers of other orientations are used (Shadmehri, Derisi, \& Hoa, 2011).

\subsubsection{Silvestre Generalized Beam Theory}

Silvestre (2009) developed a generalized beam theory (GBT) for analyzing structural behavior of laminate composite tubes. The author understands the many complexities of trying to analyze a laminated composite structure and this proposed theory incorporates non-classical effects including elastic material couplings, deformation of cross-section contour, warping deformation, and shear deformation. Silvestre derives a GBT that includes these non-classical effects and presents this derivation along with the results in his paper (Silvestre, 2009). Using a finite element model to employ the resulting set of equations, Silvestre analyzes the linear $\left(1^{\text {st }}\right.$ order) behavior of two beam situations: (i) helically wound cantilevered tube under a tip load and a (ii) clamped laminated short tube under a distributed load. He compares the GBT formulation 
results for deformations at points along the circumference with the results obtained from shell finite element analysis using ABAQUS. Fairly good agreement was shown for the two and the discrepancies are explained in the paper. The GBT had a major advantage in that it uses far less degrees of freedom than the shell finite analysis and produces a similar level of accuracy

(Silvestre, 2009). The research yields important information about the influence of shear and material coupling effects on the linear behavior of composite circular hollow section tubes, and goes to show that non-classical effects mentioned above must be incorporated into the analysis in order to obtain accurate results (Silvestre, 2009). The author is currently extending this theory for use in dynamic analysis and buckling analysis of FRP composite tubes.

\subsection{Conclusions}

During bending on of thin-walled isotropic tubes, warping of the cross section is shown to precede buckling of the tube. The moment at which this occurred was first conveyed mathematically by Brazier (1927) for the basic case of a long cylindrical shell in which endeffects due to the load application were ignored. Seide and Weingarten (1964) attempted to improve upon the understanding of the relationship of buckling stress during bending and compressive buckling stress for thin-walled tubes and concurred that for all practical purposes they can be considered to be equal.

For composite materials, the same buckling is known to occur; however, the factors that cause/restrain buckling behavior are more complex due to factors such as: fiber type, matrix type, fiber architecture/layup. Therefore a good ovalization prediction should take into account the factors mentioned above. Tennyson (1971) and Kedward (1978) present moment predictions that account for these factors. Ibrahim et al. (1999) modify Kedward's model for cantilever bending of composite utility poles and obtain good correlation with experimentation. These 
simple models are classic in nature and do not account for nonlinearity; therefore, many researchers have attempted to account for geometrical nonlinearity and also non-classical effects such as boundary condition effects and initial imperfections. Fuchs et al. (1996) developed such a theory and made several observations on the effect that non-classical conditions have on prediction ovalization and critical moments. Silvestre (2009) also presented a generalized beam theory in order to include non-classical effects such as elastic material couplings, cross section deformation, warping deformation, and shear deformation. His results proved to be more accurate compared to experimentation than the simplified methods commonly accepted by engineers and designers. Also, an overall stiffness prediction is desirable for designers to easily understand the material properties of a laminated composite. Classical methods explained by Kollár et al. (2003) are described and utilized later in this paper. A good stiffness prediction for laminated composite tubes will also account for non-classical effects such as elastic material couplings, deformation of cross section contour, warping deformation, and shear deformation. Silvestre's (2009) GBT proves useful in this area too as it describes stiffness aspects of composite tubes. Shadmehri et al. (2011) present a three-dimensional laminate theory to determine a bending stiffness equivalent (EI) for composite tubes. Their approach is numerically intensive and requires finite element analysis to employ, but the results prove more accurate compared to experimentation than that of a moment of inertia approach which is commonly accepted and simple to use. 


\section{CHAPTER 3 TESTING OF TUBE MEMBERS}

\subsection{Materials Tested}

Creative Pultrusions Inc. provided WVU-CFC with tubes of circular sections for testing. All sections were manufactured by the process of pultrusion. Four different types of circular sections were tested: a 16” outer diameter 1/2” wall thickness E-glass/polyurethane, a 16” outer diameter 1/2” wall thickness E-glass/vinyl ester, a 12” outer diameter 1/2” wall thickness Eglass/polyurethane, and a 12” outer diameter 3/8” wall thickness E-glass/polyurethane. The different sections are shown in Table 3-1. The nomenclature in this Table 3-1 will be used throughout the report. Also, it is helpful to remember that the layup for each section is generally the same and recognize that changes in diameter and wall thickness lead to slightly different fabric layup. The tests done were four-point bending under static load to failure, four-point bending fatigue, crush strength test, transverse bolt test (Connection Test A), washer test (Connection Test B), and also various coupon testing of each section size and material. The coupon level tests included testing for flexural properties (ASTM D790), compressive properties (ASTM D695), and tensile properties (ASTM 638). A breakdown of the tests performed with the exception of the coupon tests are shown in Table 3-2. The ASTM standards were used for guidance for coupon tests and four-point full section bending, and the exact methodology used for the tests are described below. The coupon samples were cut from the post-failure sections used in the crush test. 
Table 3-1 Material Sections Tested and Reported on

\begin{tabular}{|l|c|c|c|c|}
\hline \multicolumn{1}{|c|}{ Section } & $\begin{array}{c}\text { Outside } \\
\text { Diameter } \\
\text { (in) }\end{array}$ & $\begin{array}{c}\text { Wall } \\
\text { Thickness } \\
\text { (in) }\end{array}$ & $\begin{array}{c}\text { Fiber } \\
\text { Material }\end{array}$ & $\begin{array}{c}\text { Matrix } \\
\text { Material }\end{array}$ \\
\hline PU-16x0.5 & 16 & $1 / 2$ & E-glass & Polyurethane \\
\hline VE-16x0.5 & 16 & $1 / 2$ & E-glass & Vinyl Ester \\
\hline PU-12x0.5 & 12 & $1 / 2$ & E-glass & Polyurethane \\
\hline PU-12x0.375 & 12 & $3 / 8$ & E-glass & Polyurethane \\
\hline
\end{tabular}

Table 3-2 Test Matrix

\begin{tabular}{|c|c|c|c|c|c|}
\hline Section & \multicolumn{5}{|c|}{ Number of tests } \\
\hline PU-16x0.5 & 5 & $\begin{array}{c}\text { Crush } \\
\text { Bend }\end{array}$ & $\begin{array}{c}\text { 4pt Fatigue } \\
\text { Bend }\end{array}$ & $\begin{array}{c}\text { Connection } \\
\text { A }\end{array}$ & $\begin{array}{c}\text { Connection } \\
\text { B }\end{array}$ \\
\hline VE-16x0.5 & 5 & 5 & 1 & 5 & 5 \\
\hline PU-12x0.5 & 5 & 4 & 1 & 5 & 6 \\
\hline PU-12x0.375 & 4 & 5 & 1 & 5 & 6 \\
\hline
\end{tabular}

\subsection{Instrumentation}

This section describes the necessary details of the data measurement devices generally used throughout the experimental testing. In the methodology description for each experimental setup, the particular instrumentation used will be noted. The devices used to record applied loads, deflections, and strains are generally the same for each full section test, i.e. four-point bending, crush, connection, and cantilever tests. For each full section test, loads were applied through a hydraulic actuator controlled by an electric pump. The load transferred by the actuator was measured with an Omega LC8400-200-200 load cell with $\pm 0.5 \%$ accuracy. For all full sections tests except connection test A, deflections were measured using a Celesco SP3 string pot which has a maximum range of 50 inches and an accuracy of \pm 0.125 inches. For connection test A, deflections were measured with an LVDT with an accuracy of $1 / 100^{\text {th }}$ of an inch. Whenever 
strain was recorded, a Vishay 250UW strain gage with 120 ohms resistance, 1/4 inch gage length, and a strain range of $\pm 5 \%$ was used. The data acquisition system used to record all of these measurements was a StrainSmart System 5000. Data points were recorded at a rate of 10 per second in order to obtain detailed results.

\subsection{Four-Point Bending}

\subsubsection{Methodology}

The tests were conducted as per ASTM D6109 and WVU-CFC test protocol. The 12 inch tubes were setup with a clear span of 240-inches out of a total length of 288-inches, with the load span equal to $1 / 3^{\text {rd }}$ of the clear span or 80 -inches. The samples were supported and loaded by using 8-inch long steel saddles that covered slightly less than half of the circumference as shown in Figure 3-1. The 16 inch tubes were set up similarly with the clear span being 320 inches and the load span equal to $1 / 3^{\text {rd }}$ of the clear span or 106.67 inches. The saddles were loaded at the midpoint through round steel stock to simulate simply supported conditions, and with neoprene padding between the saddle and tube. Most tubes tested were instrumented with a Celesco SP3 string pot to measure deflections and an Omega LC8400-200-200 kip load cell. Vishay strain gages were installed in the longitudinal direction, with additional gages on certain samples. The load was transferred from a hydraulic actuator through the load cell and then to a steel spreader beam, a W14x90 with transverse web stiffeners at loading points (Figure 3-2). The samples were loaded to failure, and a few tests were recorded using an audio-visual system. Figure 3-2 shows the four-point bending of a 16-inch sample, which is identical to the 12-inch testing except for span length. 


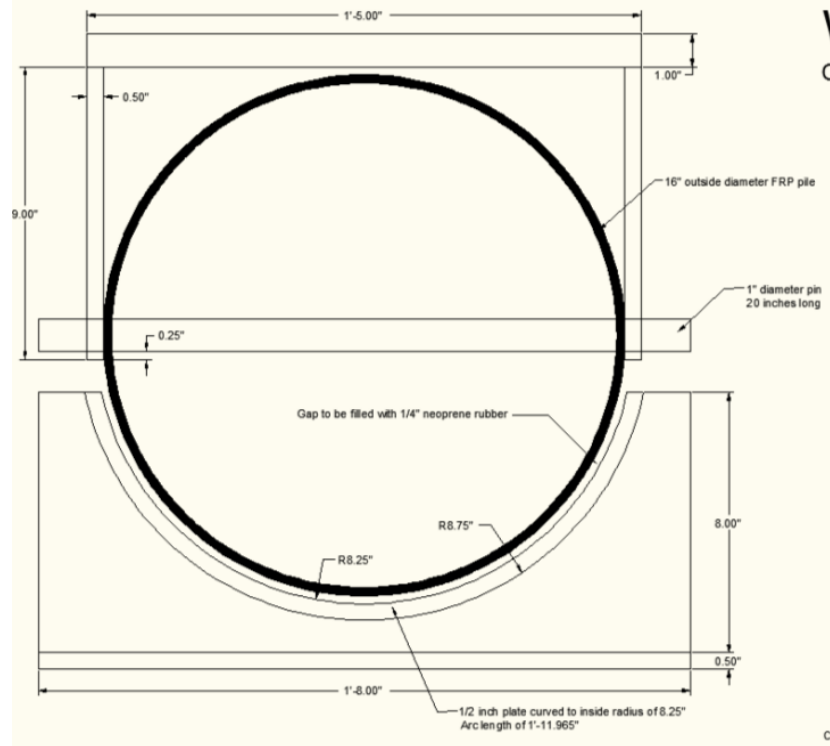

WVU-CFC

CP Saddle

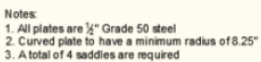

Thed
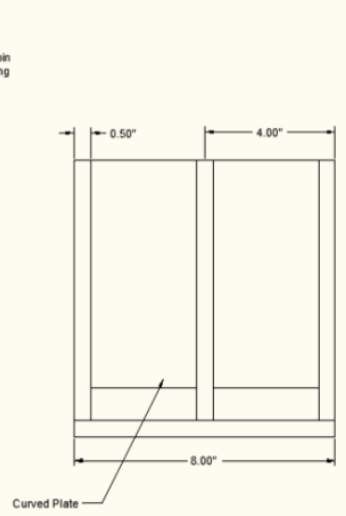

Figure 3-1 Saddle for testing

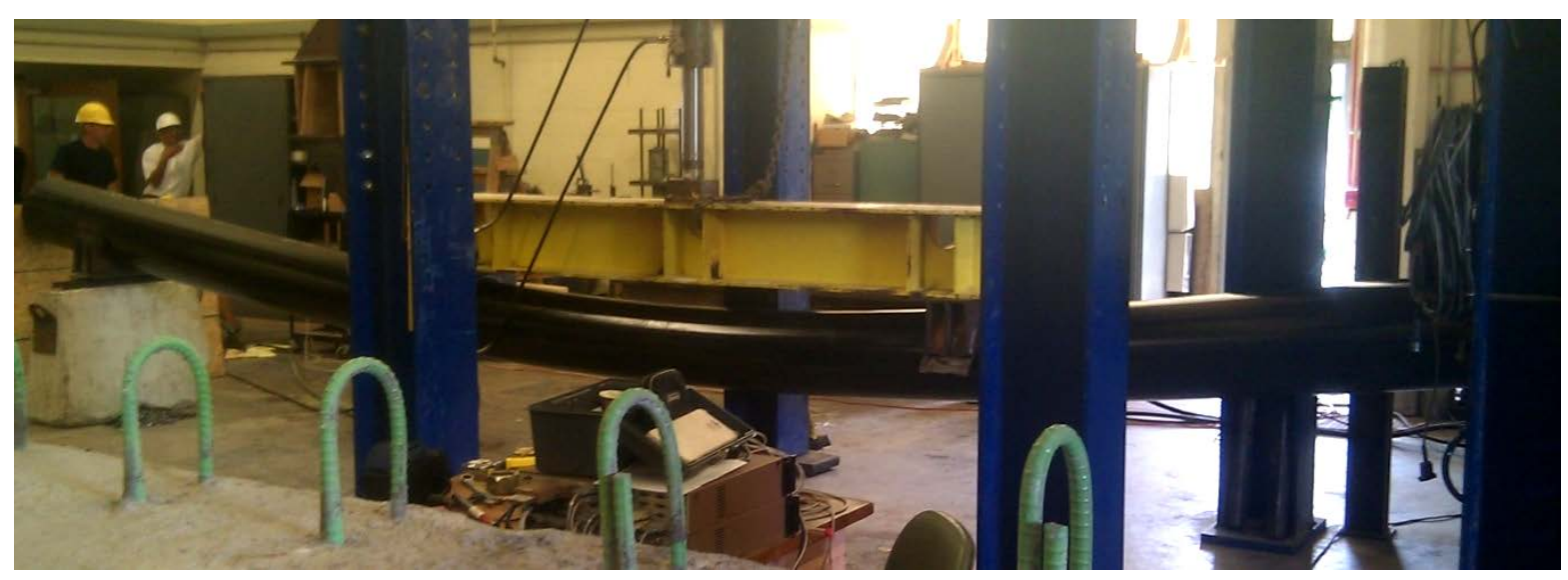

Figure 3-2 Four-Point Bending Test (Section PU-16x0.5)

All four-point bending samples had one strain gage at either the top of the cross section in the longitudinal direction or at the bottom of the cross section in the longitudinal section, but some samples had more gages on them. This was done to obtain strain data that occurs in other locations of the cross section. Also, one sample from each section was fatigued and then tested to failure under static loads (see section 3.8). These post-fatigued samples from each section set had eight gages at the midspan. Figure 3-3 shows the possible locations for strain gages at the 
midspan, and this figure will be referred to in further discussions as needed to highlight gage locations.
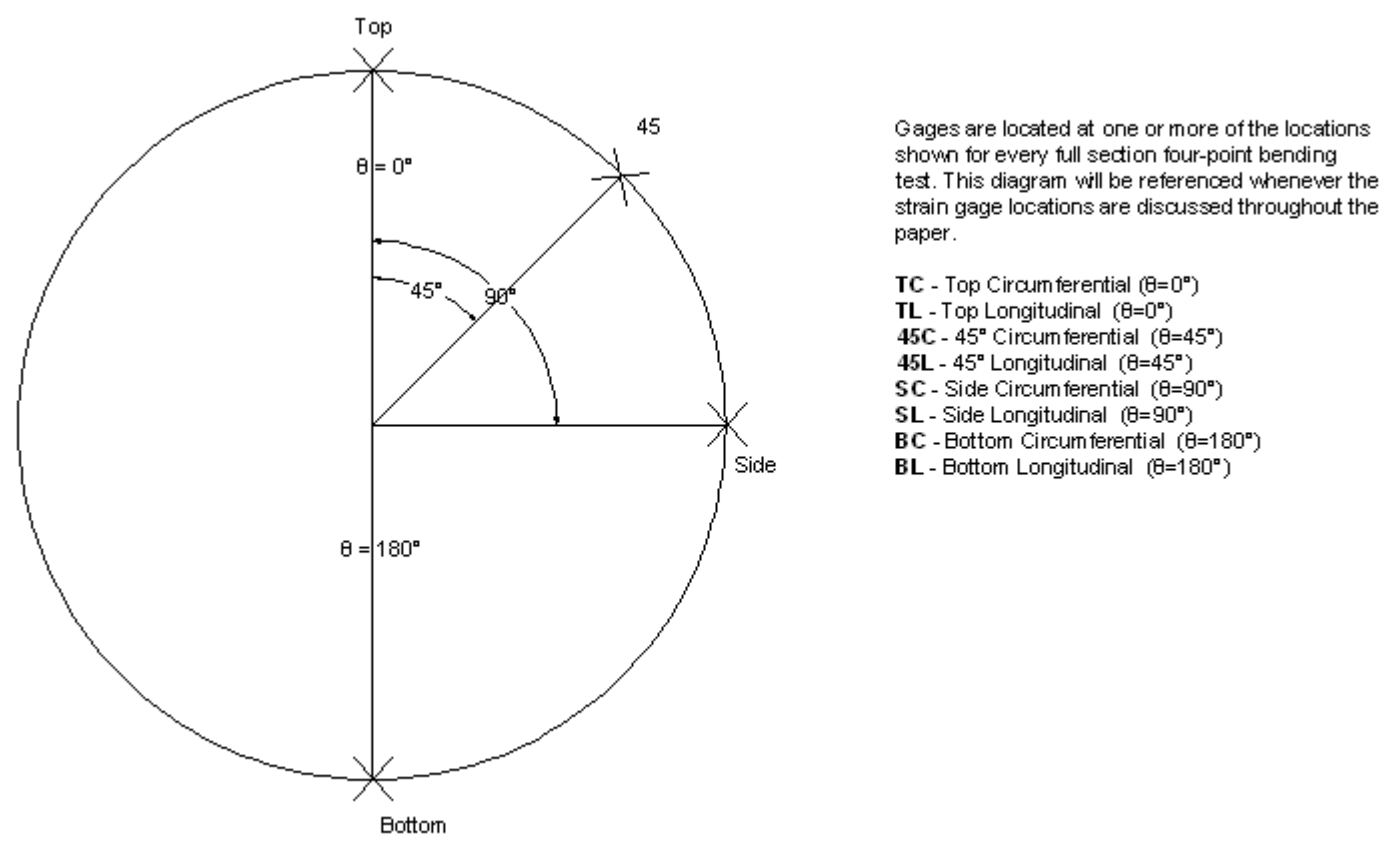

Figure 3-3 Strain Gage Diagram for Four-Point Bending Tests

Also, for Sample 4 of PU-12x0.375 a video camera was setup facing the four-point bending static test from the side so that the center span is in view. This was done in order to monitor how much, if any, cross sectional deformation was occurring during bending. The recorded footage is analyzed carefully to determine the change in diameter, and is presented in section 4.5 (see Figure 4-15).

\subsubsection{Results and Discussion}

\subsubsection{Introduction}

As mentioned above, load, center deflection, and center longitudinal strain were recorded (by instrumentation) under four-point bending. A few samples had more strain gages located at 
the center also. A summary of the test results include max load, max deflection, max moment, max stress (bending), max strain, and energy. All "max” measurements are taken at the max load (load at failure). The moment, $M$, is calculated by Equation 3-1, where $P$ is equal to the load at one point of loading, and $a$ is the distance from a point of loading to the nearest point of support.

$$
M=P a
$$

The bending stress, $\sigma$, is calculated from Equation 3-2, where $c$ is the distance from the center of the cross section to the outermost fiber, and $I$ is the moment of inertia.

$$
\sigma=\frac{M c}{I}
$$

The modulus of elasticity, $E$, is determined by fitting a linear curve through the linear portion of the stress strain curve (within $10 \%-50 \%$ of the ultimate strain). The energy is computed by finding the area under the load deflection curve using an approximation technique. The technique applied is a rectangular approximation, and it is found to be accurate due to the many number of data points acquired during the test.

\subsubsection{Section PU-16x0.5}

The results from the four-point bending tests of the 16 inch Polyurethane samples are given in Table 3-3. The moment is calculated using Equation 3-1. Crackling sounds were clearly heard on all samples at around $75 \%$ of the failure load though no cracks were visible from a safe viewing distance. Failure in all samples was sudden with the load dropping to zero in roughly 0.2 seconds. After failure, longitudinal cracks were found on the tube centered about midspan along with crushing and tearing of the section at midspan. All samples failed in the middle third zone 
of the test span as shown in Figure 3-4. Sample numbers refer only to the order in which they were tested, and they are not sequenced between different test setups.

Table 3-3 Four-Point Bending Results - Section PU-16x0.5

\begin{tabular}{|c|c|c|c|c|c|c|c|}
\hline Sample & $\begin{array}{c}\text { Max } \\
\text { Load } \\
\text { (kips) }\end{array}$ & $\begin{array}{c}\text { Max } \\
\text { Deflection } \\
\text { (in) }\end{array}$ & $\begin{array}{c}\text { Max } \\
\text { Moment } \\
\text { (kip-in) }\end{array}$ & $\begin{array}{c}\text { Max } \\
\text { Stress } \\
\text { (ksi) }\end{array}$ & $\begin{array}{c}\text { Max } \\
\text { Longitudinal } \\
\text { Strain ( } \boldsymbol{\mu \varepsilon})\end{array}$ & $\begin{array}{c}\text { Elastic } \\
\text { Modulus } \\
\text { (Msi) }\end{array}$ & $\begin{array}{c}\text { Energy } \\
\text { (kip-in) }\end{array}$ \\
\hline $\mathbf{1}$ & 102.18 & 16.39 & 5446.31 & 59.53 & 11137 & 5.94 & 944.45 \\
\hline $\mathbf{2}$ & 101.29 & 16.87 & 5398.85 & 59.01 & 11455 & 5.67 & 938.47 \\
\hline $\mathbf{3}$ & 102.58 & - & 5467.41 & 59.76 & 11794 & 5.78 & - \\
\hline $\mathbf{4}$ & 105.42 & - & 5619.05 & 61.42 & 10109 & 6.36 & - \\
\hline $\mathbf{5}$ & 96.69 & - & 5153.59 & 56.33 & 11265 & 5.87 & - \\
\hline Average & $\mathbf{1 0 1 . 6 3}$ & $\mathbf{1 6 . 6 3}$ & $\mathbf{5 4 1 7}$ & $\mathbf{5 9 . 2 1}$ & $\mathbf{1 1 1 5 2}$ & $\mathbf{5 . 9 2}$ & $\mathbf{9 4 1 . 4 6}$ \\
\hline
\end{tabular}

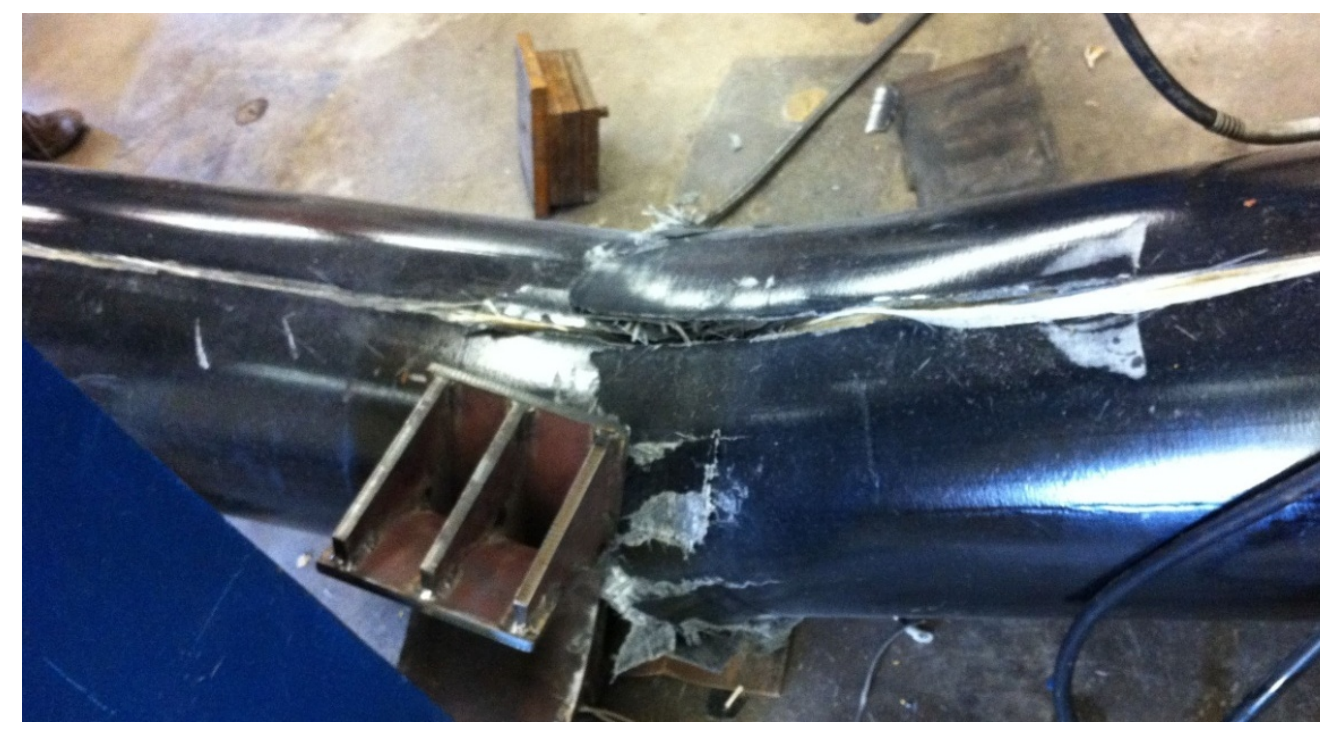

Figure 3-4 Failed Four-Point Bending Sample - Section PU-16x0.5

After failure, all samples exhibited the combination of a compression crushing failure and longitudinal cracks running along the length of the tube, which are indicative of a local buckling failure (see Figure 3-4). Another reason to show that local buckling is contributing to failure is to evaluate strain gage data. Sample 2 had a longitudinal strain gage located at the top $(\theta=0)$ and a circumferential strain gage located on the side $(\theta=90)$, both at midspan. The stress vs. strain for 
both strain gages is shown in Figure 3-5. Please note that a negative strain value indicates compression and a positive strain indicates tension.

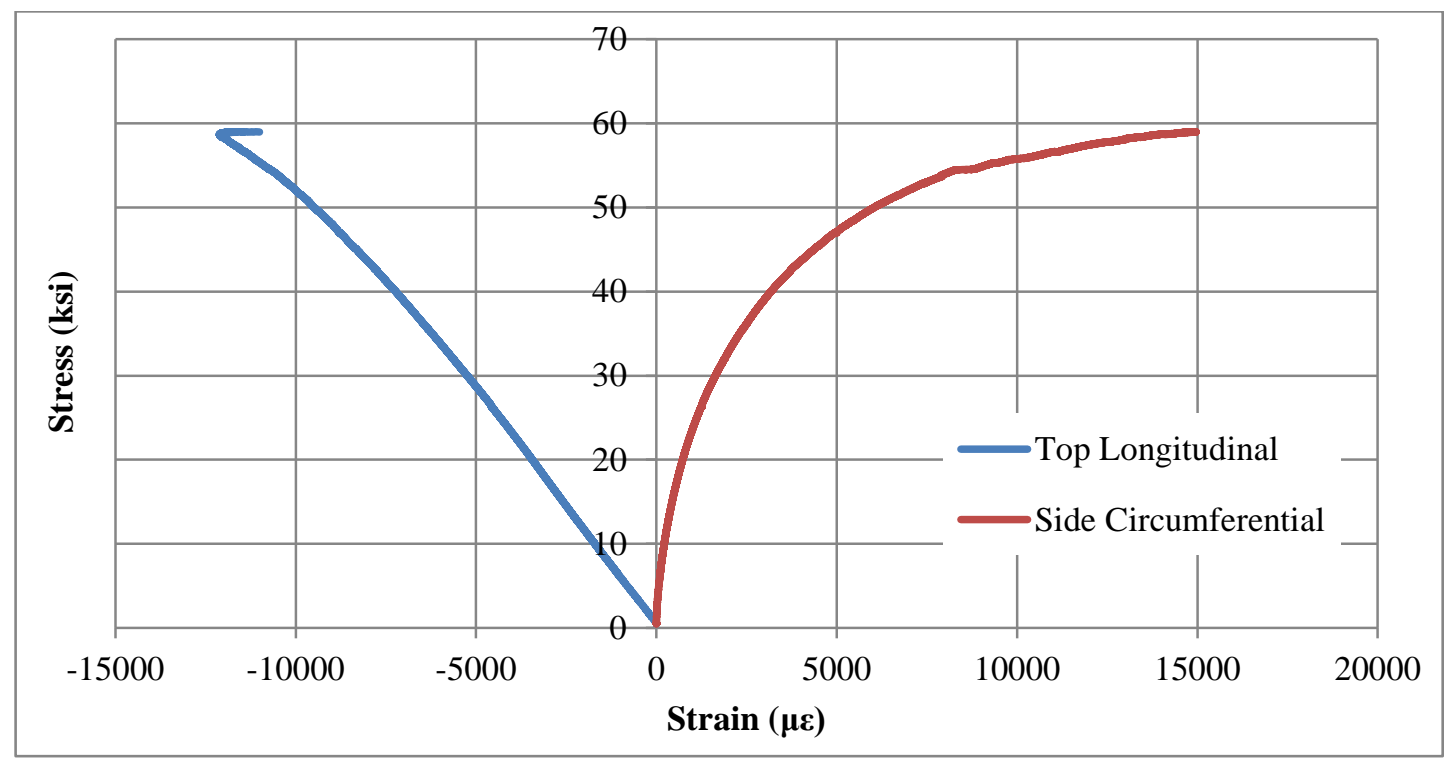

Figure 3-5 Stress vs. Strain for Sample 2 of Section PU-16x0.5

Figure 3-5 shows that the circumferential direction experienced a higher strain at the failure stress of $59 \mathrm{ksi}$. Sample 5 which is not shown here also showed high strains at multiple locations around the midspan in the circumferential direction; although, the top and bottom longitudinal strains were never surpassed by the circumferential strains. Nevertheless, a deformation of the cross section was occurring during loading of these samples and affecting the failure mode, i.e. tension along circumference or buckling along longitudinal direction. More confirmation of this effect is given in the results of the post fatigued sample.

One sample of PU-16x0.5 underwent 200 cycles of four-point bending at $40 \%$ of the ultimate load (see Section 3.8). Afterwards, it was tested to failure in static four-point bending. The static test results for this sample are shown in Table 3-4. Included with the sample's results is a comparison to the average values obtained from the static four-point bend tests given in 
Table 3-4. This comparison is given as a percentage where a negative value conveys it was lower than the average from the non-fatigued samples.

Table 3-4 Four-Point Bending Results for Post-Fatigue Sample 6 - Section PU-16x0.5

\begin{tabular}{|c|c|c|c|c|c|c|c|}
\hline Sample & $\begin{array}{c}\text { Max } \\
\text { Load } \\
\text { (kips) }\end{array}$ & $\begin{array}{c}\text { Max } \\
\text { Deflection } \\
\text { (in) }\end{array}$ & $\begin{array}{c}\text { Max } \\
\text { Moment } \\
\text { (kip-in) }\end{array}$ & $\begin{array}{c}\text { Max } \\
\text { Stress } \\
\text { (ksi) }\end{array}$ & $\begin{array}{c}\text { Max } \\
\text { Longitudinal } \\
\text { Strain ( } \boldsymbol{\mu \varepsilon})\end{array}$ & $\begin{array}{c}\text { Elastic } \\
\text { Modulus } \\
\text { (Msi) }\end{array}$ & $\begin{array}{c}\text { Energy } \\
\text { (kip-in) }\end{array}$ \\
\hline $\begin{array}{c}\text { PU-16x0.5 } \\
\text { Sample 6 }\end{array}$ & 103.72 & - & 5549 & 60.65 & 10372 & 5.76 & - \\
\hline $\begin{array}{c}\text { Percent } \\
\text { Difference } \\
\text { from Static } \\
\text { Average }\end{array}$ & $\mathbf{2 . 0 5}$ & - & $\mathbf{2 . 0 5}$ & $\mathbf{2 . 0 5}$ & $\mathbf{- 6 . 9 9}$ & $\mathbf{- 2 . 7 4}$ & - \\
\hline
\end{tabular}

Results in Table 3-4 do not show any significant decrease in strength or stiffness. Therefore, it is believed that the 200 cycles at $40 \%$ had no effect on strength or stiffness. Also, for Sample 6 during the four-point bending test to failure, many gages were applied around the circumference at midspan to further quantify any buckling behavior. Eight gages were applied in the same locations and orientations for each section. Figure 3-3 shows the placement of these gages. All of the possible locations and orientations in Figure 3-3 were used. The stress vs. strain curve for PU-16x0.5 is shown in Figure 3-6. 


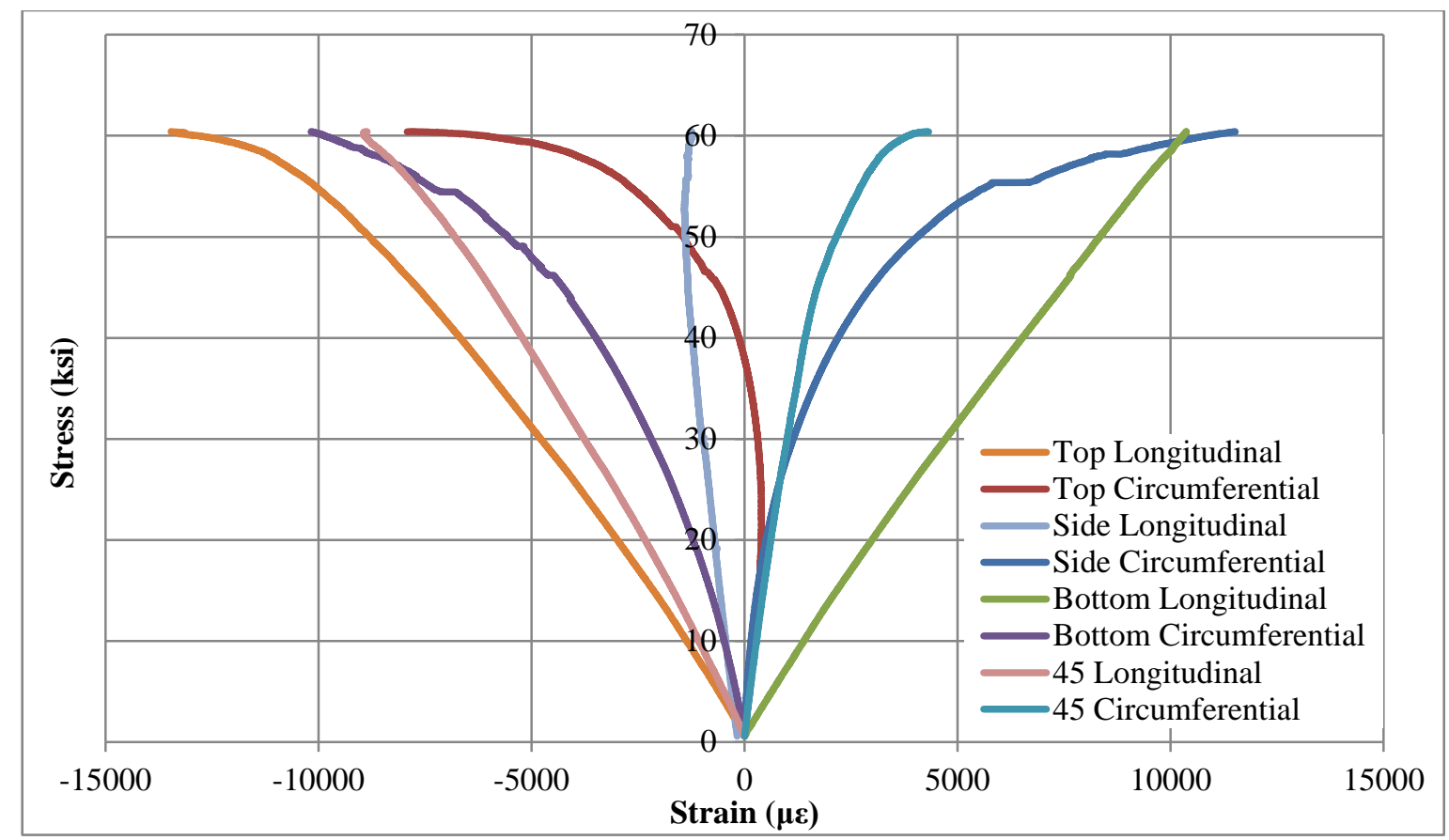

Figure 3-6 Stress vs. Strain for Sample 6 - Section PU-16x0.5

The curves shown in Figure 3-6 illustrate important information about the behavior of the circular pultruded FRP tubes. They confirm that in fact cross section deformation is occurring and also give insight into when this deformation begins. It can be estimated from this data that geometric nonlinearity begins at $\sim 25-30 \mathrm{ksi}$ which corresponds to $45-50 \%$ of the ultimate load. This phenomenon will be discussed in further detail throughout the report.

\subsubsection{Section VE-16x0.5}

The results from the four-point bending tests of the 16 inch vinyl ester samples are given in Table 3-5. Crackling sounds were not clearly heard on any samples until the applied load was within roughly $95 \%$ of the failure load. No cracks were visible from a safe viewing distance until failure. Failure of all samples was sudden and abrupt with the load dropping to zero in roughly 0.2 seconds. After failure, longitudinal cracks were found on the test specimen centered about midspan along with crushing and tearing of the section at midspan. This material failed similarly 
to PU-16x0.5 (see Figure 3-4) for failure, but there were significantly less longitudinal cracks. This indicates that stresses in circumferential direction affected the failure of VE-16x0.5 less than PU-16x0.5. All samples failed at the center of the span with the exception of Sample 5 which failed beneath one of the loading saddles. Although neoprene padding was used between the saddles, there is probably some digging of the saddle with the tube near failure loads. It should be noted that the failure results from Sample 5 (Table 3-5) are very close to the average. Sample numbers refer only to the order in which they were tested, and they are not sequenced between different test setups.

Table 3-5 Four-Point Bending Results - Section VE-16x0.5

\begin{tabular}{|c|c|c|c|c|c|c|c|}
\hline Sample & $\begin{array}{c}\text { Max } \\
\text { Load } \\
\text { (kips) }\end{array}$ & $\begin{array}{c}\text { Max } \\
\text { Deflection } \\
\text { (in) }\end{array}$ & $\begin{array}{c}\text { Max } \\
\text { Moment } \\
\text { (kip-in) }\end{array}$ & $\begin{array}{c}\text { Max } \\
\text { Stress } \\
\text { (ksi) }\end{array}$ & $\begin{array}{c}\text { Max } \\
\text { Longitudinal } \\
\text { Strain }(\boldsymbol{\mu \varepsilon})\end{array}$ & $\begin{array}{c}\text { Elastic } \\
\text { Modulus } \\
\text { (Msi) }\end{array}$ & $\begin{array}{c}\text { Energy } \\
\text { (kip- } \\
\text { in) }\end{array}$ \\
\hline $\mathbf{1}$ & 87.41 & 13.85 & 4720.31 & 51.59 & 9891 & 5.66 & 687.45 \\
\hline $\mathbf{2}$ & 64.53 & 9.77 & 3484.60 & 38.09 & 7136 & 5.54 & 340.97 \\
\hline $\mathbf{3}$ & 86.70 & 12.98 & 4681.57 & 51.17 & 9311 & 5.43 & 624.76 \\
\hline $\mathbf{4}$ & 90.31 & 13.27 & 4876.61 & 53.30 & 9461 & 5.45 & 667.60 \\
\hline $\mathbf{5}$ & 86.35 & - & 4662.86 & 50.96 & 8763 & 5.80 & - \\
\hline Average & $\mathbf{8 3 . 0 6}$ & $\mathbf{1 2 . 4 7}$ & $\mathbf{4 4 8 5}$ & $\mathbf{4 9 . 0 2}$ & $\mathbf{8 9 1 3}$ & $\mathbf{5 . 5 7}$ & $\mathbf{5 8 0 . 1 9}$ \\
\hline
\end{tabular}

The failure mode of the samples of section VE-16x0.5 was less in the way of local buckling when compared to PU-16x0.5. This is evident by the lack of longitudinal cracks at failure and also the strain data acquired from Sample 1 of VE-16x0.5 which is shown in Figure 3-7. Please note that a negative strain indicates compression and a positive strain indicates tension. 


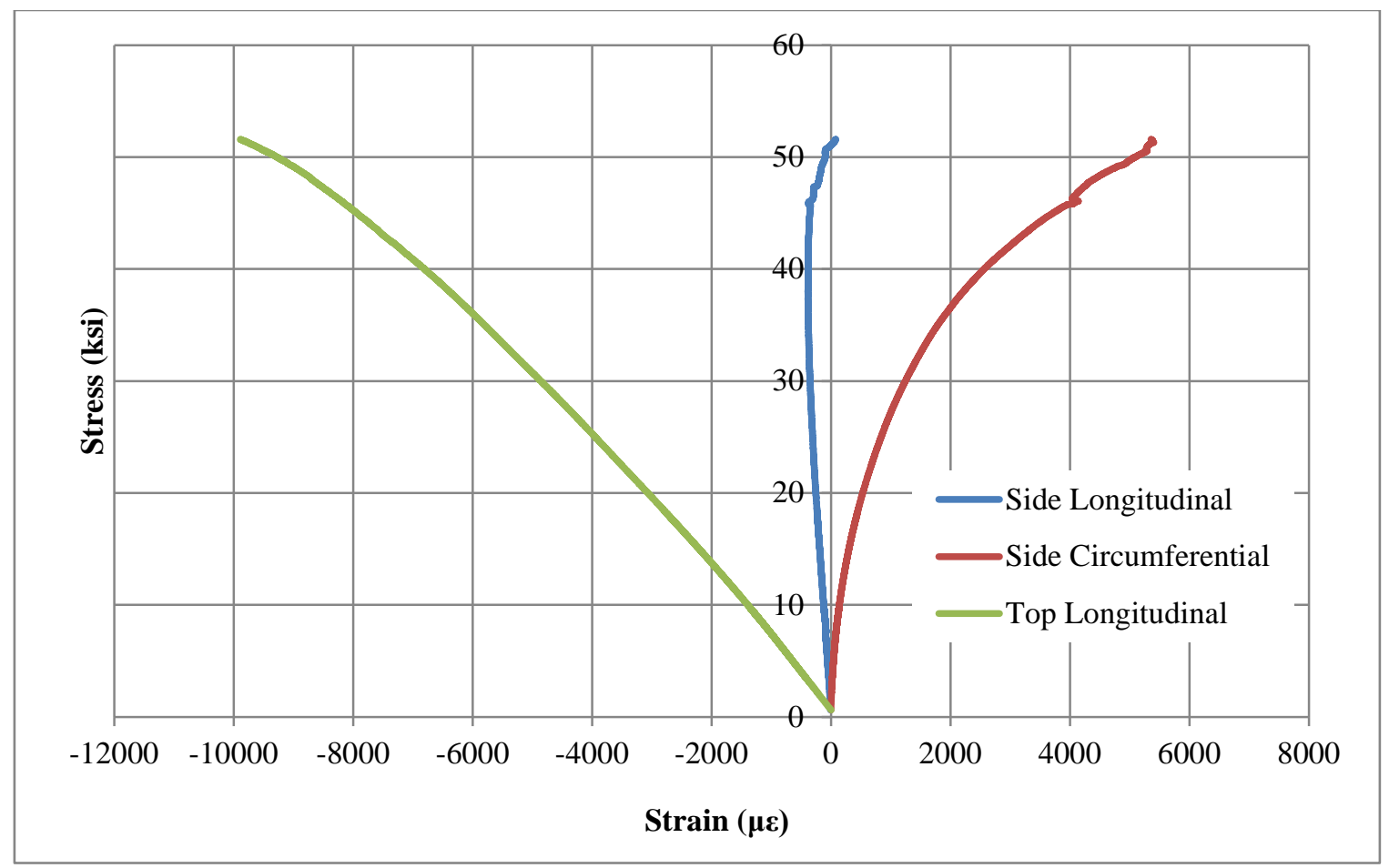

Figure 3-7 Stress vs. Strain for Sample 1 of Section VE-16x0.5

Figure 3-7 shows that the circumferential strain at the side of the sample was significantly less than the longitudinal strain at the top. This does not mean that local buckling and cross sectional warping were not occurring, but that it was less than that of the polyurethane counterpart (see Figure 3-5). In fact local buckling was occurring some in this section, but crushing in the compression zone is the primary mode of failure. More confirmation of this is given in the stress vs. strain data recorded from the post fatigue sample.

One sample of section VE-16x0.5 underwent 200 cycles of four-point bending at $40 \%$ of the ultimate load (see section 3.8). Afterwards, it was tested to failure in static four-point bending. The static test results for this sample are shown in Table 3-6. Included with the sample's results is a comparison to the average values obtained from the static four-point bend tests given in Table 3-6. This comparison is given as a percentage where a negative value conveys it was lower than the average of the non-fatigued samples. 
Table 3-6 Four-Point Bending Results for Post-Fatigue Sample 6 - Section VE-16x0.5

\begin{tabular}{|c|c|c|c|c|c|c|c|}
\hline Sample & $\begin{array}{c}\text { Max } \\
\text { Load } \\
\text { (kips) }\end{array}$ & $\begin{array}{c}\text { Max } \\
\text { Deflection } \\
\text { (in) }\end{array}$ & $\begin{array}{c}\text { Max } \\
\text { Moment } \\
\text { (kip-in) }\end{array}$ & $\begin{array}{c}\text { Max } \\
\text { Stress } \\
\text { (ksi) }\end{array}$ & $\begin{array}{c}\text { Max } \\
\text { Longitudinal } \\
\text { Strain ( } \boldsymbol{\mu \varepsilon})\end{array}$ & $\begin{array}{c}\text { Elastic } \\
\text { Modulus } \\
\text { (Msi) }\end{array}$ & $\begin{array}{c}\text { Energy } \\
\text { (kip- } \\
\text { in) }\end{array}$ \\
\hline $\begin{array}{c}\text { VE-16x0.5 } \\
\text { Sample 6 }\end{array}$ & 79.00 & 7.89 & 4227 & 46.20 & 7545 & 6.05 & 347.65 \\
\hline $\begin{array}{c}\text { Percent } \\
\text { Difference } \\
\text { from Static } \\
\text { Average }\end{array}$ & $\mathbf{- 4 . 8 8}$ & $\mathbf{- 3 6 . 7 2}$ & $\mathbf{- 4 . 8 8}$ & $\mathbf{- 4 . 8 8}$ & $\mathbf{- 1 5 . 3 5}$ & $\mathbf{8 . 4 7}$ & $\mathbf{- 4 0 . 0 8}$ \\
\hline
\end{tabular}

Results in Table 3-6 do not show any significant decrease in stiffness. Therefore, it is believed that the 200 cycles at $40 \%$ had no effect on stiffness. It is unclear whether the strength was affected by the fatigue cycling or not. Although, according to Table 3-6, Sample 6 failed at a much lower load and deflection than the average results from the non-fatigued samples, Sample 6 actually failed at the one of the points of load application as opposed to the center of the span. This failure is the same as Sample 2 from the non-fatigued set (Table 3-5). Also, for Sample 6 during the four-point bending test to failure, many gages were applied around the circumference at midspan to further quantify any buckling behavior. Figure 3-3 shows the placement of these eight gages. All of the possible locations and orientations in Figure 3-3 were used. The stress vs. strain curve for section VE-16x0.5 is shown in Figure 3-8. 


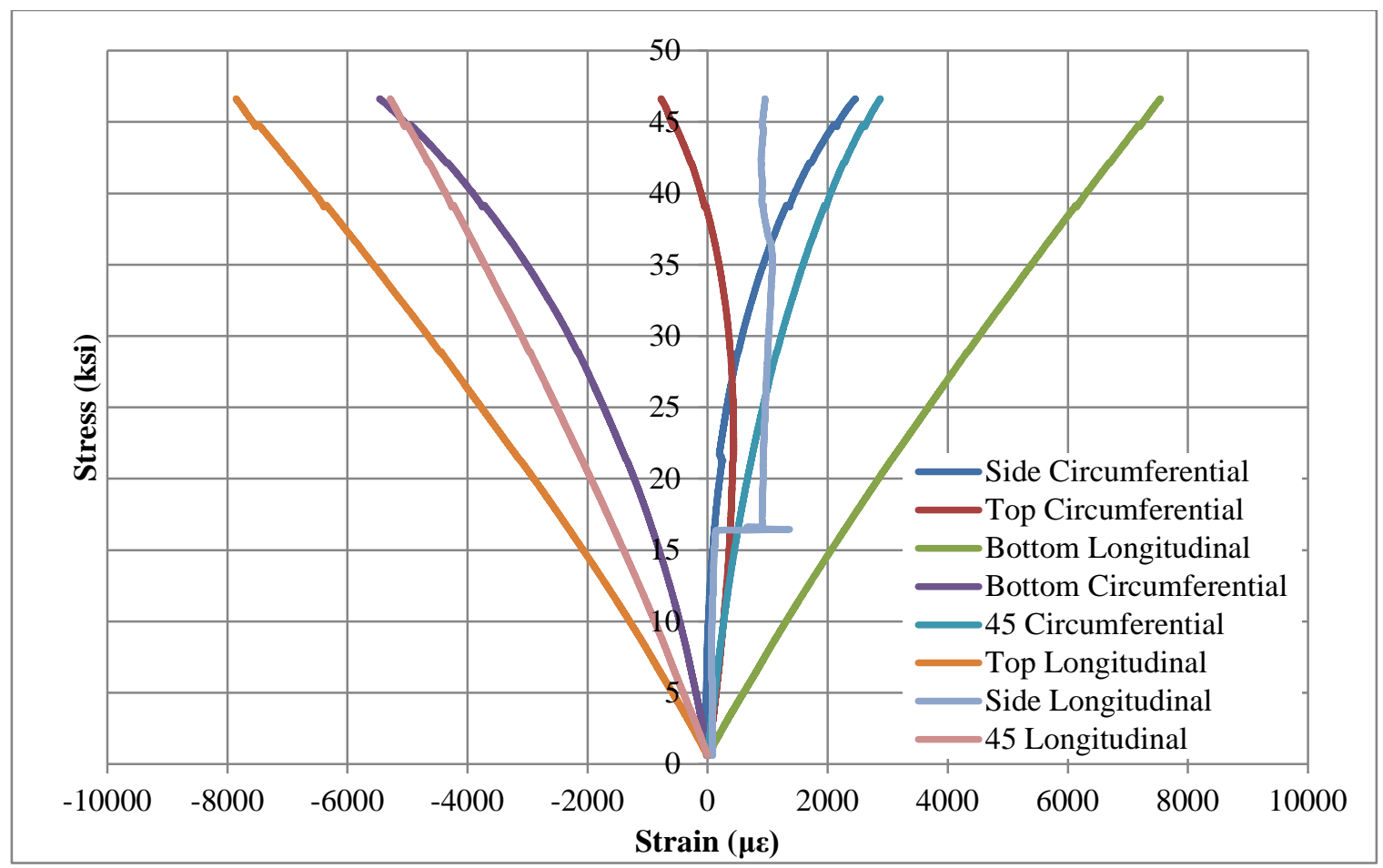

Figure 3-8 Stress vs. Strain for Sample 6 - Section VE-16x0.5

The curves shown in Figure 3-8 give insight into the cross section distortion that occurs throughout the bending test. Compared to its polyurethane counterpart (see Figure 3-6), section VE-16x0.5 deformed less. The circumferential strain at the top $(\theta=0)$ is practically zero throughout the duration of the test. It is difficult to say when exactly geometrical nonlinearity begins for this section, but it appears to be at 25-30 ksi bending stress which corresponds to 54$65 \%$ of the ultimate stress.

\subsubsection{Section PU-12x0.5}

The results from the four-point bending tests are given in Table 3-7. Crackling sounds were clearly heard on all samples starting at around $75 \%$ of the failure load and continued regularly until failure, though no cracks were visible from a safe viewing distance. Failure in all samples was sudden and abrupt, though preceded by much crackling. After failure, longitudinal cracks were found on the tube primarily centering about midspan along with crushing and tearing 
of the section in the middle third zone of a test specimen. All samples failed in the middle third zone of the test span as shown in Figure 3-9. However, some samples showed damage at one or both points of loading due to load concentration. Sample numbers refer only to the order in which they were tested, and they are not sequenced between different test setups.

Table 3-7 Four-Point Bending Results - Section PU-12x0.5

\begin{tabular}{|c|c|c|c|c|c|c|c|}
\hline Sample & $\begin{array}{c}\text { Max } \\
\text { Load } \\
\text { (kips) }\end{array}$ & $\begin{array}{c}\text { Max } \\
\text { Deflection } \\
\text { (in) }\end{array}$ & $\begin{array}{c}\text { Max } \\
\text { Moment } \\
\text { (kip-in) }\end{array}$ & $\begin{array}{c}\text { Max } \\
\text { Stress } \\
\text { (ksi) }\end{array}$ & $\begin{array}{c}\text { Max } \\
\text { Longitudinal } \\
\text { Strain }(\boldsymbol{\mu \varepsilon})\end{array}$ & $\begin{array}{c}\text { Elastic } \\
\text { Modulus } \\
\mathbf{( M s i )}\end{array}$ & $\begin{array}{c}\text { Energy } \\
\text { (kip-in) }\end{array}$ \\
\hline $\mathbf{1}$ & 93.55 & 13.42 & 3741.93 & 75.04 & 13206 & 6.65 & 705.29 \\
\hline $\mathbf{2}$ & 100.35 & 13.78 & 4014.06 & 80.50 & 13325 & 6.62 & 781.12 \\
\hline $\mathbf{3}$ & 80.36 & 11.03 & 3214.50 & 64.46 & 9657 & 7.06 & 489.20 \\
\hline $\mathbf{4}$ & 87.76 & 11.39 & 3510.38 & 70.40 & 11584 & 6.24 & 566.26 \\
\hline $\mathbf{5}$ & 92.61 & 12.35 & 3704.33 & 74.29 & 15829 & 6.47 & 631.69 \\
\hline Average & $\mathbf{9 0 . 9 3}$ & $\mathbf{1 2 . 3 9}$ & $\mathbf{3 6 3 7}$ & $\mathbf{7 2 . 9 4}$ & $\mathbf{1 2 7 2 0}$ & $\mathbf{6 . 6 1}$ & $\mathbf{6 3 4 . 7 1}$ \\
\hline
\end{tabular}

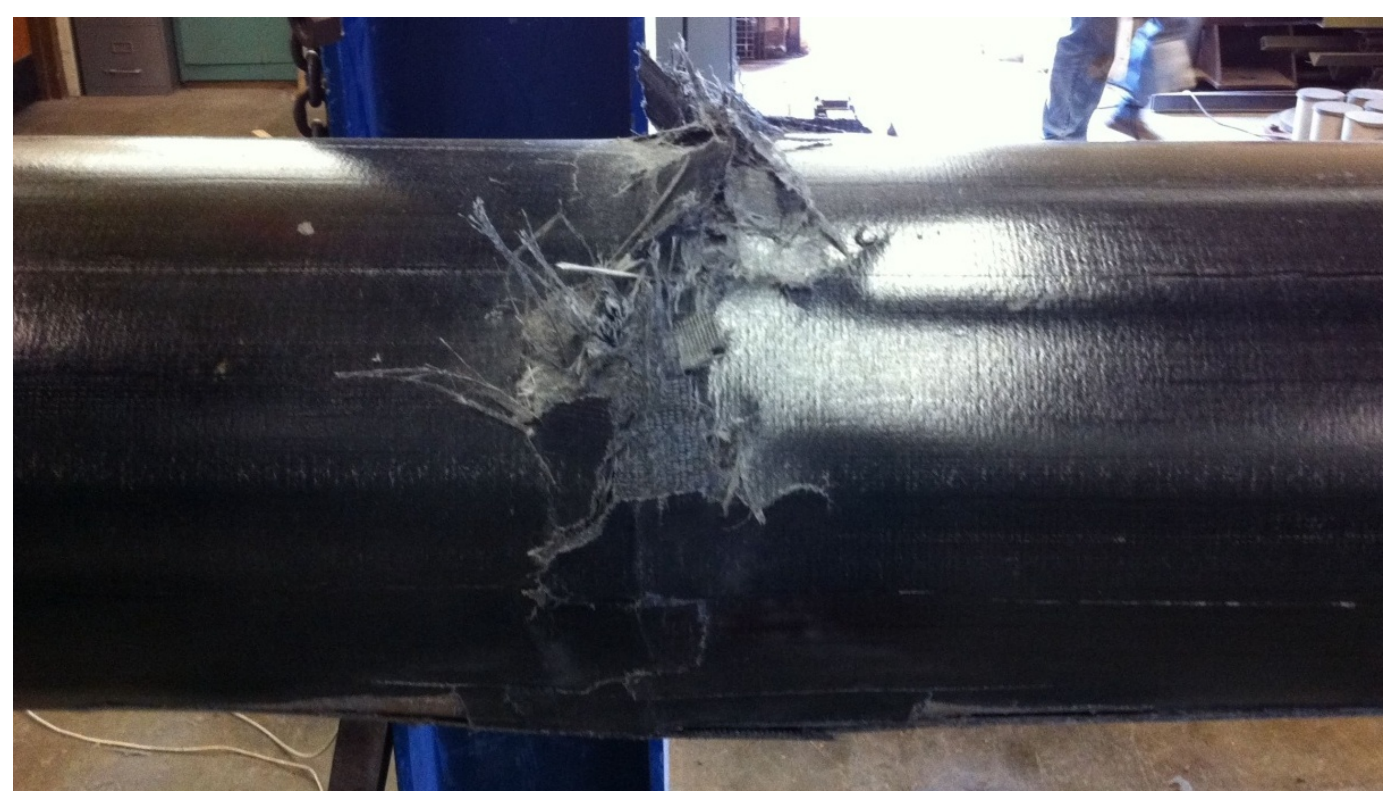

Figure 3-9 Failed Four-Point Bending Failure - Section PU-12x0.5 
The failure mode of these tubes is primarily crushing in the compressive face with some attribution from local buckling; although less buckling is occurring than the direction 16 in diameter counterpart. This is due to the PU-12x0.5 tube's D/t ratio of 24 compared to the PU16x0.5 tube's D/t ratio of 32. Sample 2 of section PU-12x0.5 had five gages located at varying locations and orientations to quantify any local buckling. The stress vs. strain relationship for Sample 2 is shown in Figure 3-10. Please note that a negative strain indicates compression and a positive strain indicates tension.

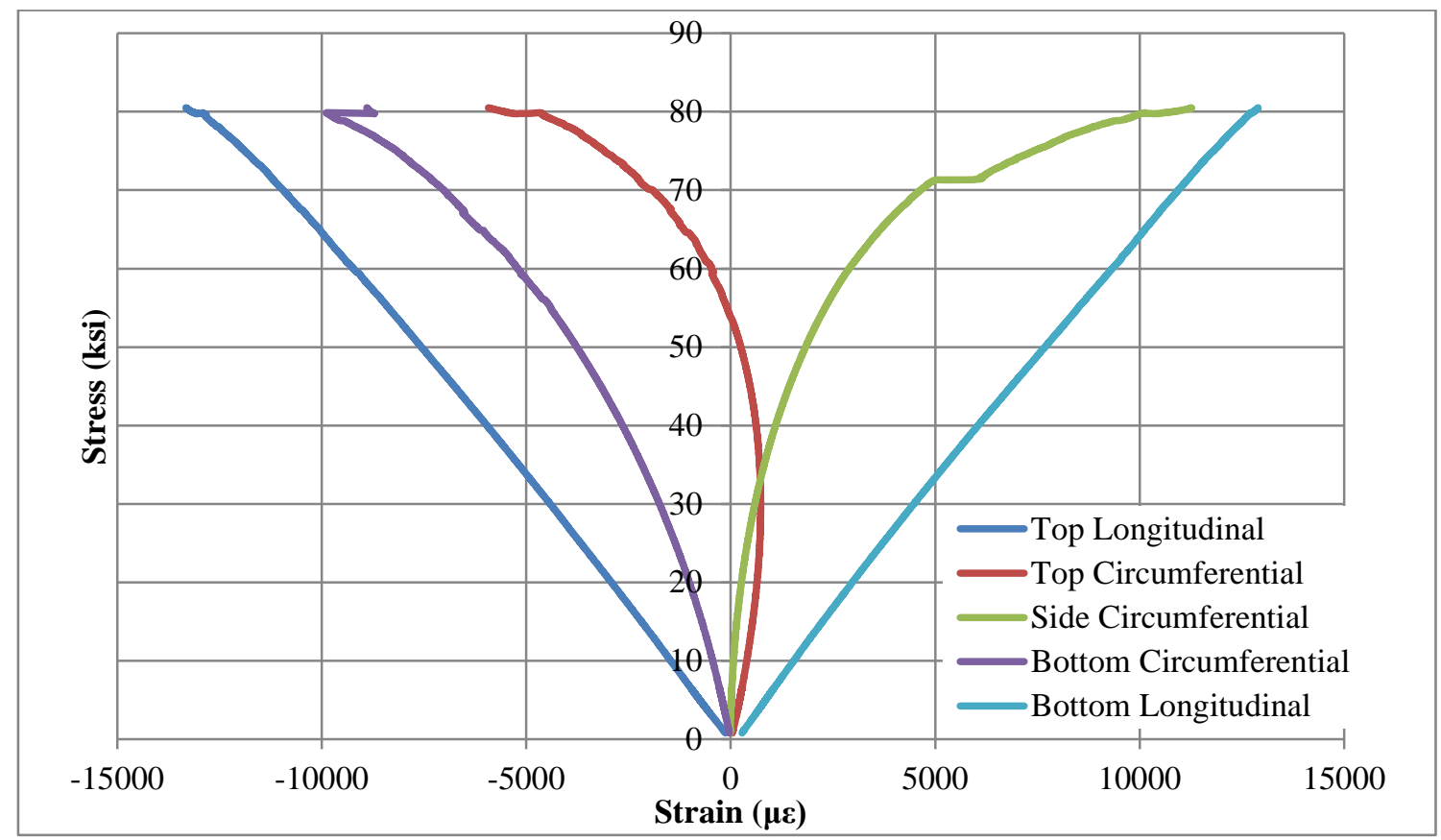

Figure 3-10 Stress vs. Strain for Sample 2 of Section PU-12x0.5

Figure 3-10 shows the side circumferential approaching strain magnitudes close to both the top and bottom longitudinal values indicating some cross sectional warping. It is also helpful to see the top circumferential strain being highly nonlinear starting at around 35\% of the failure load. This shows when the local buckling is starting to begin. This also matches well with the failure mode observed after the experiment. There were no longitudinal splits and the failure 
occurred mostly in the compressive zone as a result of local crushing/buckling (see Figure 3-9). More confirmation of this is given in the stress vs. strain data recorded from the post fatigue sample.

One sample of section PU-12x0.5 underwent 200 cycles of four-point bending at $40 \%$ of the ultimate load (see section 3.8). Afterwards, it was tested to failure in static four-point bending. The static test results for this sample are shown in Table 3-8. Included with the sample's results is a comparison to the average values obtained from the static four-point bend tests given in Table 3-7. This comparison is given as a percentage where a negative value conveys it was lower than the average from the non-fatigued samples.

Table 3-8 Four-Point Bending Results for Post-Fatigued Samples

\begin{tabular}{|c|c|c|c|c|c|c|c|}
\hline Sample & $\begin{array}{c}\text { Max } \\
\text { Load } \\
\text { (kips) }\end{array}$ & $\begin{array}{c}\text { Max } \\
\text { Deflection } \\
\text { (in) }\end{array}$ & $\begin{array}{c}\text { Max } \\
\text { Moment } \\
\text { (kip-in) }\end{array}$ & $\begin{array}{c}\text { Max } \\
\text { Stress } \\
\text { (ksi) }\end{array}$ & $\begin{array}{c}\text { Max } \\
\text { Longitudinal } \\
\text { Strain }(\boldsymbol{\mu \varepsilon})\end{array}$ & $\begin{array}{c}\text { Elastic } \\
\text { Modulus } \\
\text { (Msi) }\end{array}$ & $\begin{array}{c}\text { Energy } \\
\text { (kip- } \\
\text { in) }\end{array}$ \\
\hline $\begin{array}{c}\text { PU-12x0.5 } \\
\text { Sample 6 }\end{array}$ & 95.85 & - & 3834 & 76.89 & 12941 & 5.82 & - \\
\hline $\begin{array}{c}\text { Percent } \\
\text { Difference } \\
\text { from Static } \\
\text { Average }\end{array}$ & $\mathbf{5 . 4 1}$ & - & $\mathbf{5 . 4 1}$ & $\mathbf{5 . 4 1}$ & $\mathbf{1 . 7 4}$ & $\mathbf{- 1 1 . 9 4}$ & - \\
\hline
\end{tabular}

The results in Table 3-8 do not show any significant decrease in strength. Therefore, it is believed that the 200 cycles at $40 \%$ had no effect on strength. It appears that there could have been some decrease in stiffness due to the cyclic loading; however, more tests would need to be done to confirm this. Also, for Sample 6 during the four-point bending test to failure, many gages were applied around the circumference at midspan to further quantify any buckling behavior. Figure 3-3 shows the placement of these gages. All of the possible locations and 
orientations in Figure 3-3 were used. The stress vs. strain curve for section PU-12x0.5 is shown in Figure 3-11.

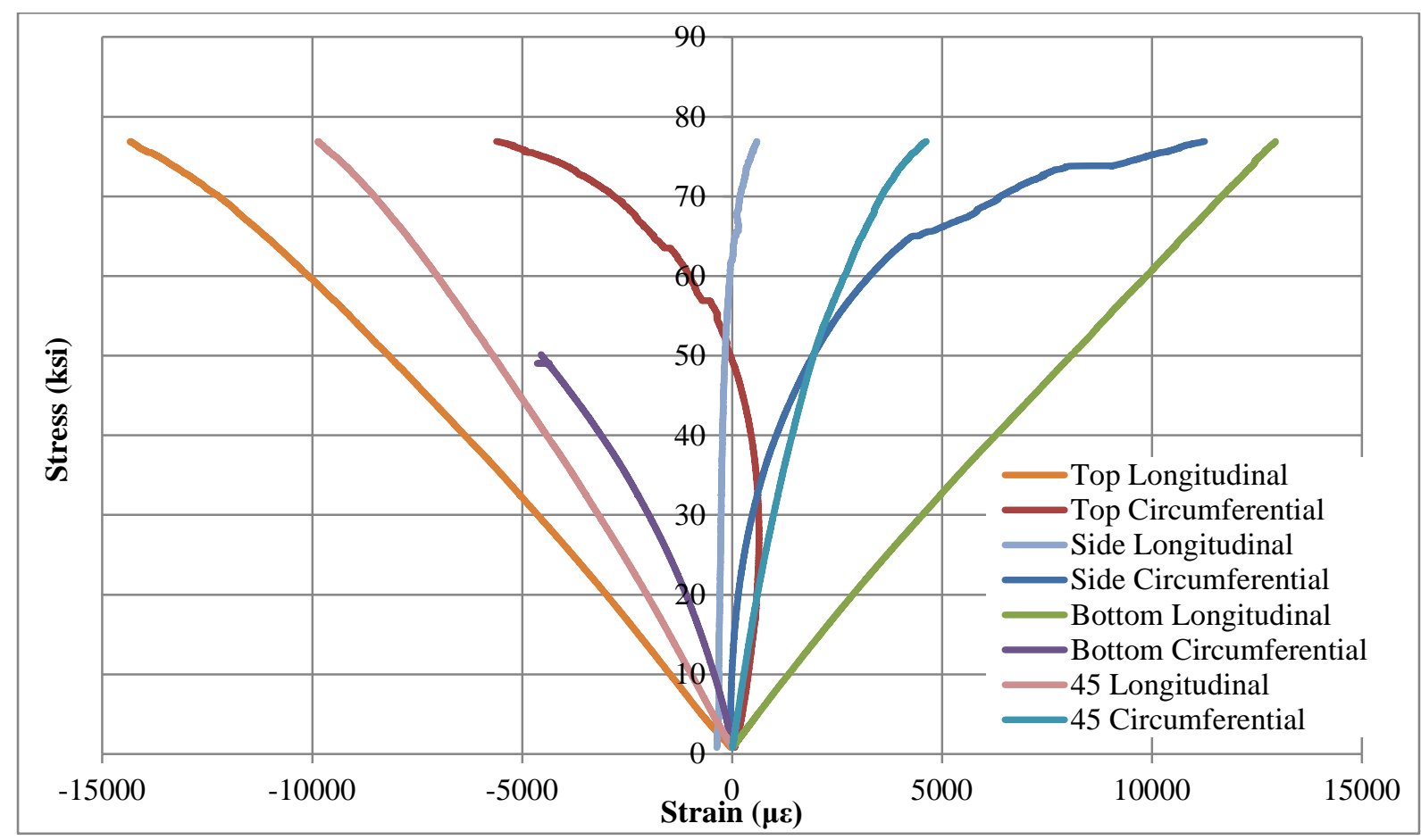

Figure 3-11 Stress vs. Strain for Sample 6 - Section PU-12x0.5

The curves shown in Figure 3-11 illustrate that cross sectional deformation was even occurring for section PU-12x0.5. The top and bottom of the cross section begin showing nonlinear behavior at $~ 30-35$ ksi bending stress which corresponds to $39-46 \%$ of the ultimate stress.

\subsubsection{Section PU-12x0.375}

The results from the four-point bending tests are given in Table 3-9. Crackling sounds were clearly heard on all samples starting around $80 \%$ of the failure load and continued regularly until failure though no cracks were visible from a safe viewing distance. Failure in all samples was sudden and abrupt, though preceded by much crackling. After failure, longitudinal cracks were found on the tube primarily centering about midspan along with crushing and tearing of the 
section in the middle third zone of a test specimen. Most samples failed in the middle third zone of the test span as shown in Figure 3-12. However, some samples showed damage at one or both points of loading due to load concentration. Sample 4 underwent a cantilever bending test (see section 3.9) up to $33 \%$ of its projected ultimate strain prior to bending testing in static bending. It is clear by the results of shown in Table 3-9, that these tests did not have any effect on the ultimate strength or stiffness of the specimen. Sample numbers refer only to the order in which they were tested, and they are not sequenced between different test setups.

Table 3-9 Four-Point Bending Results - Section PU-12x0.375

\begin{tabular}{|c|c|c|c|c|c|c|c|}
\hline Sample & $\begin{array}{c}\text { Max } \\
\text { Load } \\
\text { (kips) }\end{array}$ & $\begin{array}{c}\text { Max } \\
\text { Deflection } \\
\text { (in) }\end{array}$ & $\begin{array}{c}\text { Max } \\
\text { Moment } \\
\text { (kip-in) }\end{array}$ & $\begin{array}{c}\text { Max } \\
\text { Stress } \\
\text { (ksi) }\end{array}$ & $\begin{array}{c}\text { Max } \\
\text { Longitudinal } \\
\text { Strain }(\boldsymbol{\mu \varepsilon})\end{array}$ & $\begin{array}{c}\text { Elastic } \\
\text { Modulus } \\
\text { (Msi) }\end{array}$ & $\begin{array}{c}\text { Energy } \\
\text { (kip-in) }\end{array}$ \\
\hline $\mathbf{1}$ & 52.93 & 11.16 & 2117.39 & 54.86 & 10989 & 5.10 & 316.95 \\
\hline $\mathbf{2}$ & 52.72 & 11.19 & 2108.62 & 54.63 & 10772 & 5.20 & 331.88 \\
\hline $\mathbf{3}$ & 55.35 & 11.93 & 2213.88 & 57.36 & 10718 & 5.47 & 375.33 \\
\hline $\mathbf{4}$ & 50.92 & 11.74 & 2036.61 & 52.76 & 10894 & 5.02 & 333.70 \\
\hline Average & $\mathbf{5 2 . 9 8}$ & $\mathbf{1 1 . 5 1}$ & $\mathbf{2 1 1 9 . 1 2}$ & $\mathbf{5 4 . 9 0}$ & $\mathbf{1 0 8 4 3}$ & $\mathbf{5 . 2 0}$ & $\mathbf{3 3 9 . 4 6}$ \\
\hline
\end{tabular}




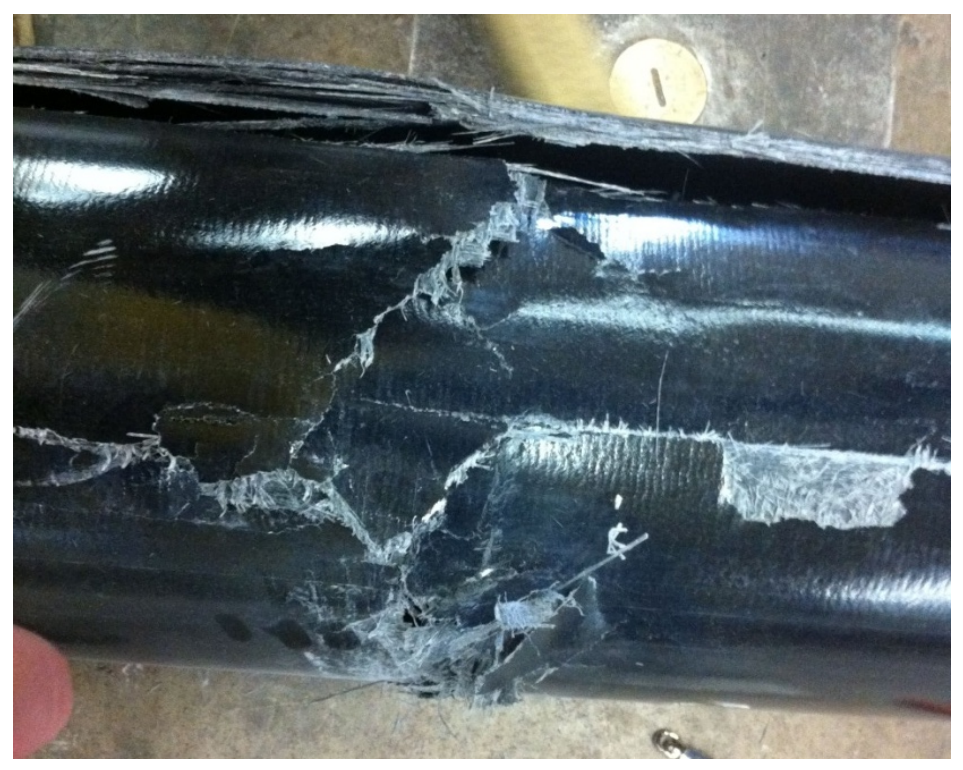

Figure 3-12 Failed Four-Point Bending Sample - Section PU-12x0.375

Crushing on the compression face was the primary mode of failure for these sections, and it appears to have been contributed to by local buckling behavior. As shown in Figure 3-12, the failure was explosive and resulted in cracks forming in longitudinal and circumferential directions. This was typical for all samples. Section PU-12x0.375 has a D/t ratio of 32 which is the same as both 16 in diameter sections, and the same fiber-resin system as PU-16x0.5; therefore, it was expected to have similar failure behavior. Also, for Sample 4 during the fourpoint bending test to failure, many gages were applied around the circumference at midspan to further quantify any buckling behavior. Figure 3-3 shows the placement of these gages. All of the possible locations and orientations in Figure 3-3 were used. The stress vs. strain curve for section PU-12x0.375 is shown in Figure 3-13. 


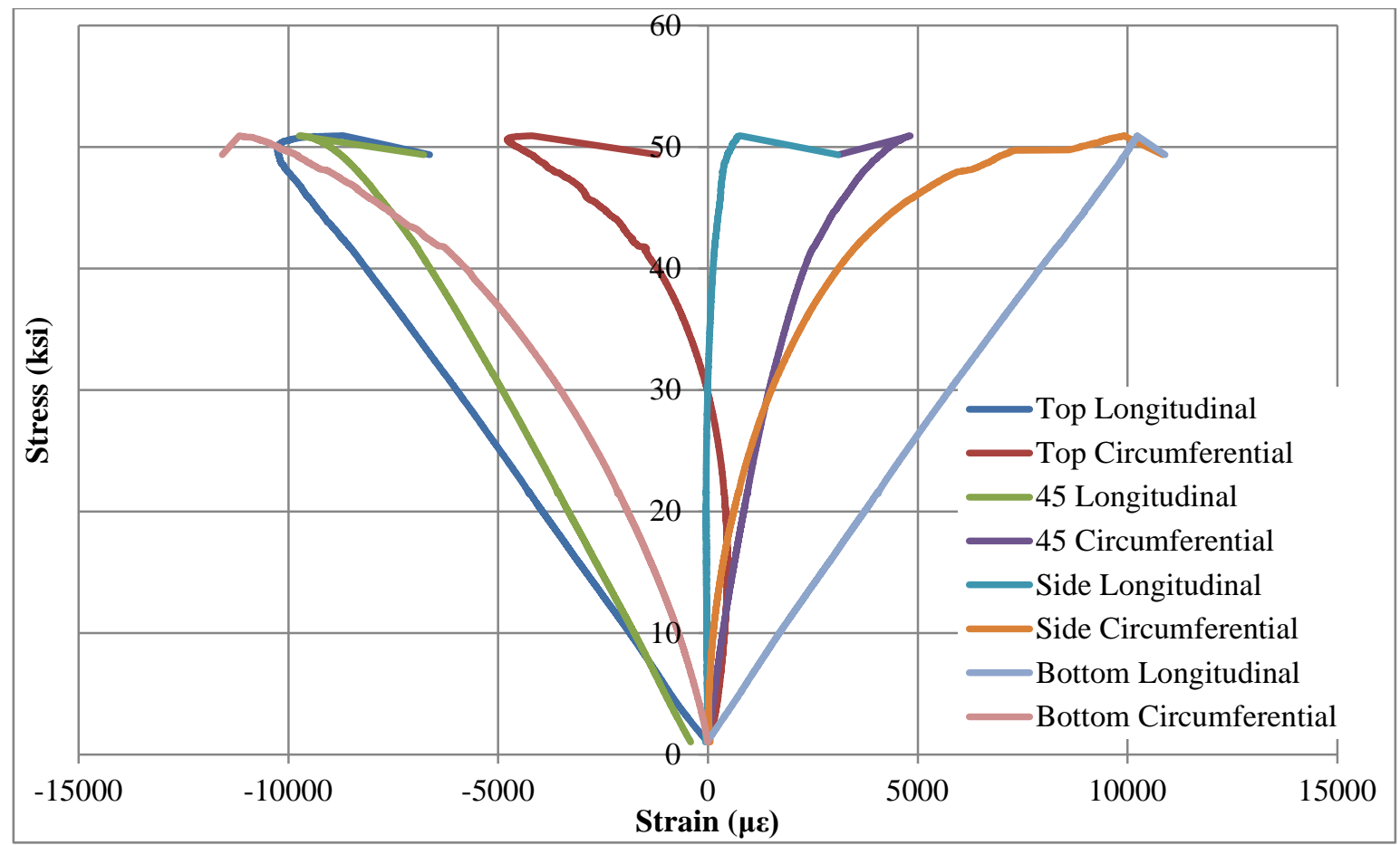

Figure 3-13 Stress vs. Strain for Sample 4 - Section PU-12x0.375

The curves shown in Figure 3-13 give insight into the cross section distortion that occured throughout the bending test. The circumferential strain at the top $\left(\theta=0^{\circ}\right)$ and the circumferential strain on the side $\left(\theta=90^{\circ}\right)$ begin to behavior nonlinearly at $\sim 15-20$ ksi which corresponds to 27 $36 \%$ of the ultimate stress.

\subsection{Crush Testing}

\subsubsection{Methodology}

The "crush test" is a test that uses a reinforced square block, or "wale section", to press under point load on the tube section laterally (see Figure 3-14). The four-point bending tests led to the failure in the middle (mostly) of the tubes, with the ends showing no signs of distress after testing to failure. Therefore for sections PU-16x0.5, VE-16x0.5, and PU-12x0.5 the tested tubes were cut near the ends to harvest undamaged ends so that they can be used for crush testing. For 
section PU-12x0.375, undamaged 60" samples were provided by CP. The samples were set in the same saddles used in the four-point bend test with the rollers under the saddles removed. For the 16-inch tubes, the saddles were set at 6-feet apart and the damaged end from four-point testing was left to hang off the end, supported by a gantry crane to keep the specimen level. For the 12-inch tubes, 4-foot sections of the tubes were cut from the undamaged ends and set in the saddles, with the saddles supporting roughly 4 inches at each end of the tube as shown in Figure 3-14. For each test, the area between the saddles under the tube was fully supported longitudinally on solid steel plates with a neoprene pad between the steel support plate and the FRP composite. Load was transferred from a hydraulic actuator through a steel plate to an Omega LC-8400-200-200 kip load cell and then through another plate into a 10-inch by 10-inch solid polymer wale section that was supplied by CP (see Figure 3-14). The wale section was connected to the steel plates by threaded rods for stability during testing. Deflection readings were taken from the overhang of the wale section by a Celesco SP3 string pot. This position for the deflection measurement was practically ideal; however, the readings will only show the deflection of one side which could be more or less than the other side. This is due to loading through a square wale section against the tube; therefore, it is difficult to maintain perfect balance during loading. All test samples were loaded until the area around the application of the load (i.e. top of the tube) failed to the point at which the section was no longer circular and the wale section was nearly touching the sides of the tube (see Figure 3-16). Testing was stopped before the sides were loaded as this caused damage to the wale section (cutting into surface of wale section) and additional loading would simply crush flat the already failed structural system. 


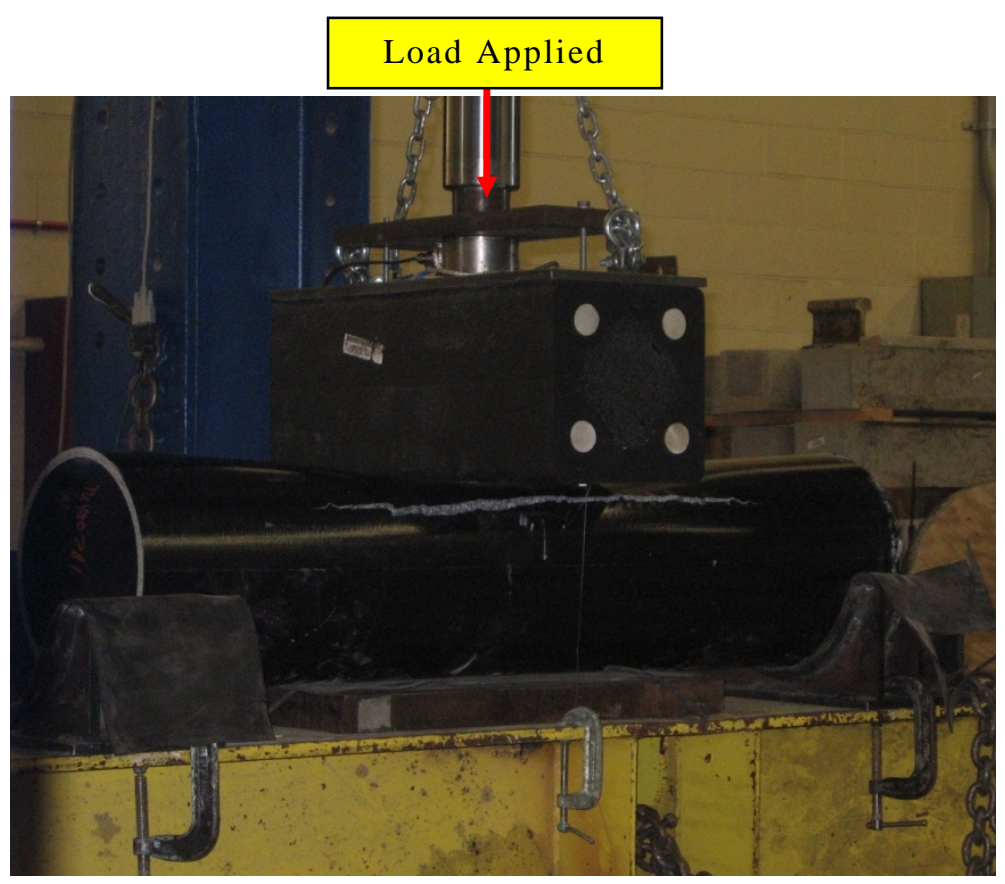

Figure 3-14 Crush Test Being Performed - Section PU-12x0.5

\subsubsection{Results and Discussion}

\subsubsection{Section $P U-16 \times 0.5$}

The results from the crush testing are given in Table 3-10 and Figure 3-15. Typically there was little deflection induced under vertical loading until the specimen started cracking, then deflection started to grow quickly. After around 2 inches of deflection, the top of the tube had flattened out and longitudinal cracks were visible on both sides as shown in Figure 3-16, which shows a tube under full load. Upon releasing the load, the tube returned to a circular shape as shown in Figure 3-17. It should be noted that the ends of the tubes remained circular, and no boundary effects were visible from the steel saddles. The string pot used to measure deflection did not work properly for Sample 4, so no deflection readings were measured. To further investigate if the failure load was peaked when the top flattened out, Sample 2 was loaded beyond the failure load. As shown in Figure 3-15, after Sample 2 passed the reported maximum 
load of 28.29 kips at 2.28 inches, the load maintained a plateau until approximately 3 inches. This approximately corresponds to the location of the longitudinal cracks as seen in Figure 3-16 Figure 3-17. At this point, the load was being primarily supported by the vertical faces of the tube which resulted in the tube cutting into the wale section slightly at these locations. Any further loading would simply crush the sample flat and would not accurately demonstrate its strength. Sample numbers refer only to the order in which they were tested, and they are not sequenced between different test setups.

Table 3-10 Crust Test Results - Section PU-16x0.5

\begin{tabular}{|c|c|c|}
\hline Sample & $\begin{array}{c}\text { Max } \\
\text { Load } \\
\text { (kips) }\end{array}$ & $\begin{array}{c}\text { Deflection } \\
\text { at Max } \\
\text { Load (in) }\end{array}$ \\
\hline $\mathbf{1}$ & 28.40 & 1.54 \\
\hline $\mathbf{2}$ & 29.29 & 2.28 \\
\hline $\mathbf{3}$ & 24.86 & 2.22 \\
\hline $\mathbf{4}$ & 24.59 & N/A \\
\hline $\mathbf{5}$ & 30.50 & 2.04 \\
\hline Average & $\mathbf{2 7 . 5 3}$ & $\mathbf{2 . 0 2}$ \\
\hline
\end{tabular}




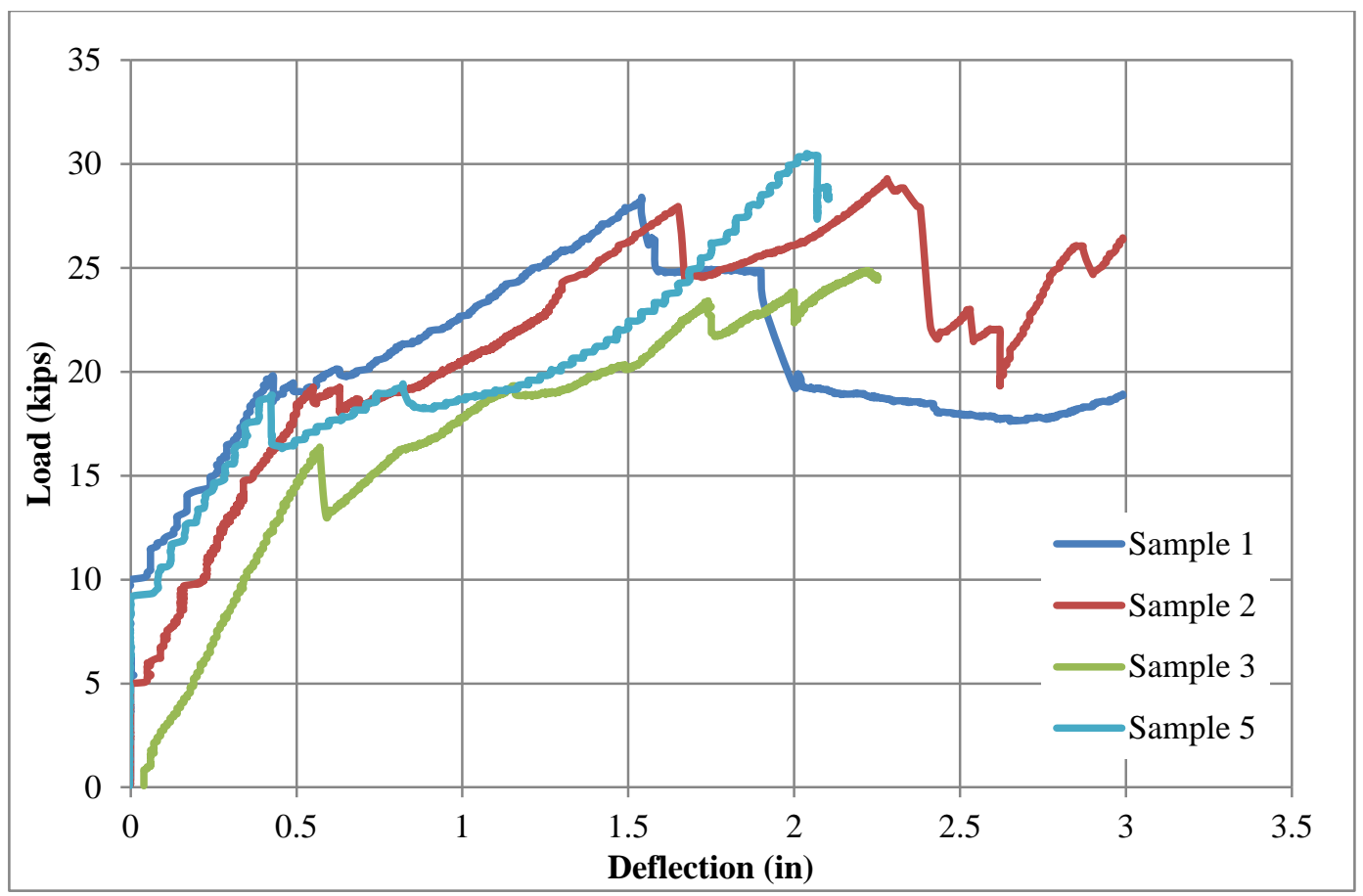

Figure 3-15 Crush Test Load vs. Deflection Response - Section PU-16x0.5

Looking at Figure 3-15, each sample experiences a significant crack at $\sim 0.5$ inches of deflection which was audibly heard. Another significant crack occurred at $~ 1.5$ for each sample, but the highest load attained for each sample immediately precedes the most significant damage, cracks occurring on the sides of the sample, which seemed to happen at $2-2.25$ inches of deflection. The load-deflection result for Samples 1, 2 and 5 do not start deflecting until high loads, and this is due to an imbalance of the square section on the tube and deflection only being measured on one side. 


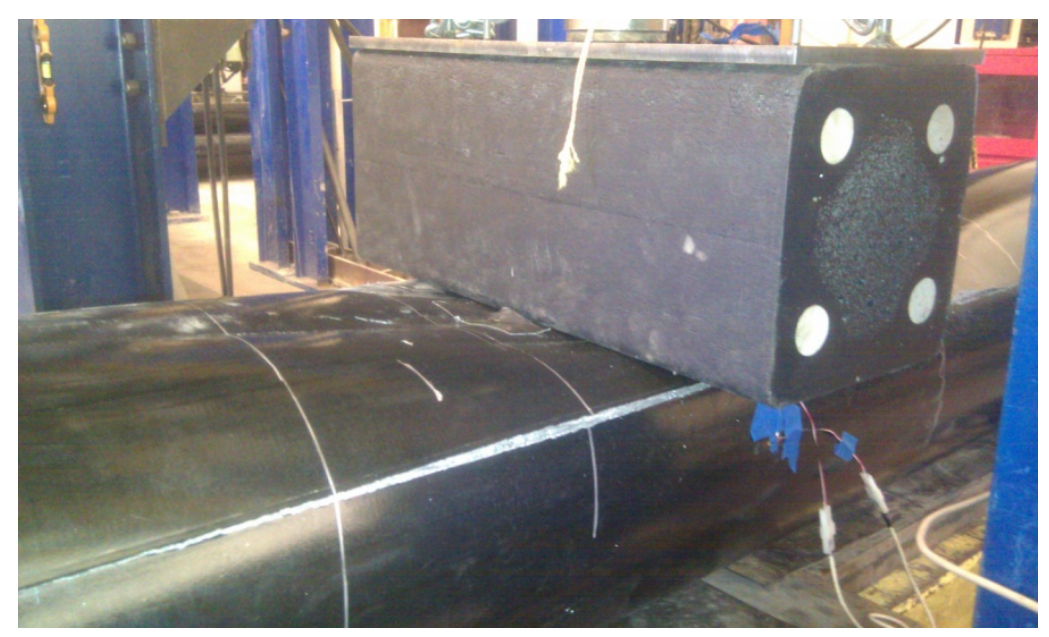

Figure 3-16 Crush Test at Failure Load - Section PU-16x0.5

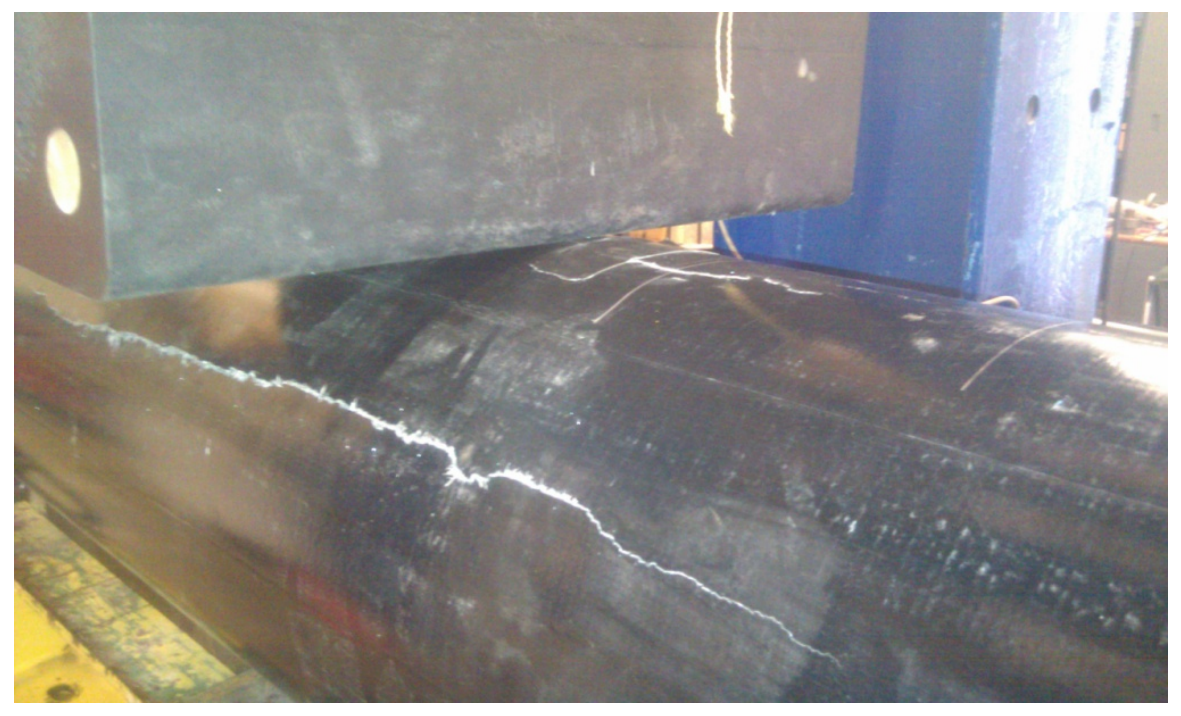

Figure 3-17 Crust Test after Load was Released - Section PU-16x0.5

\subsubsection{Section VE-16x0.5}

The results from section VE-16x0.5 are very similar to those of section PU-16x0.5. As noted above when the loading block reaches the sides of the cylinder it can take more load, but 
this was not allowed to happen during these samples. Table 3-11 provides maximum load per sample and deflections for all 4 test samples. It is noted that the vinyl ester samples failed at lower loads than polyurethane samples and deflected less. However, Figure 3-18 which reveals the energy absorption and ductility from the load versus deflection results. Each steep drop in loading indicates a cracking/failing of the section, perhaps on a layer-by-layer basis. Sample numbers refer only to the order in which they were tested, and they are not sequenced between different test setups.

Table 3-11 Crush Test Results - Section VE-16x0.5

\begin{tabular}{|c|c|c|}
\hline Sample & $\begin{array}{c}\text { Max } \\
\text { Load } \\
\text { (kips) }\end{array}$ & $\begin{array}{c}\text { Deflection } \\
\text { at Max } \\
\text { Load (in) }\end{array}$ \\
\hline $\mathbf{1}$ & 15.34 & 1.25 \\
\hline $\mathbf{2}$ & 21.03 & 2.33 \\
\hline $\mathbf{3}$ & 22.04 & 1.53 \\
\hline $\mathbf{4}$ & 16.58 & 1.78 \\
\hline Average & $\mathbf{1 8 . 7 5}$ & $\mathbf{1 . 7 2}$ \\
\hline
\end{tabular}




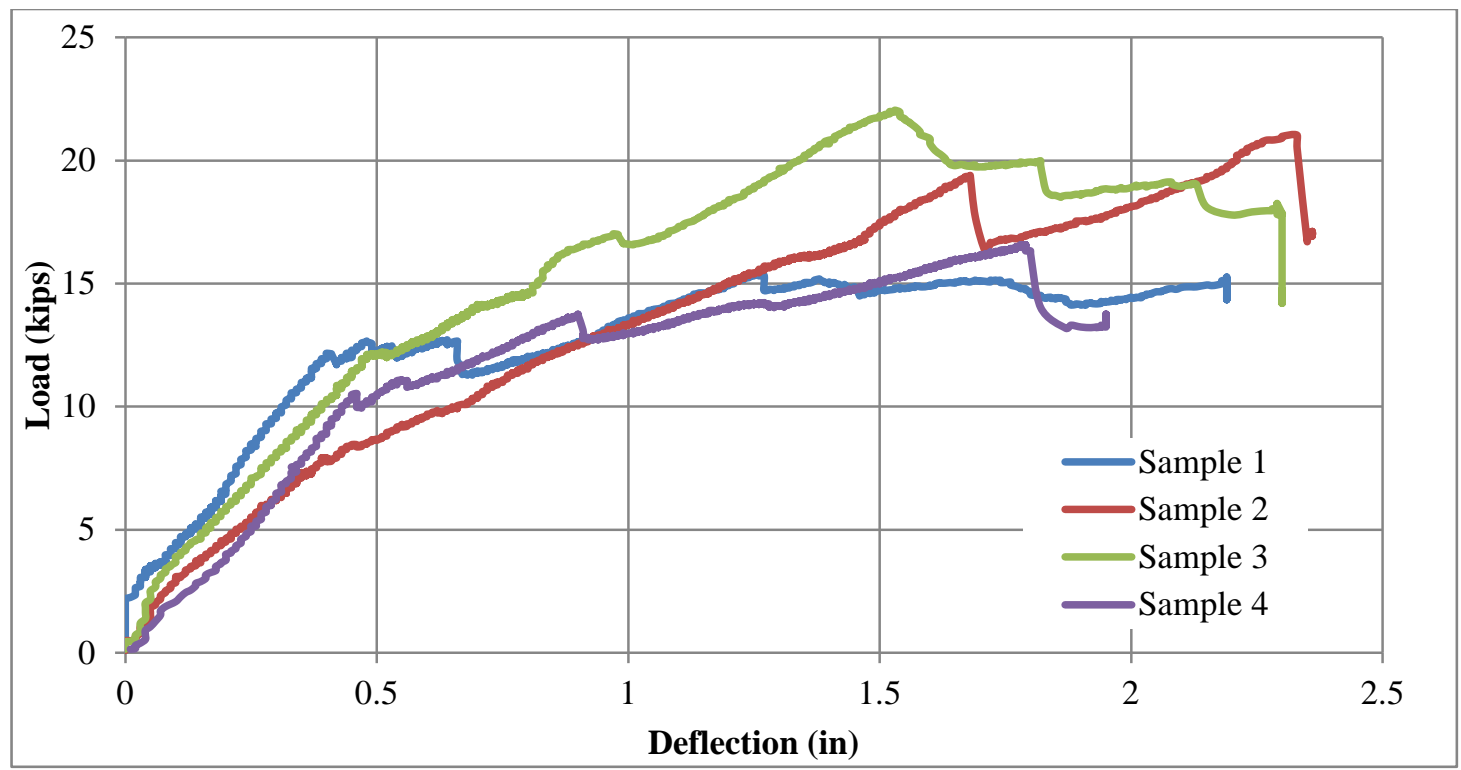

Figure 3-18 Crush Test Load vs. Deflection Response - Section VE-16x0.5

As explained for section PU-16x0.5, crackling was audible and damage was occurring at around $\sim 0.5$ inches deflection and up until the most significant damage which occurs at $\sim 1.75$ inches of deflection. It is at this deflection at which the wall of the tube showed a significant crack along the side of the tube.

\subsubsection{Section $P U-12 \times 0.5$}

The results from the crush testing are given in Table 3-12 and Figure 3-19. Little deflection occurred with the increase in loading until the specimen started crackling, then deflection started to increase quickly. After 2 inches of deflection, the top of the tube had flattened out and longitudinal cracks were visible on both sides, which show the tube under full failure load on the tube (see Figure 3-16). Upon releasing the load, the tube returned to its original circular shape. It should be noted that the ends of the tubes remained near circular in cross section, and no reinforcement effects were visible from the saddles. Sample numbers refer only to the order in which they were tested, and they are not sequenced between different test setups. 
Table 3-12 Crush Test Results - Section PU-12x0.5

\begin{tabular}{|c|c|c|}
\hline Sample & $\begin{array}{c}\text { Max } \\
\text { Load } \\
\text { (kips) }\end{array}$ & $\begin{array}{c}\text { Deflection } \\
\text { at Max } \\
\text { Load (in) }\end{array}$ \\
\hline $\mathbf{1}$ & 28.05 & 1.52 \\
\hline $\mathbf{2}$ & 26.77 & 1.42 \\
\hline $\mathbf{3}$ & 25.98 & 1.3 \\
\hline $\mathbf{4}$ & 27.91 & 0.62 \\
\hline $\mathbf{5}$ & 29.02 & 1.08 \\
\hline Average & $\mathbf{2 7 . 5 4}$ & $\mathbf{1 . 1 9}$ \\
\hline
\end{tabular}

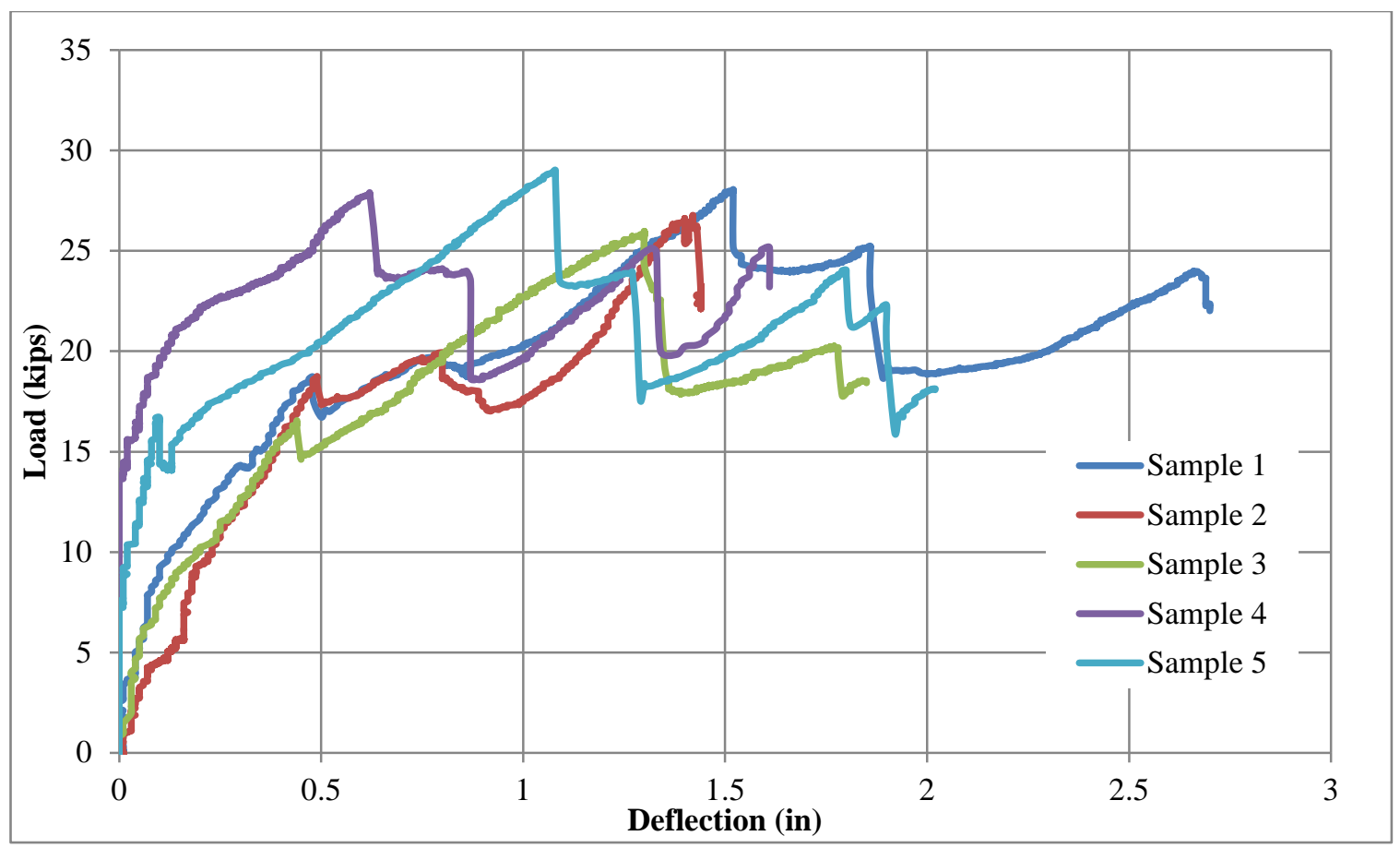

Figure 3-19 Crush Test Load vs. Deflection Response - Section PU-12x0.5

Looking at Figure 3-19, each sample experiences a significant crack at $\sim 0.5$ inches of deflection which was audibly heard. Continued crackling is heard on the sample until the highest load is attained for each sample which immediately precedes the most significant damage, cracks occurring on the sides of the sample, which seems to happen at 1-1.5 inches of deflection. The load-deflection result for Samples 4 and 5 do not start deflecting until high loads, and this is due 
to an imbalance of the square section on the tube and deflection only being measured on one side. This also explains why these two samples experienced the most major damage at a lower deflection. It cannot be said which samples were most accurate with the deflection readings, but this data provides a good range and a general approximation of failure load and deflection at failure.

\subsubsection{Section PU-12x0.375}

The results from the crush testing are given in Table 3-13 and Figure 3-20. Little deflection occurred with the increase in loading until the specimen started crackling, then deflection started to increase quickly. After 2 inches of deflection, the top of the tube had flattened out and longitudinal cracks were visible on both sides. Figure 3-21 shows the tube failure but with full failure load on the tube. Upon releasing the load, the tube returned to a circular shape. It should be noted that the ends of the tubes remained near circular in cross section, and no reinforcement effects were visible from the saddles. Sample numbers refer only to the order in which they were tested, and they are not sequenced between different test setups.

Table 3-13 Crush Test Results - Section PU-12x0.375

\begin{tabular}{|c|c|c|}
\hline Sample & $\begin{array}{c}\text { Max } \\
\text { Load } \\
\text { (kips) }\end{array}$ & $\begin{array}{c}\text { Deflection } \\
\text { at Max } \\
\text { Load (in) }\end{array}$ \\
\hline $\mathbf{1}$ & 17.16 & 2.10 \\
\hline $\mathbf{2}$ & 17.33 & 2.07 \\
\hline $\mathbf{3}$ & 20.59 & 2.02 \\
\hline Average & $\mathbf{1 8 . 3 6}$ & $\mathbf{2 . 0 6}$ \\
\hline
\end{tabular}




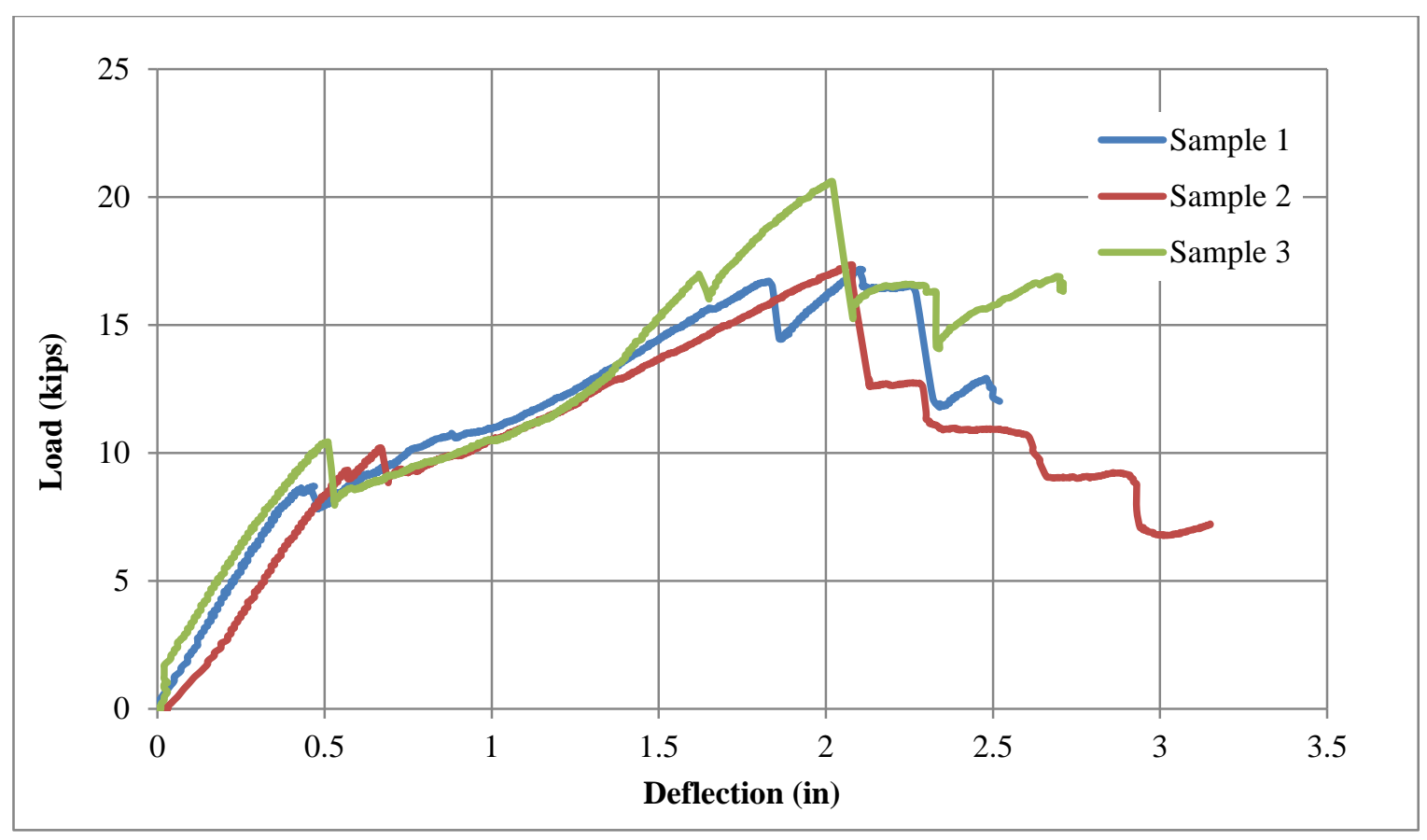

Figure 3-20 Crush Test Load vs. Deflection Response - Section PU-12x0.375

Looking at Figure 3-20, each sample experienced a significant crack at $\sim 0.5$ inches of deflection which was audibly heard. Continued crackling was heard on the sample until the highest load was attained for each sample which immediately preceded the most significant damage, cracks occurring on the sides of the sample, which seemed to happen at $\sim 2$ inches of deflection. 


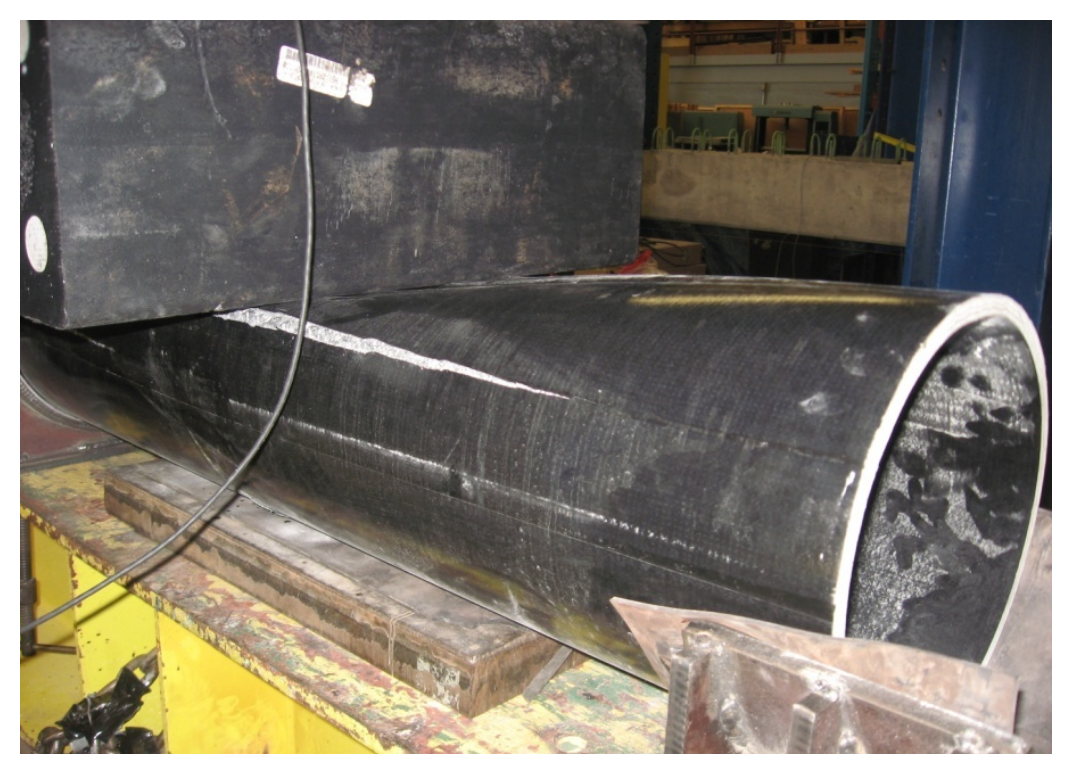

Figure 3-21 Crust Test at Failure Load - Section PU-12x0.375

\subsection{Connection Testing A}

\subsubsection{Methodology}

The purpose of this test was to simulate the effect of a load being applied to a bolt that connects tubes together in a mooring pile situation. The goal is to determine the mode of failure, the failure load, and to compare the tested sections to each other. A 1" diameter steel pin was inserted through the middle of the 16” and 12” diameter tubes (see Figure 3-1 and Figure 3-22). The holes for the pins were prepared by drilling through the material. Each tube length was roughly 24”. The load was applied through the 1 ” diameter pin as shown in Figure 3-22. The load versus deflection of the pin was recorded at each point that it touched the pipe as shown in Figure 3-22. Two LVDTs were used directly under the pin on the outside of the load frame (see Figure 3-22). This positioning yielded accurate deflections and conveys how much the pin hole enlarged during loading to failure. Each specimen with the exception of first few Samples (1-3) 
was loaded until the frame was about to be in contact with the top of the pipe; this was done in order to obtain a good load-deflection curve with many points beyond the maximum load resistance offered by the tube.

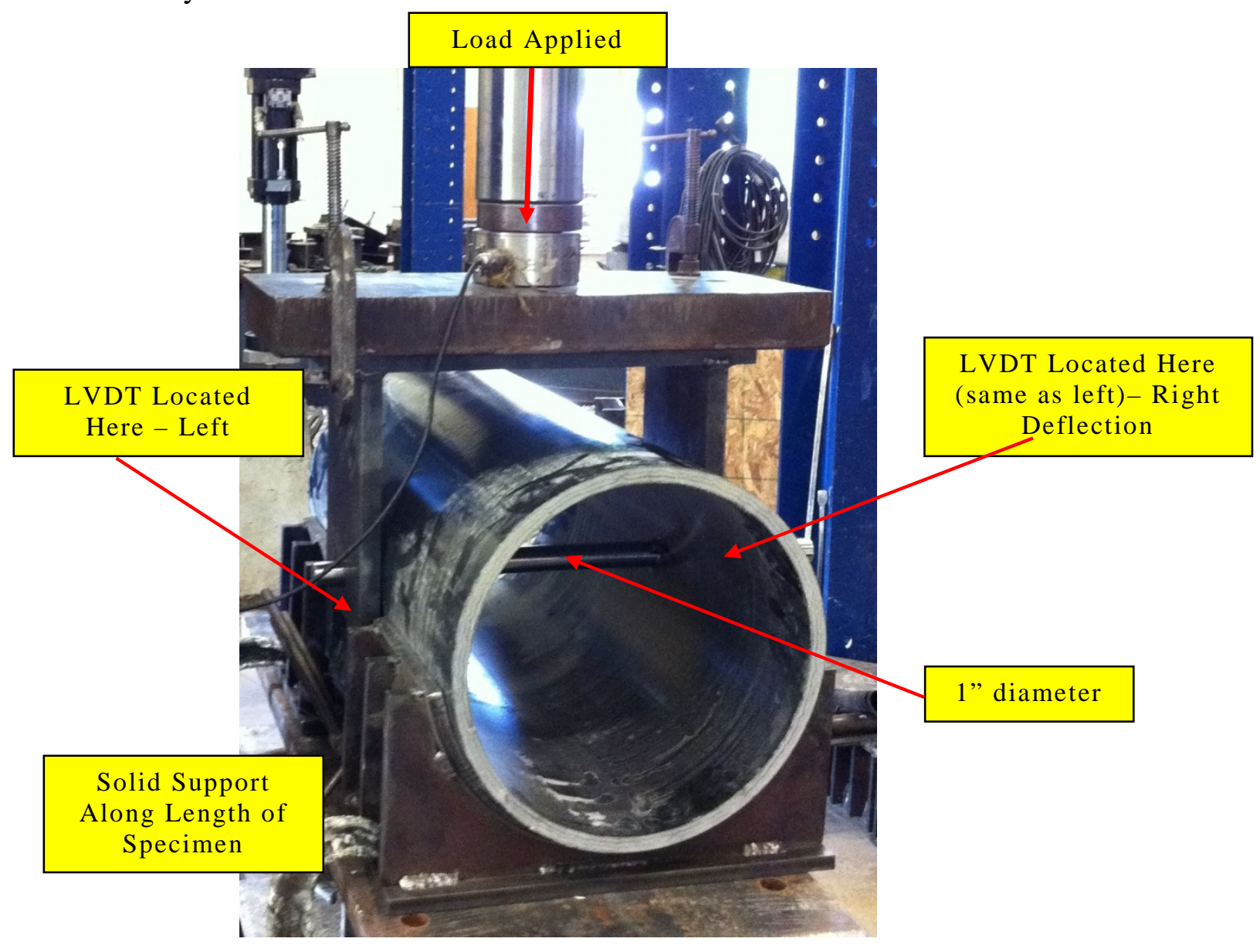

Figure 3-22 Connection Test A Setup

\subsubsection{Results and Discussion}

\subsubsection{Introduction}

For each section tested, similar types of load and deflection results were found. Although the maximum loads differ for each section, the behavior was always the same. Eventually the load would not go any higher because the pin deflection was steadily increasing. As opposed to a 
catastrophic failure characterized by global cracking and delamination as seen in the bending and crush tests, this type of loading seemed to push its way through the material locally (See Figure 3-23), i.e., large ductility was noted after initial cracking. It is difficult to quantify a maximum or failure load because the pin just pushed its way through the material as the loading was sustained. Therefore the maximum load is considered as the point where load stops increasing and deflection continues to increase.

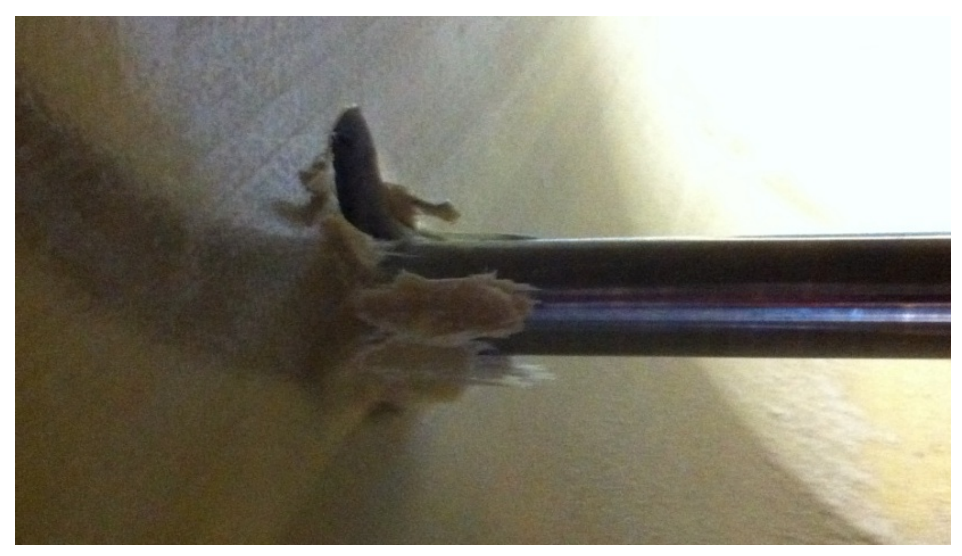

Figure 3-23 Connection Testing A at Failure - Section PU-16x0.5

Samples 1-3 were not loaded as far as others because of setup uncertainties. Right deflection in Sample 4 also had an error at about 0.58 inches, but every sample tested after Samples 1-4 was without error.

\subsubsection{Section VE-16x0.5}

The load vs. deflection curve is shown in Figure 3-24. It can be seen that the maximum load occurs whenever the load cannot increase anymore and deflection continues to increase. Thus the max load is $18-21$ kips. Sample 1 is not shown because the LVDTs were not working properly and the load was terminated before failure. Samples 1-3 were not loaded as far as others 
because of setup uncertainties. Deflection on one side of Sample 4 also had a deflection error at about 0.58 inches due to a snag in the LVDT wire, but every sample tested after Samples 1-4 was without error. The results from this test, i.e. max load and stiffness, reveal the properties of the resin system.

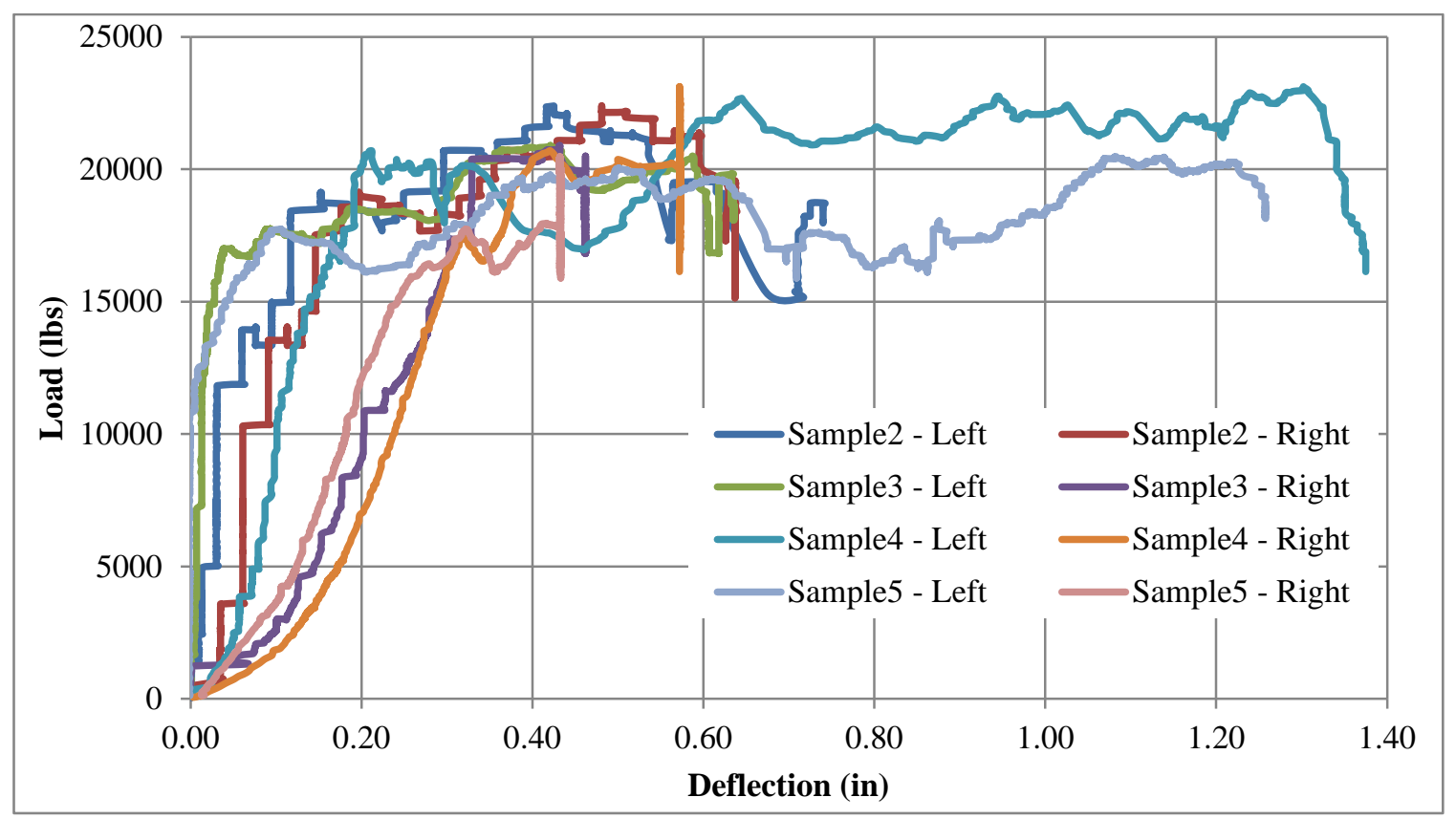

Figure 3-24 Load/Deflection Plot of Connection Test A - Section VE-16x0.5

\subsubsection{Section PU-16x0.5}

The load deflection curve is show in Figure 3-25. It can be seen that the maximum load is identified as the load that cannot increase anymore, while deflection continues to increase. Thus the max load is $\sim 23-25$ kips. This maximum load is slightly higher than that of VE-16x0.5, revealing that the polyurethane resin system is superior in terms of ultimate strength with regards to local bolt loading. 


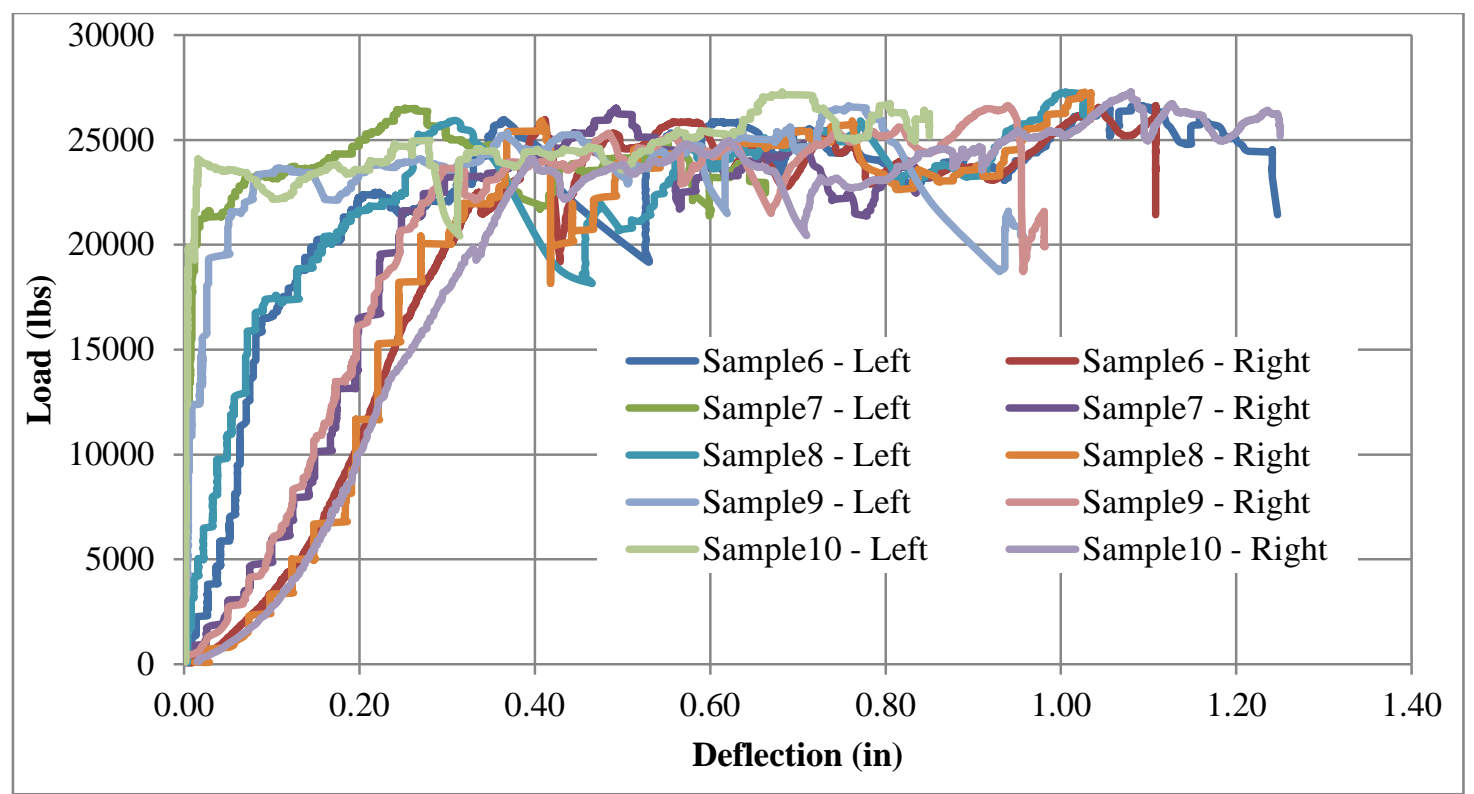

Figure 3-25 Load/Deflection Plot of Connection Test A - Section PU-16x0.5

\subsubsection{Section $P U-12 \times 0.5$}

The load deflection curve is shown in Figure 3-26. It can be seen that the maximum load is identified as the load that cannot increase anymore, while deflection continues to increase. Thus the max load is $\sim 21-23$ kips. The maximum load reached by PU-12x0.5 is near that of PU16x0.5 which is to be expected since the only difference in the tubes is diameter. The minor differences can probably be attributed to a difference in diameter which might allow the transverse bolt to bend more in the case of a longer diameter tube. 


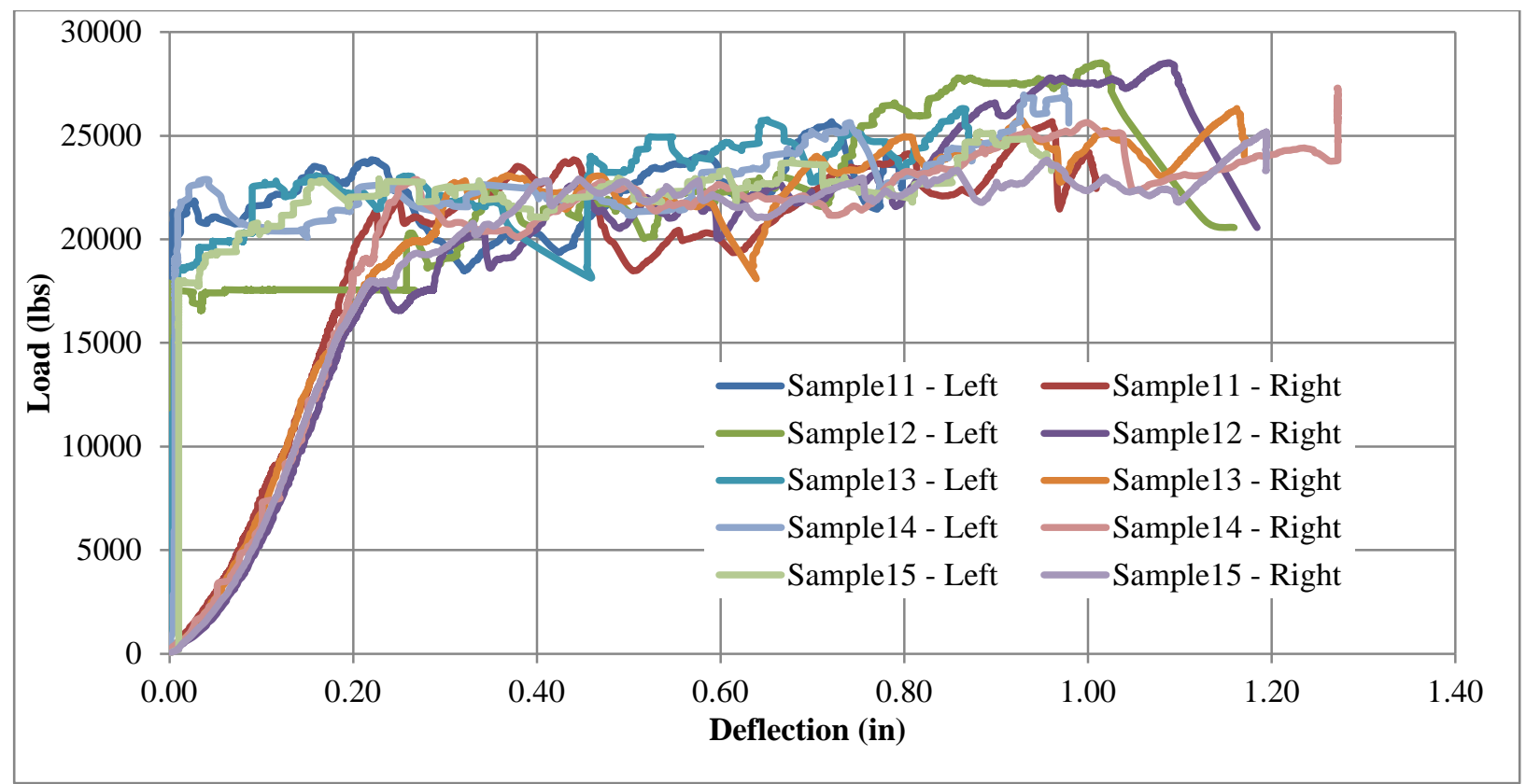

Figure 3-26 Load/Deflection Plot of Connection Test A - Section PU-12x0.5

\subsection{Connection Testing B}

\subsubsection{Methodology}

This investigation includes the testing of two different sized washers. This was done in order to determine the optimal size washer to be used for connections. The optimal sized washer will protect the tube from as much damage as possible due to a direct load. A bolt hole of 1 inch diameter was drilled straight through sections of the samples (same as Connection Test A). In this test however, a bolt and a washer that were provided by Creative Pultrusions Inc. were placed in the hole (See Figure 3-27). Two different sizes of washers were tested on test samples with three repetitions, except only two repetitions were performed for the 16 inch polyurethane pipe with a 6 inch washer. A 4” x 4” washer and a 6” x 6” were used, and these washers were curved to the fit the tubes better (See Figure 3-27). The span lengths used for the 12" and 16” 
diameter samples were 5' and 6' respectively. In all test specimens, 6 inches of overhang was provided beyond the support. Load was measured with an Omega LC-8400-200-200 kip load cell.

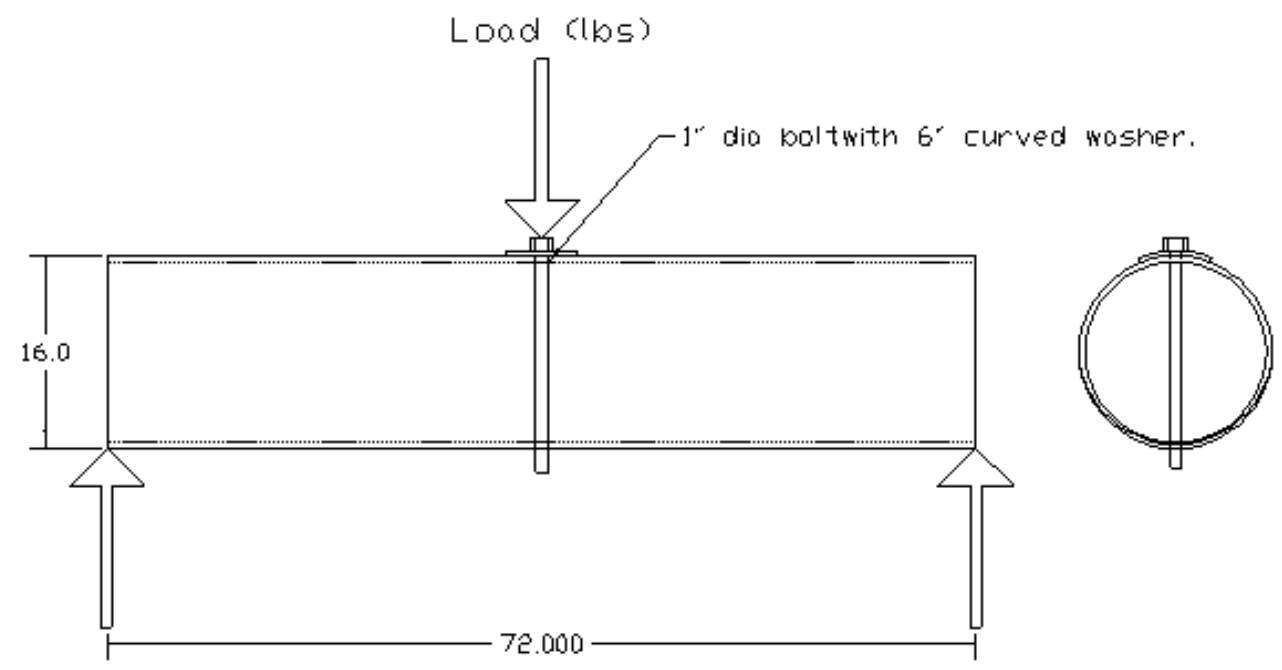

Figure 3-27 Connection Test B Setup

\subsubsection{Results and Discussion}

The failure behavior of the washer testing was found to be local depression around the area of the washer and the washer itself deformed greatly until the load application tools were flat against the test samples (Figure 3-28 and Figure 3-29). Loading was taken up to about the same point on each sample after initial crack failure was witnessed. The results for all the sections tested are given in Table 3-14. 
Table 3-14 Connection Test B Results - All Sections

\begin{tabular}{|c|c|c|c|c|}
\hline Section & $\begin{array}{l}\text { Washer } \\
\text { Size (in) }\end{array}$ & $\begin{array}{c}\text { Sample } \\
\text { (ID \#) }\end{array}$ & $\begin{array}{c}\text { Max Load } \\
\text { (lbs) }\end{array}$ & $\begin{array}{c}\text { Average } \\
\text { Max Load } \\
\text { (lbs) }\end{array}$ \\
\hline \multirow{5}{*}{$\begin{array}{l}\text { PU-16x0.5 } \\
72 \text { inch } \\
\text { span }\end{array}$} & \multirow{3}{*}{$4 \times 4$} & 1 & 16,402 & \multirow{3}{*}{17,210} \\
\hline & & 2 & 17,540 & \\
\hline & & 3 & 17,688 & \\
\hline & \multirow{2}{*}{$6 x 6$} & 1 & 23,230 & \multirow{2}{*}{22,228} \\
\hline & & 2 & 21,226 & \\
\hline \multirow{6}{*}{$\begin{array}{l}\text { VE-16x0.5 } \\
72 \text { inch } \\
\text { span }\end{array}$} & \multirow{3}{*}{$4 \times 4$} & 1 & 13,161 & \multirow{3}{*}{14,291} \\
\hline & & 2 & 15,115 & \\
\hline & & 3 & 14,596 & \\
\hline & \multirow{3}{*}{$6 x 6$} & 1 & 17,738 & \multirow{3}{*}{17,837} \\
\hline & & 2 & 18,851 & \\
\hline & & 3 & 16,921 & \\
\hline \multirow{6}{*}{$\begin{array}{l}\text { PU-12x0.5 } \\
60 \text { inch } \\
\text { span }\end{array}$} & \multirow{3}{*}{$4 \times 4$} & 1 & 21,275 & \multirow{3}{*}{19,569} \\
\hline & & 2 & 17,985 & \\
\hline & & 3 & 19,445 & \\
\hline & \multirow{3}{*}{$6 x 6$} & 1 & 24,219 & \multirow{3}{*}{27,642} \\
\hline & & 2 & 24,120 & \\
\hline & & 3 & 34,585 & \\
\hline
\end{tabular}

The values in Table 3-14 show the maximum load at initial cracking failure. As seen in Figure 3-28, the 6 in washer eventually dug into the FRP material and created cracks that propagated along a significant longitudinal distance from the washer. The 6 in washers generally caused less local damage to the sample at equal loads when compared to the 4 in washer. The washer testing results had similar cracking and failure modes on all sections and even all washers; however, the 4 inch washer would create a more local depression and generally caused more local damage (Figure 3-29). 


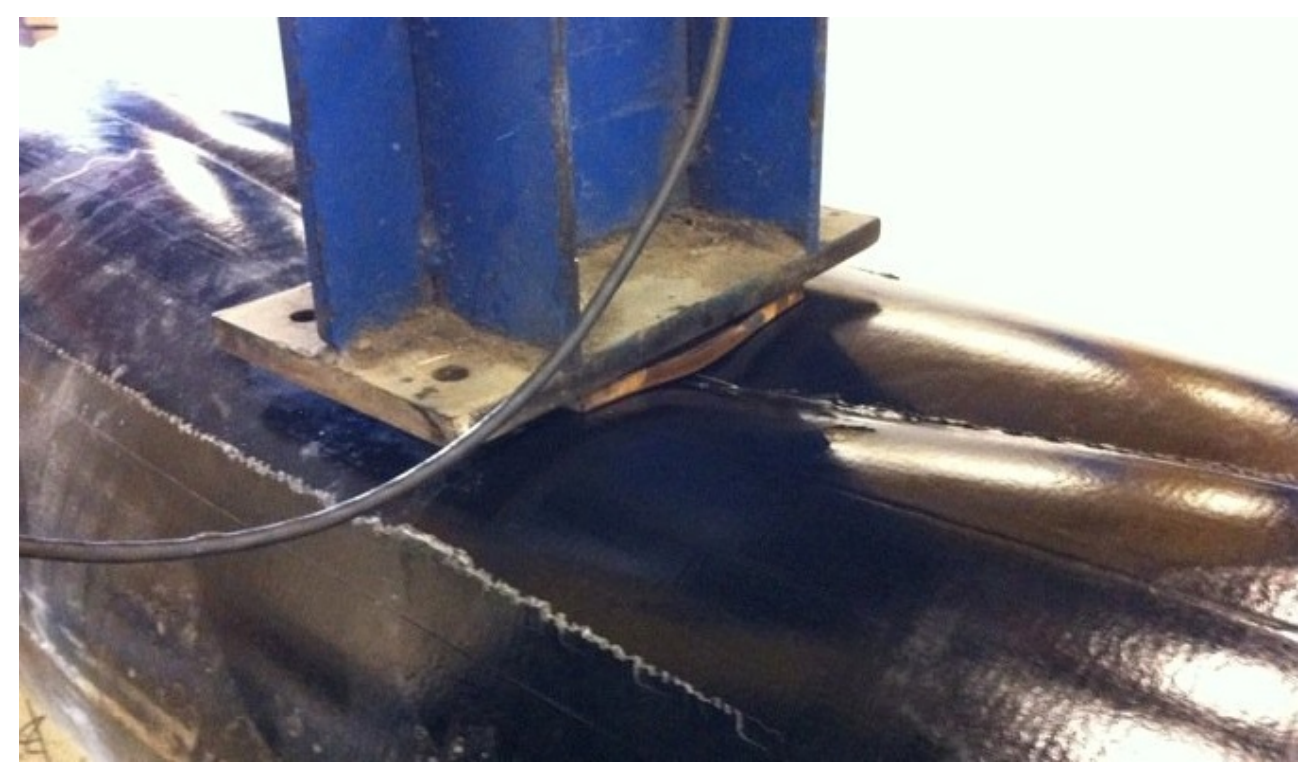

Figure 3-28 Connection Test B Sample with 6-in Washer at 21 kip (failure) Load - Section PU-16x0.5

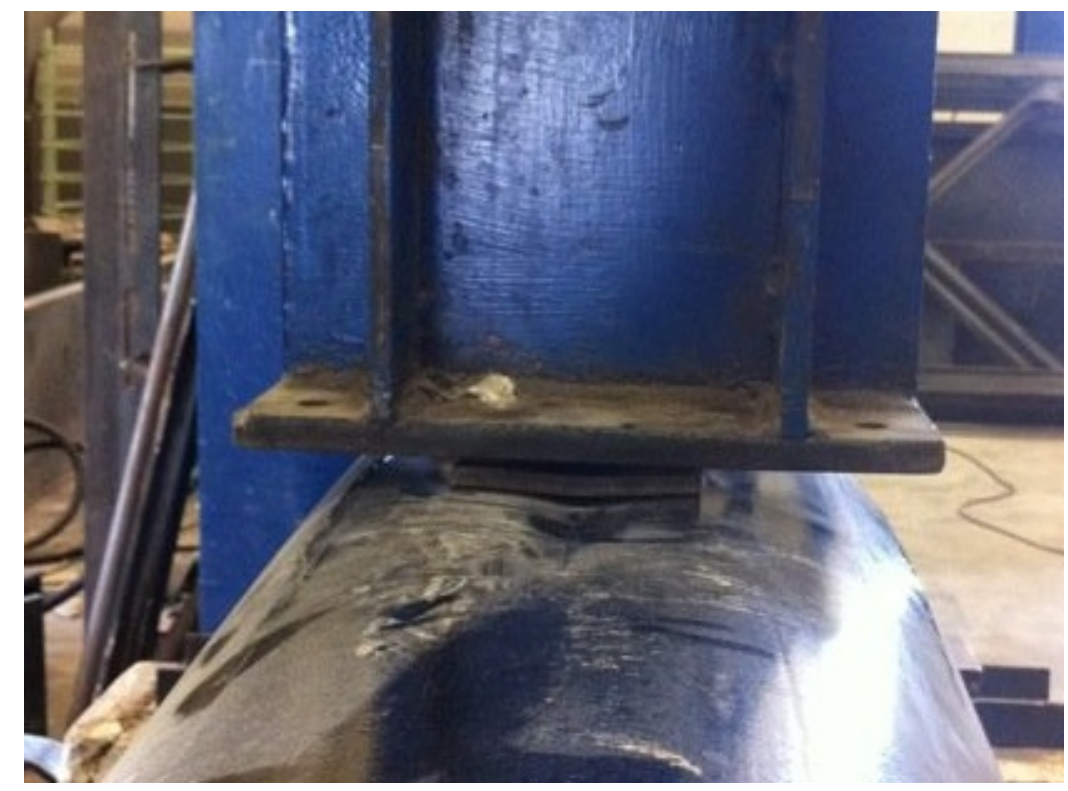

Figure 3-29 Connection Test B Sample with 4-in Washer during Loading - Section PU-12x0.5 


\subsection{Coupon Tests}

The purpose of coupon testing is to obtain properties of the material for comparison to the material properties found from full section tests. Manufacturers who test coupon samples can use the correlations presented in this work to determine the general behavior of a full section FRP tube. The coupon samples were cut from the failed samples from the crush testing. The ends of these failed sections do not appear to have any damage; however, such inference is made from a visual inspection of coupons. It is not truly known if there was any internal damage. Samples were cut first using a handheld circular saw and then were cut to size using a table saw with both having a diamond blade.

\subsubsection{Tensile}

\subsubsection{Methodology}

The methodology of the tensile coupon testing is primarily based on ASTM D3039. The tensile coupon samples were cut to widths of 1 inch and lengths of 19 inches. The gage length of these samples was 9 inches. This was done in order to fit into the Instron machine used for this test. The testing machine used was an Instron $\mathrm{Hdx} 1000$. The samples were rectangular in shape and no tabs were affixed to the samples with the exception of Sample 16-4 (Table 3-15). It can generally be seen that higher strength can be attained by attaching steel tabs to the ends of the samples where the testing machine grips the sample (ASTM D3039-08) however, no tabs were affixed to the samples due to time constraints, and because the results of Sample 16-4 (Table 3-15) matched closely with the results from samples without tabs. Load and deflection data were recorded by the Instron's onboard data acquisition software. Strain gages were applied to seven samples in order to obtain an accurate modulus of elasticity value. The modulus of elasticity is found as the slope of the initial linear portion of the stress-strain curve (generally $15-30 \%$ of the 
ultimate strain). The speed of testing was $0.15 \mathrm{in} / \mathrm{min}$. A sample (of section PU-12x0.375) is shown seated in the tension testing machine in Figure 3-30.

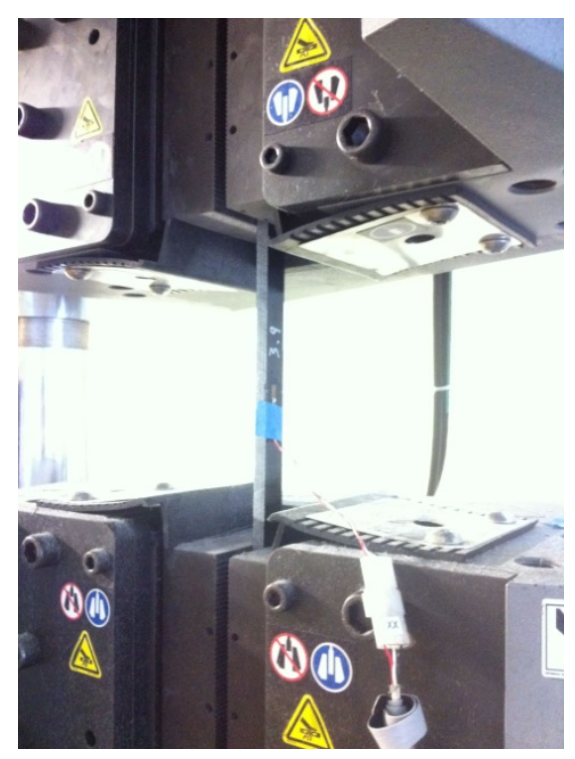

Figure 3-30 Tension Test Sample in Instron Machine

\subsubsection{Results and Discussion}

It is important to remember that section PU-16x0.5 and PU-12x0.5 are made up of the same fiber and resin materials and also have similar layups. Tensile tests were only performed on sections PU-16x0.5, PU-12x0.5, and PU-12x0.375; therefore, no tests were performed on vinyl ester specimens. The results are for all sections are shown in the following three tables.

Table 3-15 Coupon Static Tension Test Results - Section PU-16x0.5

\begin{tabular}{|c|c|c|c|c|c|}
\hline Sample & $\begin{array}{c}\text { Max } \\
\text { Load } \\
(\mathbf{l b s})\end{array}$ & $\begin{array}{c}\text { Deflection } \\
\text { at Max } \\
\text { Load (in) }\end{array}$ & $\begin{array}{c}\text { Max } \\
\text { Stress } \\
(\mathbf{p s i})\end{array}$ & $\begin{array}{c}\text { Max } \\
\text { Strain } \\
(\boldsymbol{\mu} \boldsymbol{\varepsilon})\end{array}$ & $\begin{array}{c}\text { Elastic } \\
\text { Modulus } \\
(\mathbf{M s i})\end{array}$ \\
\hline $\mathbf{1 6 - 1}$ & 50504 & 0.672 & 110391 & - & 6.30 \\
\hline $\mathbf{1 6 - 2}$ & 49460 & 0.618 & 95834 & - & - \\
\hline $\mathbf{1 6 - 3}$ & 51578 & 0.667 & 99938 & - & - \\
\hline $\mathbf{1 6 - 4} *$ & 52331 & 0.552 & 104079 & - & - \\
\hline Average & $\mathbf{5 0 9 6 8}$ & $\mathbf{0 . 6 2 7}$ & $\mathbf{1 0 2 5 6 1}$ & - & - \\
\hline \multicolumn{7}{|c|}{} & $\mathbf{1 6 - 4}$ has end tabs affixed \\
\hline
\end{tabular}


Table 3-16 Coupon Static Tension Test Results - Section PU-12x0.5

\begin{tabular}{|c|c|c|c|c|c|}
\hline Sample & $\begin{array}{c}\text { Max } \\
\text { Load } \\
(\mathbf{l b s})\end{array}$ & $\begin{array}{c}\text { Deflection } \\
\text { at Max } \\
\text { Load (in) }\end{array}$ & $\begin{array}{c}\text { Max } \\
\text { Stress } \\
(\mathbf{p s i})\end{array}$ & $\begin{array}{c}\text { Max } \\
\text { Strain } \\
(\boldsymbol{\mu \varepsilon})\end{array}$ & $\begin{array}{c}\text { Elastic } \\
\text { Modulus } \\
\mathbf{( M s i )}\end{array}$ \\
\hline $\mathbf{1 2 - 1}$ & 48846 & 0.636 & 94370 & - & - \\
\hline $\mathbf{1 2 - 2}$ & 46411 & 0.658 & 89944 & - & - \\
\hline $\mathbf{1 2 - 3}$ & 51412 & 0.705 & 98321 & - & - \\
\hline $\mathbf{1 2 - 4}$ & 47008 & 0.644 & 92046 & - & - \\
\hline $\mathbf{1 2 - 5}$ & 52495 & 0.656 & 100621 & 19198 & 5.34 \\
\hline Average & $\mathbf{4 9 2 3 4}$ & $\mathbf{0 . 6 6 0}$ & $\mathbf{9 5 0 6 0}$ & - & - \\
\hline
\end{tabular}

Table 3-17 Coupon Static Tension Test Results - Section PU-12x0.375

\begin{tabular}{|c|c|c|c|c|c|}
\hline Sample & $\begin{array}{c}\text { Max } \\
\text { Load } \\
\text { (lbs) }\end{array}$ & $\begin{array}{c}\text { Deflection } \\
\text { at Max } \\
\text { Load (in) }\end{array}$ & $\begin{array}{c}\text { Max } \\
\text { Stress } \\
(\mathbf{p s i})\end{array}$ & $\begin{array}{c}\text { Max } \\
\text { Strain } \\
(\boldsymbol{\mu \varepsilon})\end{array}$ & $\begin{array}{c}\text { Elastic } \\
\text { Modulus } \\
\mathbf{( M s i )}\end{array}$ \\
\hline $\mathbf{3 - 7}$ & 41978 & 0.683 & 114914 & - & - \\
\hline $\mathbf{3 - 5}$ & 36776 & 0.597 & 98463 & - & - \\
\hline $\mathbf{3 - 8}$ & 42694 & 0.658 & 119357 & - & - \\
\hline $\mathbf{3 - 2}$ & 38012 & 0.652 & 105942 & 22052 & 4.861 \\
\hline $\mathbf{3 - 1}$ & 34241 & 0.640 & 100561 & 22058 & 4.658 \\
\hline $\mathbf{3 - 3}$ & 40004 & 0.622 & 106877 & 20821 & 5.112 \\
\hline $\mathbf{3 - 6}$ & 37068 & 0.609 & 100103 & 22468 & 4.560 \\
\hline $\mathbf{3 - 9}$ & 42112 & 0.657 & 109752 & 25023 & 4.658 \\
\hline Average & $\mathbf{3 9 1 1 1}$ & $\mathbf{0 . 6 4 0}$ & $\mathbf{1 0 6 9 9 6}$ & $\mathbf{2 2 4 8 4}$ & $\mathbf{4 . 7 7 0}$ \\
\hline
\end{tabular}

The deflection at max load measurements recorded by the Instron shown above should be viewed with caution because of the fact that steel tabs were not used. It was noted that after all the failures the grips were digging into the sample in the grip area during testing. This shows that some extra deflection, although minor, is occurring throughout the entire test (Note that the sample with tabs, 16-4, from Table 3-15 shows less deflection than the others). As shown in Figure 3-31, failure of the samples is more pronounced near the gripped ends which shows that 
failure may have initiated at the grip edge; although, failure throughout the entire gage length occurred suddenly. This failure can be seen clearly in Sample 16-4 shown in Figure 3-32.

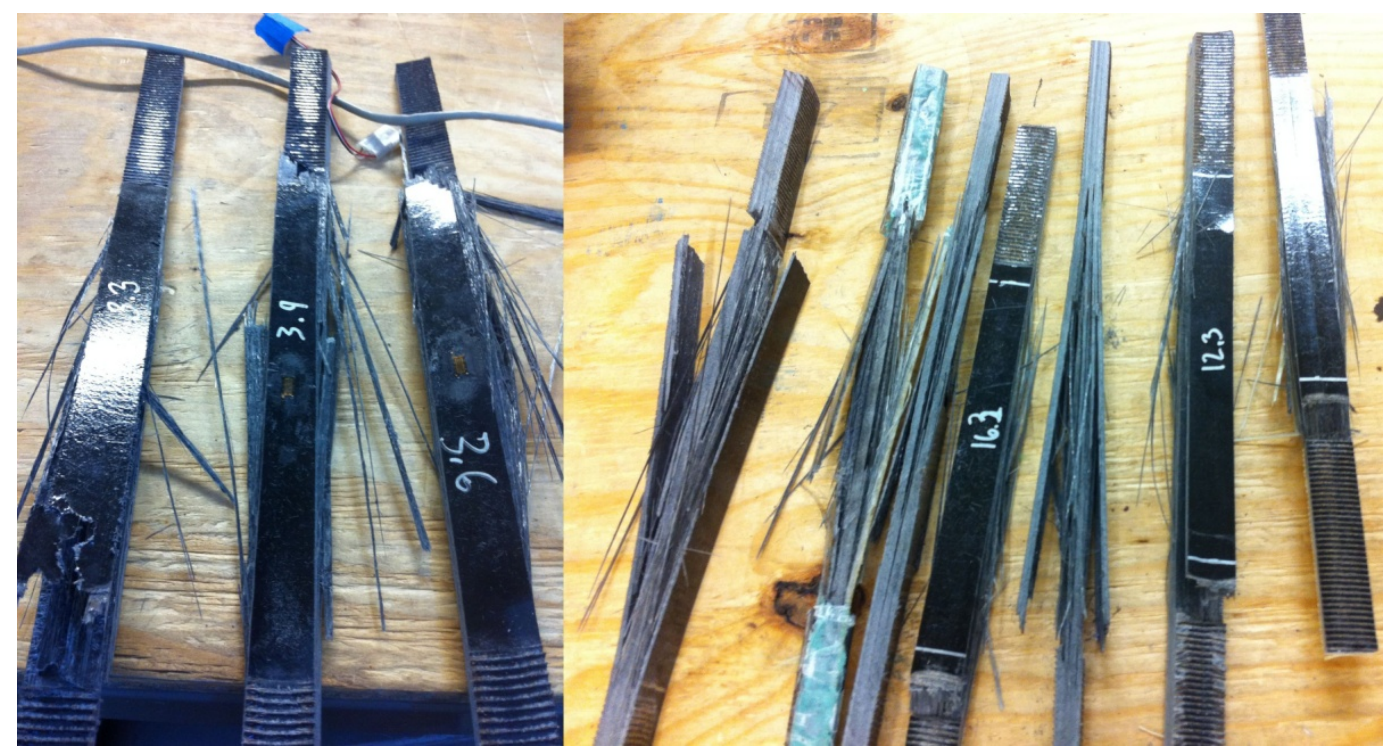

Figure 3-31 Failed Samples from Tensile Coupon Test 


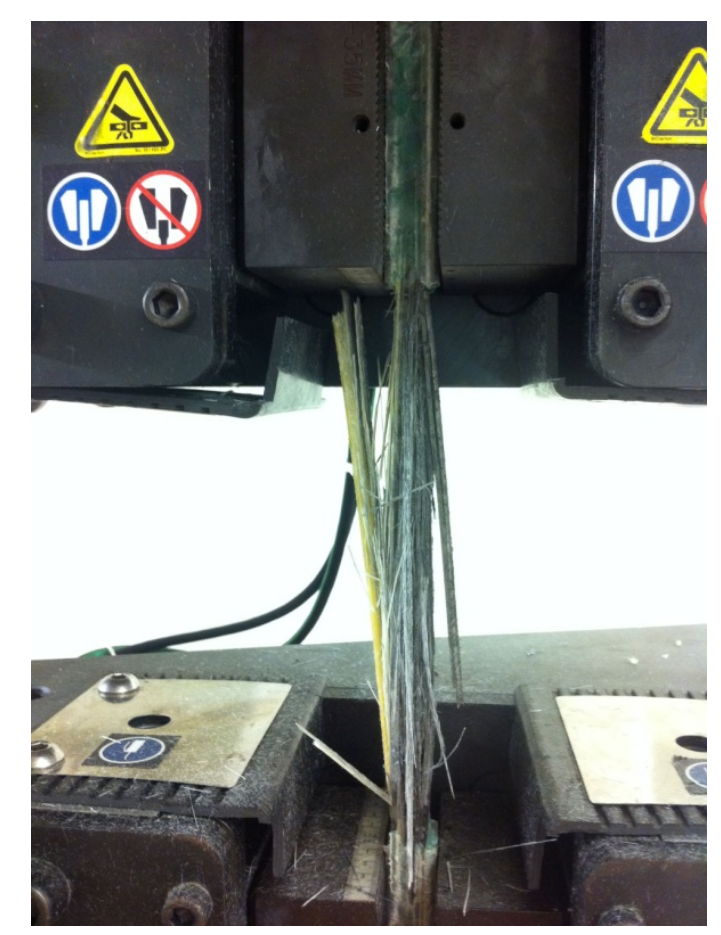

Figure 3-32 Coupon Tension Failed with Grips (Sample 16-4)

\subsubsection{Bending}

\subsubsection{Methodology}

The only section that was tested in coupon bending is PU-12x0.375, the $3 / 8$ ” thick polyurethane. This test was done in order to provide more data about the section and allow for correlation to the full section. Just as was done for the tension tests, bending coupon samples were cut from the specimens that failed under crushing. The ends of these sections do not appear to have any damage; however, this is based on a visual inspection. It is not truly known if there was any internal damage. Nine samples were cut first using a handheld circular saw and then were cut to size using a table saw both having a diamond blade. The methodology for sample preparation and test setup is followed from ASTM D790. The samples were cut to widths of 1 inch and lengths of 10 inches. Measurements of each specimen were taken along the gage length 
in three places with respect to width and thickness and then averaged in order to obtain accurate flexural strength results. The span length used was 6 inches which corresponds to a span to depth ratio of 16:1. In order to rule out the possibility of shear deformation effects, an additional sample with a span length of 9 inches was used (24:1 span to depth ratio). The machine used to test these samples was an Instron 8800, and a three point bending fixture was used (see Figure 3-34). Load and deflection data were recorded by the Instron's onboard data acquisition software. For one sample, a strain gage was installed along the bottom in the center in order to obtain a modulus of elasticity for comparison to those obtained from the load-deflection curve. The speed of testing for the 6 inch samples was $0.16 \mathrm{in} / \mathrm{min}$ and $0.36 \mathrm{in} / \mathrm{min}$ for the 9 inch sample.

\subsubsection{Results and Discussion}

The results of coupons under bending are shown in Table 3-18 and Figure 3-33. A typical failure is shown in Figure 3-34. All samples failed very similar to the one pictured in Figure 3-34, with failure occurring in the middle under the applied load. It should be noted that the modulus of elasticity is calculated using the formula given in ASTM D790 for tangent modulus of elasticity. A strain gage was applied to Sample 3-10 and the modulus from the resulting stressstrain curve was 3.126 Msi which is $10 \%$ higher than the modulus of elasticity obtained from the load-deflection curve. This indicates that some slippage or other inaccuracy that occurred in the testing machine which is yielding lower moduli of elasticity based on load-deflection data. Sample 3-4 was the 9 inch span length specimen. Its results (moment, stress, and modulus) are close to the average of the other samples. This further conveys that little to no shear strength is affecting the results. 
Table 3-18 Coupon Bending Test Results - Section PU-12x0.375

\begin{tabular}{|c|c|c|c|c|c|}
\hline Sample & $\begin{array}{c}\text { Max } \\
\text { Load } \\
\text { (lbs) }\end{array}$ & $\begin{array}{c}\text { Max } \\
\text { Moment } \\
\text { (lb-in) }\end{array}$ & $\begin{array}{c}\text { Deflection } \\
\text { at Max } \\
\text { Load (in) }\end{array}$ & $\begin{array}{c}\text { Max } \\
\text { Stress } \\
\text { (psi) }\end{array}$ & $\begin{array}{c}\text { Modulus } \\
\text { of } \\
\text { Elasticity } \\
\text { (Msi) }\end{array}$ \\
\hline $3-10$ & 1454 & 2182 & 0.552 & 94104 & 2.843 \\
\hline $3-11$ & 1663 & 2495 & 0.528 & 110391 & 3.465 \\
\hline $3-12$ & 1739 & 2609 & 0.590 & 109507 & 3.207 \\
\hline $3-13$ & 1492 & 2239 & 0.584 & 100685 & 3.018 \\
\hline $3-14$ & 1644 & 2466 & 0.611 & 104861 & 2.975 \\
\hline $3-15$ & 1639 & 2458 & 0.508 & 104657 & 3.256 \\
\hline $3-16$ & 1648 & 2473 & 0.541 & 107896 & 3.511 \\
\hline $3-17$ & 1585 & 2378 & 0.606 & 106037 & 2.973 \\
\hline Average & $\mathbf{1 6 0 8}$ & $\mathbf{2 4 1 2}$ & $\mathbf{0 . 5 6 5}$ & $\mathbf{1 0 4 7 6 7}$ & $\mathbf{3 . 1 5 6}$ \\
\hline & & & & & \\
\hline $3-4 *$ & 1087 & $\mathbf{2 4 4 5}$ & 1.152 & $\mathbf{1 0 2 9 9 4}$ & $\mathbf{3 . 3 1 3}$ \\
\hline
\end{tabular}

*Span length on this sample is 9 in.

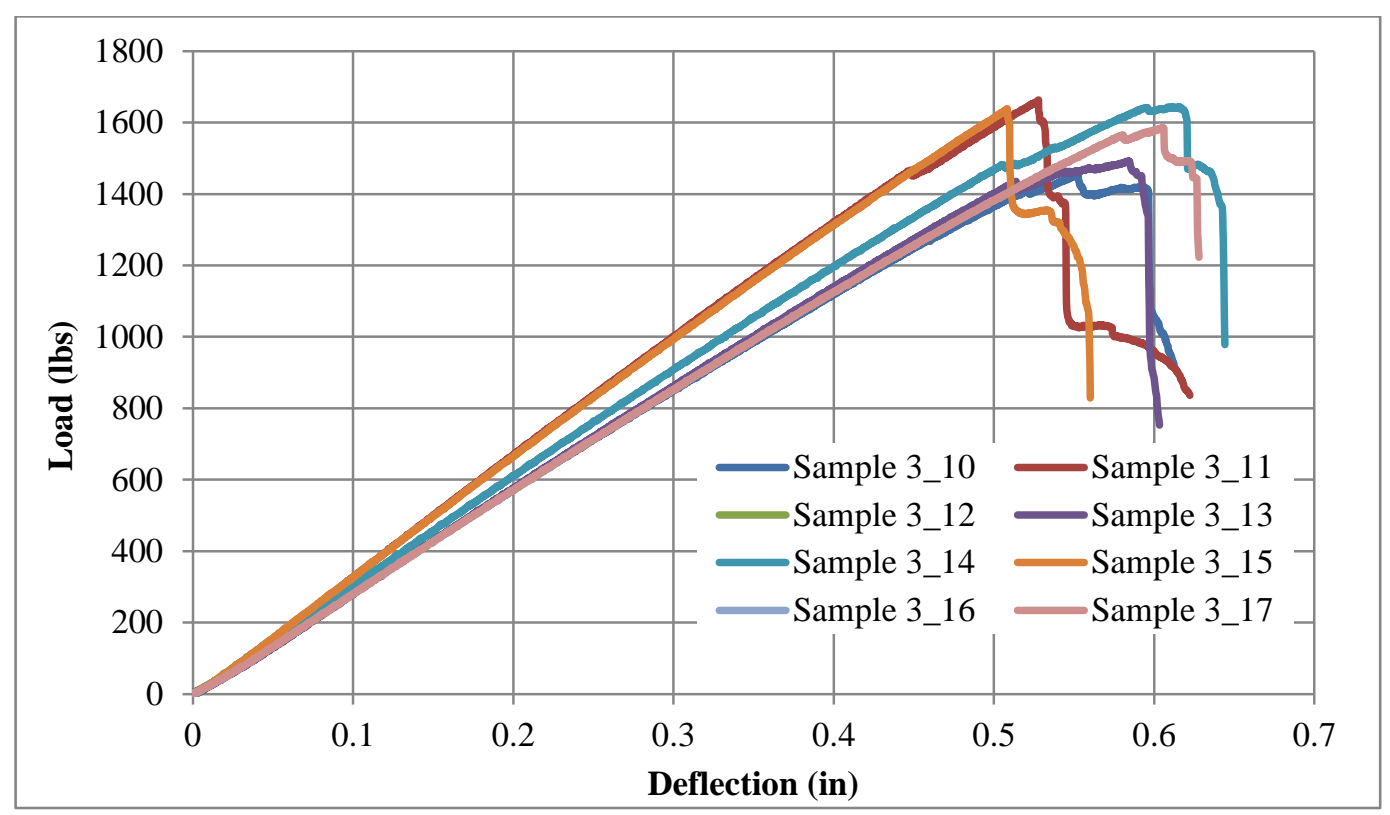

Figure 3-33 Load/Deflection Response for Coupon Bending Tests - Section PU-12x0.375 


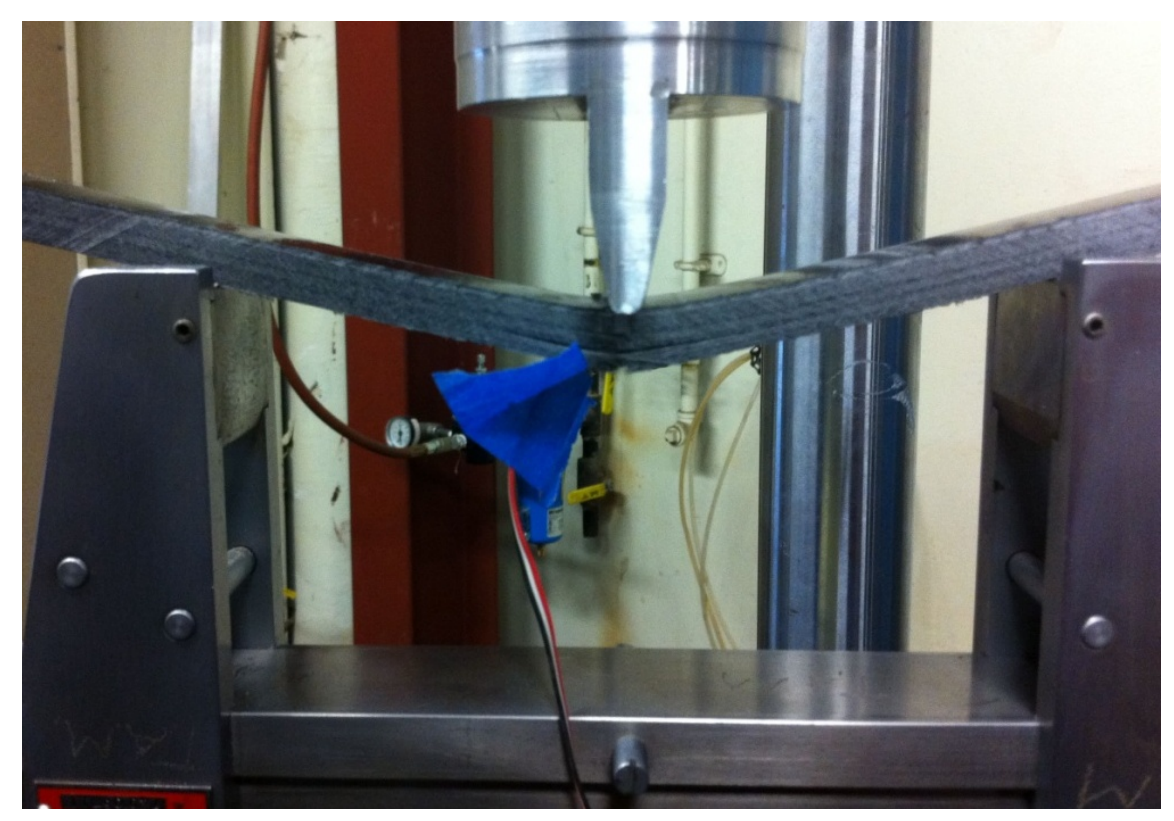

Figure 3-34 Typical Failure for Coupon Bending Tests - Section PU-12x0.375

\subsubsection{Compression}

\subsubsection{Methodology}

The only section that was tested in coupon compression was PU-12x0.375, the 3/8” thick polyurethane. These tests were performed in accordance with ASTM D695 Just as was done for the tension and bending tests, compression coupon samples were cut from the specimens that failed under crushing. The ends of these sections do not appear to have any damage; however, this is only speculation from a visual inspection. It is not truly known if there was any internal damage. Six samples were cut first using a handheld circular saw and then were cut to size using a table saw both having a diamond blade. The samples were cut to widths of $1 / 2$ inch and lengths of 1.75”. The dimensions were chosen in order to remove the chance of buckling behavior and conform to ASTM D695. Measurements of each specimen were taken along the gage length in three places with respect to width and thickness and then averaged in order to obtain accurate 
axial compressive strength results. The same Instron machine was used for the compression tests as for the bending tests, the Instron 8800; however, two flat hardened and ground plates were used as fixtures. The bottom plate was a fixture with the ability to rock in any direction. This was used to ensure the plates would be parallel while compressing the sample. The speed of testing was $0.05 \mathrm{in} / \mathrm{min}$.

\subsubsection{Results and Discussion}

The coupon test results under compression are shown in Table 3-19. A typical failure is shown in Figure 3-35. All samples failed very similar to the one pictured, with failure occurring at either the top or bottom of the sample in a crushing manner.

Table 3-19 Coupon Compression Test Results - Section PU-12x0.375

\begin{tabular}{|c|c|c|c|c|}
\hline Sample & $\begin{array}{c}\text { Max } \\
\text { Load } \\
\text { (lbs) }\end{array}$ & $\begin{array}{c}\text { Cross } \\
\text { Section } \\
\text { Area } \\
\text { (in }^{2} \text { ) }\end{array}$ & $\begin{array}{c}\text { Deflection } \\
\text { at Max } \\
\text { Load (in) }\end{array}$ & $\begin{array}{c}\text { Max } \\
\text { Stress } \\
\text { (psi) }\end{array}$ \\
\hline $\mathbf{3 - 2 1}$ & 8739 & 0.1611 & 0.065 & 54246 \\
\hline $\mathbf{3 - 2 4}$ & 9653 & 0.1715 & 0.074 & 56288 \\
\hline $\mathbf{3 - 1 8}$ & 7820 & 0.1695 & 0.079 & 46135 \\
\hline $\mathbf{3 - 2 3}$ & 9961 & 0.1664 & 0.082 & 59861 \\
\hline $\mathbf{3 - 1 9}$ & 9005 & 0.1656 & 0.072 & 54376 \\
\hline $\mathbf{3 - 2 0}$ & 8123 & 0.1663 & 0.073 & 48847 \\
\hline Average & $\mathbf{8 8 8 4}$ & $\mathbf{0 . 1 6 6 7}$ & $\mathbf{0 . 0 7 4}$ & $\mathbf{5 3 2 9 2}$ \\
\hline
\end{tabular}




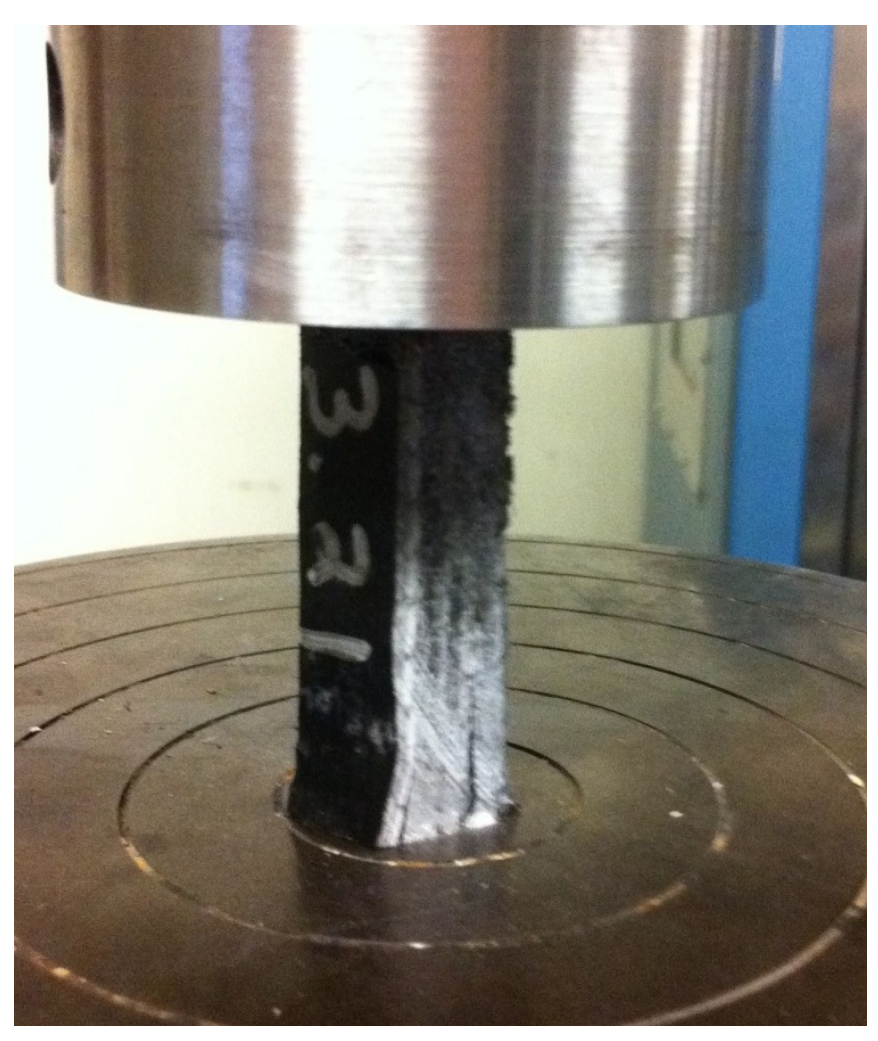

Figure 3-35 Typical Failure for Coupon Compression Tests - Section PU-12x0.375

The results from the compression coupon testing in Table 3-19 yield low stresses to failure when compared to the tensile results in Table 3-17 (about half). This reason for this is possibly due to the size of the compression samples. Because of using a table saw and circular saw with relatively large diameter blades ( 1/8 in thick) compared to the sample size, damage is likely to have occurred to the resin and fibers that affected the results. Therefore, it appears these results should be taken with caution and it is recommended that testing on large samples should be done. 


\subsection{Four-Point Bending Fatigue}

\subsubsection{Methodology}

One full section sample of sections PU-16x0.5, VE-16x0.5, and PU-12x0.5 was tested in bending fatigue. Using the same test setup for four-point static bending as described in section 3.3, each sample underwent 200 cycles of approximately $40 \%$ of its respective average maximum load. After the sections were subjected to the 200 cycle fatigue test, they were tested to failure in static four-point bending fashion as described in section 3.3. It should be noted that a cycle consisted of roughly a 2 kip minimum load and a maximum load of $40 \%$ of the average failure load of previous samples. The actual loads applied under fatigue were slightly different and are recorded as shown in Table 3-20. At a rate of loading of $0.075 \mathrm{~Hz}$ (cycle/sec), each test endured 44 minutes to attain 200 cycles. This was chosen because of the MTS fatigue actuator's ability to run smoothly at this rate of loading. The machine used was an MTS Teststar Controller with a maximum compression load of 330 kips. It contains an internal load cell which was calibrated in February 2011 by MTS. Deflection was measured by a Celesco SP3 string pot.

\subsubsection{Results and Discussion}

A summary of the bending fatigue test results is shown in Table 3-20. Within each section set the last sample was set aside for fatigue, and they are each labeled "S6". The R-ratio relates the ratio of the minimum load to maximum load of the fatigue test. It is calculated based on the results after the test was run. The deflection range shows the average of the difference between the maximum and minimum deflections experienced during the testing. The goal for load level was $40 \%$; however, the machine's ability to attain these loads is restricted by the servo-hydraulic system. The values shown in Table 3-20 were the actual load levels achieved by the machine. 
Table 3-20 Four-Point Bending Fatigue Results

\begin{tabular}{|c|c|c|c|c|c|c|c|c|}
\hline $\begin{array}{c}\text { Section, } \\
\text { Sample \# }\end{array}$ & $\begin{array}{c}\text { Rate } \\
\mathbf{( H z )}\end{array}$ & R-ratio & $\begin{array}{c}\text { Load } \\
\text { Level } \\
\text { (\%) }\end{array}$ & $\begin{array}{c}\text { Avg } \\
\text { Min } \\
\text { Load } \\
\text { (kips) }\end{array}$ & $\begin{array}{c}\text { Avg } \\
\text { Max } \\
\text { Load } \\
\text { (kips) }\end{array}$ & $\begin{array}{c}\text { Load } \\
\text { Range } \\
\text { (kips) }\end{array}$ & $\begin{array}{c}\text { Avg } \\
\text { Deflection } \\
\text { Range } \\
\text { (in) }\end{array}$ & $\begin{array}{c}\text { Number } \\
\text { of Cycles }\end{array}$ \\
\hline PU-16x0.5, S6 & 0.075 & 0.18 & 38.0 & 6.94 & 38.64 & 31.70 & 3.84 & 200 \\
\hline VE-16x0.5, S6 & 0.075 & 0.15 & 43.9 & 5.39 & 36.44 & 31.05 & 3.92 & 200 \\
\hline PU-12x0.5, S6 & 0.075 & 0.13 & 40.0 & 4.8 & 36.41 & 31.61 & 3.58 & 200 \\
\hline
\end{tabular}

After the fatigue test of 200 cycles, the samples were tested in static four-point bend to failure. The results for each of these samples are given earlier in section 3.3.2.

\subsection{Cantilever Bending Test}

\subsubsection{Methodology}

One full section of section PU-12x0.375 was tested in cantilever to a load well below expected failure (8000 lbs) in order to further examine the section. The test setup, shown in Figure 3-36, uses a full section of 280 inches length, but the member is partially fixed at the midpoint of the span. A chain link choker is attached to the specimen at a distance of 40 inches from the end which is connected to a torsion crank. A flaw in this test setup is introduced where the tube is intended to be fixed. Since the tube extends 140 inches beyond this point in the direction opposite the loading, it is allowed somewhat to bend therefore not representing true fixed conditions. In between the crank and the choker a 10 kip S-type tension-compression load cell was placed. Deflection is measured by a Celesco SP3 string pot directly under the point of load. Eight strain gages were attached near the fixed point at all locations shown in Figure 3-3. 


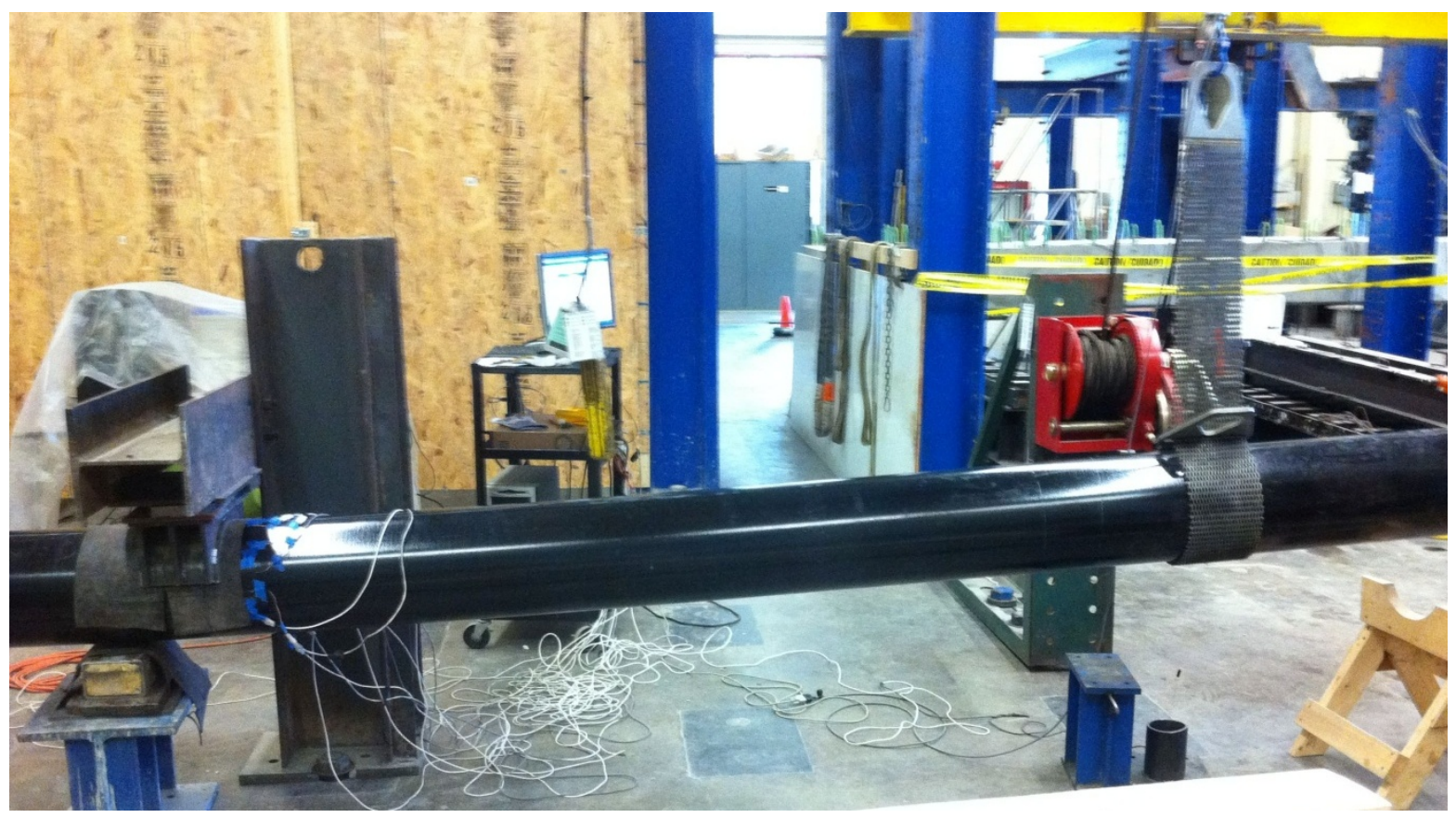

Figure 3-36 Cantilever Bending Test Setup

\subsubsection{Results and Discussion}

A summary of the results are presented in Table 3-21. Because this test did not go to failure of the section, but to the predetermined maximum load of 8.12 kips, the values shown are what were measured with respect to that maximum load.

Table 3-21 Cantilever Bending Test Results - Section PU-12x0.375

\begin{tabular}{|c|c|c|c|c|c|c|}
\hline $\begin{array}{c}\text { Max } \\
\text { Load } \\
\text { (kips) }\end{array}$ & $\begin{array}{c}\text { Max } \\
\text { Deflection } \\
\text { (in) }\end{array}$ & $\begin{array}{c}\text { Max } \\
\text { Moment } \\
\text { (k-in) }\end{array}$ & $\begin{array}{c}\text { Max } \\
\text { Stress } \\
\text { (ksi) }\end{array}$ & $\begin{array}{c}\text { Max } \\
\text { Longitudinal } \\
\text { Strain }(\boldsymbol{\mu \varepsilon})\end{array}$ & $\begin{array}{c}\text { Elastic } \\
\text { Modulus } \\
\text { (Msi) }\end{array}$ & $\begin{array}{c}\text { Energy } \\
\text { (kip-in) }\end{array}$ \\
\hline 8.12 & 6.78 & 779 & 20.19 & 3601 & 5.74 & 25.919 \\
\hline
\end{tabular}

The deflection shown in Table 3-21 is the result of the inability to fully restrain the specimen at the fixed support. It is much higher than expected. However, the strain measurements provide more reliable information. The elastic modulus here shows some 
disagreement with the average modulus obtained from the four-point bend test, 5.26 Msi, which yields a percent difference of $13.5 \%$. This is due to the cantilever section only undergoing $33 \%$ of the maximum strain recorded during four-point bending (Table 3-9). The portion of the stressstrain curve used to calculate this modulus is the initial portion of the would-be entire curve (15\%-33\% of the ultimate strain) and is therefore more linear than the portion of the stress-strain curve used in the four-point bend tests (10\%-50\% of the ultimate strain).

\subsection{Conclusions}

The extensive mechanical tests performed on the four different sections provide a wealth of information about their mechanical behavior. The difference between polyurethane and vinyl ester resin systems is shown by comparing the results of section PU-16x0.5 and section VE16x0.5. From the four-point bending test, the average ultimate bending stress for section PU16x0.5 was found to be $59.21 \mathrm{ksi}$ and the elastic modulus was calculated as 5.92 Msi. The average ultimate bending stress for section VE-16x0.5 was found to be $49.02 \mathrm{ksi}$ and the elastic modulus was calculated as $5.57 \mathrm{Msi}$. This is a $17 \%$ and 6\% drop respectively with relation to PU-16x0.5. While the two base materials have similar material properties, polyurethane has a much higher percent strain to failure. This difference in percent strain to failure of the resins is believed to be the reason why polyurethane withheld higher loads, had a higher stiffness, and also experience more cross sectional deformation during loading. PU-12x0.5 had an average ultimate bending stress of $72.94 \mathrm{ksi}$ and an elastic modulus of $6.61 \mathrm{Msi}$. This section has a diameter to wall thickness ratio of $24(\mathrm{D} / \mathrm{t}=24)$ which resulted in less local buckling contribution to failure and is therefore why this section sustained a higher failure stress than section PU-16x0.5 (D/t = 32). PU-12x0.375 had an average ultimate bending stress of $55.61 \mathrm{ksi}$ and an elastic modulus of 5.26 Msi. 
Surveying the coupon results for sections PU-16x0.5 and PU-12x0.5 shows very similar results. This is to be expected due to the similarity of the layup. The maximum tensile stress for these coupons is approximately $100 \mathrm{ksi}$. When observing the coupon results for tension and compression for section PU-12x0.375, the max stress for compression is $53.3 \mathrm{ksi}$ and the max stress for tension is $107.0 \mathrm{ksi}$. The coupon bending tests for PU-12x0.375 yield an ultimate bending stress of $103 \mathrm{ksi}$ and an elastic modulus of $3.31 \mathrm{Msi}$.

In the crush testing, the polyurethane section PU-16x0.5 again outperformed its vinyl ester counterpart, section VE-160.25, due to the greater ductility of the polyurethane resin system. PU$16 \times 0.5$ boasts a maximum crush loading of 27.53 kips and VE-16x0.5 resulted in a maximum crush loading of 18.75 kips. PU-12x0.5 and PU-12x0.375 had maximum crush loadings of 27.54 and 18.36 kips, respectively. For connection testing A, flattening of the cross section is a real possibility as well; however, it presumably would not affect the failure load much. PU-16x0.5 had a failure load of 23-25 kips, and VE-16x0.5 had a failure load of 18-21 kips. Section PU12x0.5 had a maximum failure load of 21-23 kips. The PU-12x0.5 showed a $~ 8 \%$ lower failure load than section PU-16x0.5. This is due to the higher curvature of the wall in the 12" diameter section, and also probably due to the length of the bolt used across the diameter of the tube. Connection Test B, the washer test, yielded insight into each section's ability to withstand a localized washer load. In every case the washer yielded and failed, but failure loads were recorded when each section showed initial cracking that ran longitudinally. PU-16x0.5 showed failure loads of 17.2 and 22.2 kips for the 4 inch and 6 inch washer respectively. VE-16x0.5 showed failure loads of 14.3 and 17.8 kips for the 4 inch and 6 inch washer respectively. PU12x0.5 showed failure loads of 19.6 and 27.6 kips for the 4 inch and 6 inch washer respectively. 
The cantilever bending test performed on PU-12x0.375 resulted in an elastic modulus of 5.74 Msi. 


\section{CHAPTER 4 BENDING BEHAVIOR PREDICTION OF GFRP}

\section{TUBES}

\subsection{Introduction and Scope}

For thin-walled cylindrical sections, designers and engineers need to know as much as possible about the stiffness behavior, ultimate strength, and susceptibility to buckling geometric instability. Laminated composites are more complex than metals due to anisotropy and inhomogeneity not to mention the variety of fiber architectures and resin systems. Therefore accurate prediction for the mechanical behavior will require material properties of varying elements and constituents of laminated composites.

Of particular interest is the change in stiffness that occurred during the full-section bending tests to failure described earlier in the paper (see section 3.3). The results of these tests indicate a primary failure mode of crushing on the compression face including local buckling. This behavior will be analyzed in further detail in this section. An attempt is made to define a viable methodology for predicting the stiffness and ultimate strength of the large diameter thin walled cylindrical composite tubes that were tested in four-point bending. Finite element analysis is also used for comparison, particularly in regards to the stiffness.

\subsection{Analysis Methodology}

In order to quantify the change in flexural stiffness reduction during testing, a graph of the derivative of the stress-strain curve will be analyzed for each section. This graph is made by taking the change in stress at intervals of $250 \mu \varepsilon$ and dividing by the change in strain (250 $\mu \varepsilon)$ throughout the loading. Figure 4-1 and Figure 4-2 show the stiffness change plotted against the 
percent of ultimate strain in the tension face and compression face, respectively, for Sample 6 of VE-16x0.5. This sample is representative of all samples of section VE-16x0.5 with the exception of Sample 1 in which case Sample 1 dropped more dramatically to near 4 Msi at failure.

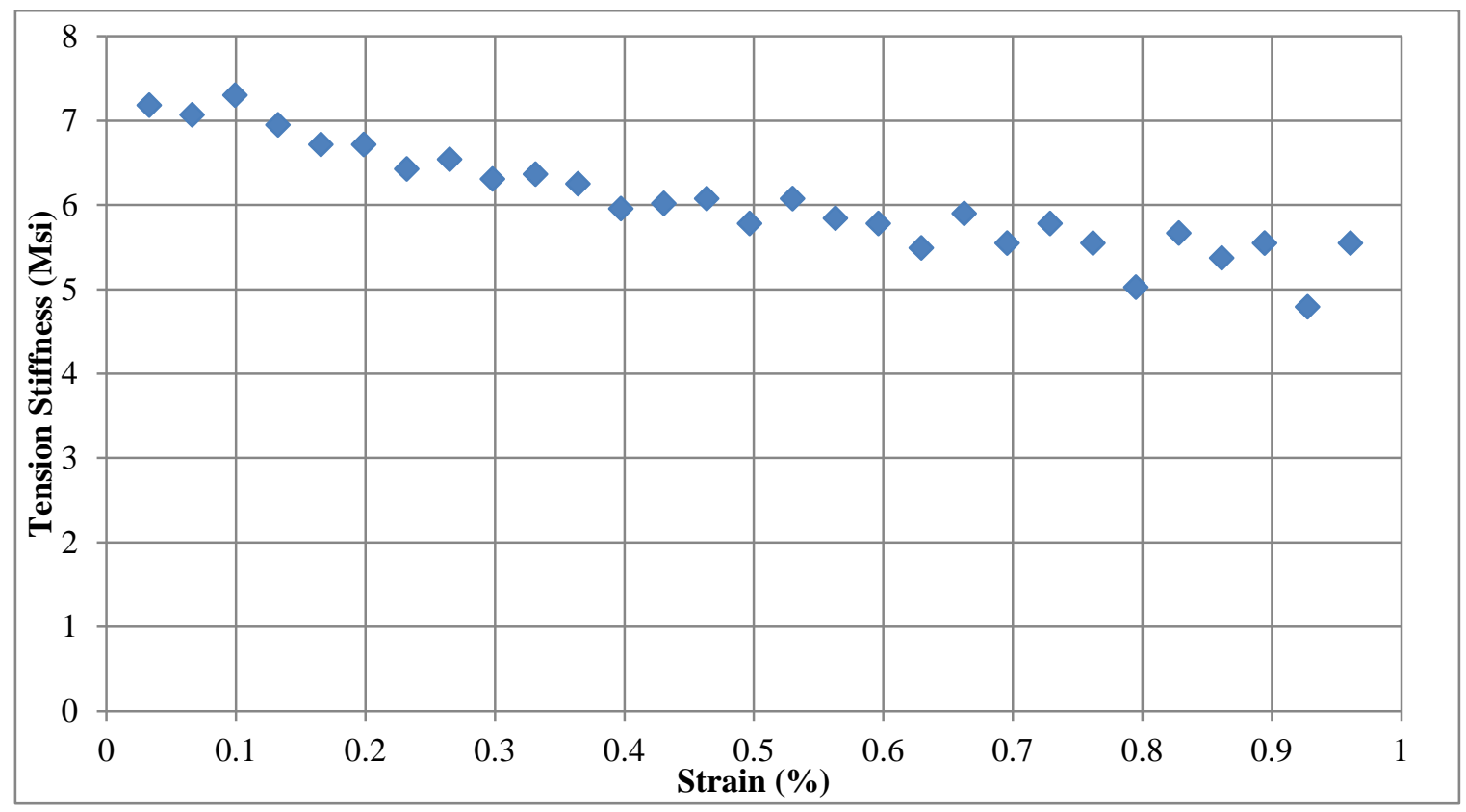

Figure 4-1 Change in Stiffness Curve from Four-Point Bend Sample 6 (Tension Face) - Section VE-16x0.5 


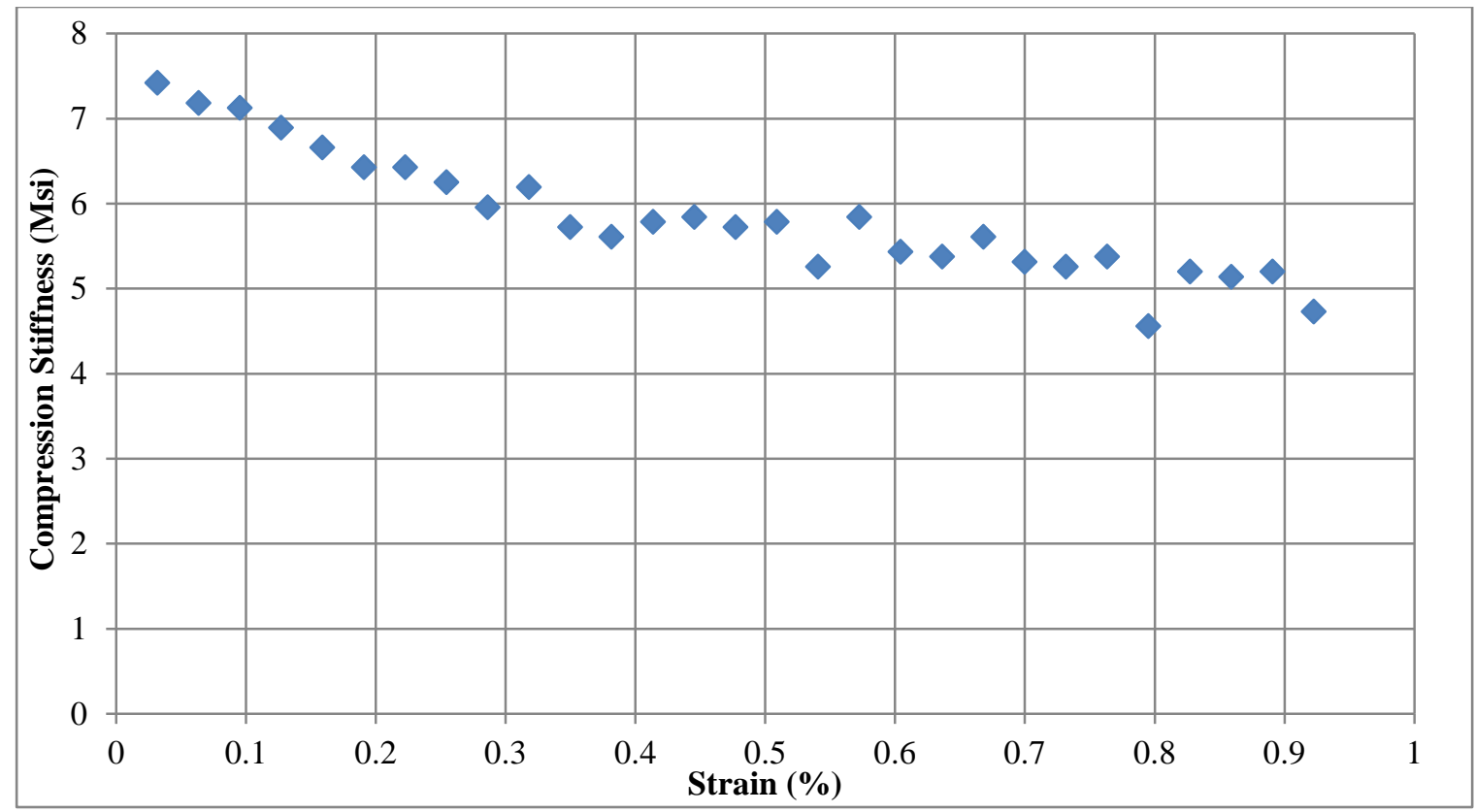

Figure 4-2 Change in Stiffness Curve from Four-Point Bend Sample 6 (Compression Face) - Section VE-16x0.5

The change in stiffness throughout loading for section VE-16x0.5 is generally linear. The change in stiffness on the compression face and on the tension face is mostly the same. Therefore with section VE-16x0.5, an exact point where stiffness reduction begins is undeterminable. This makes clear that local buckling does not contribute much, if any, to stiffness changes in VE$16 \times 0.5$.

Different behavior was found in section PU-16x0.5. While the flexural stiffness reduced during the test, it reduced in a different fashion than VE-16x0.5. Samples 2, 3 and 5 had a longitudinal strain gage at the top of the specimen while Samples 1, 4, and 5 had a longitudinal strain gage on the bottom (Sample 5 had both). There is a difference in the stiffness reduction based on whether the strain was measured on the top (compression face) or the bottom (tension face) of the specimen. Figure 4-3 and Figure 4-4 illustrate the flexural stiffness reduction for sample 5 of section PU-16x0.5 both on the compression face and tension face. 


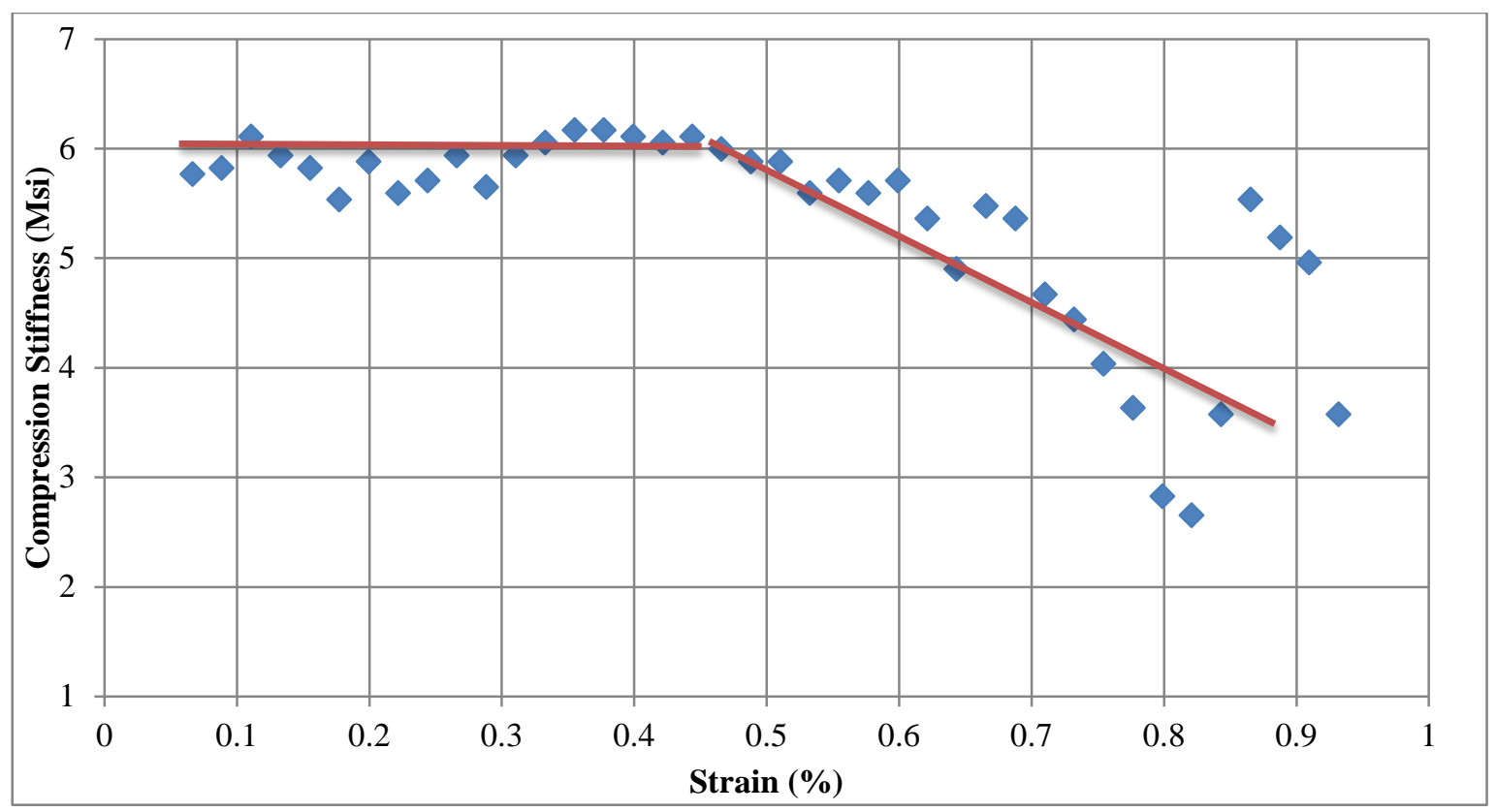

Figure 4-3 Change in Stiffness Curve from Four-Point Bend Sample 5 (Compression Face) - Section PU-16x0.5

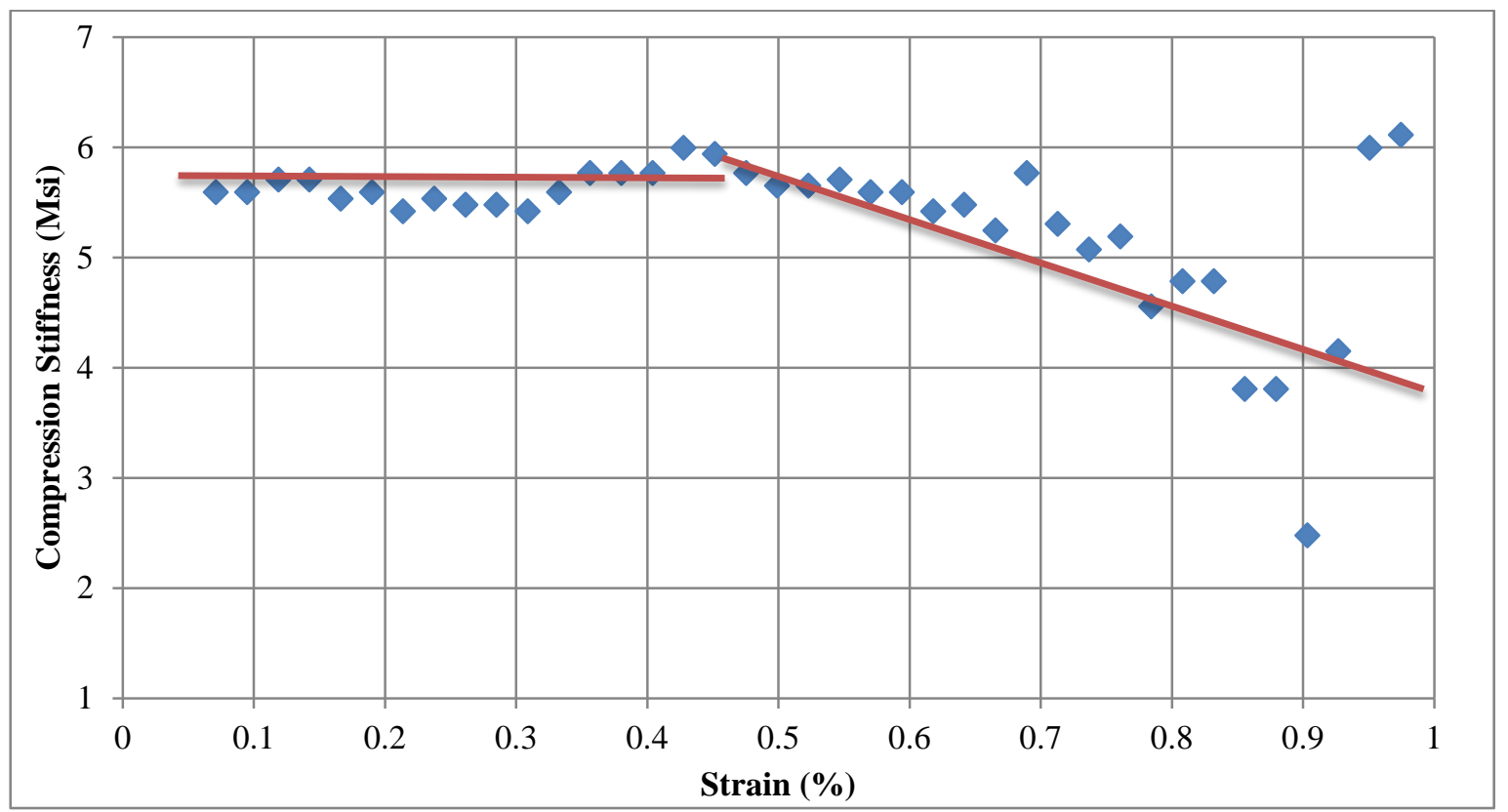

Figure 4-4 Change in Stiffness Curve from Four-Point Bend Sample 5 (Tension Face) - Section PU-16x0.5 
These graphs are both typical of the other samples from this section set. Consistently, the bottom stiffness change (Figure 4-4) follows a less dramatic reduction while the top stiffness change (Figure 4-3) experiences a drastic change. This is because local buckling occurs on the compression face of the specimens. From $0-45 \%$ strain the stiffness is fairly constant and then from $45-100 \%$, the stiffness takes on a linear decrease with increase in strain. At around $45 \%$ of ultimate strain change in slope begins to occur in the specimen and the cross section starts deforming. To back up this claim, the stiffness change for sample 2 (gage located at top) is shown in Figure 4-5.

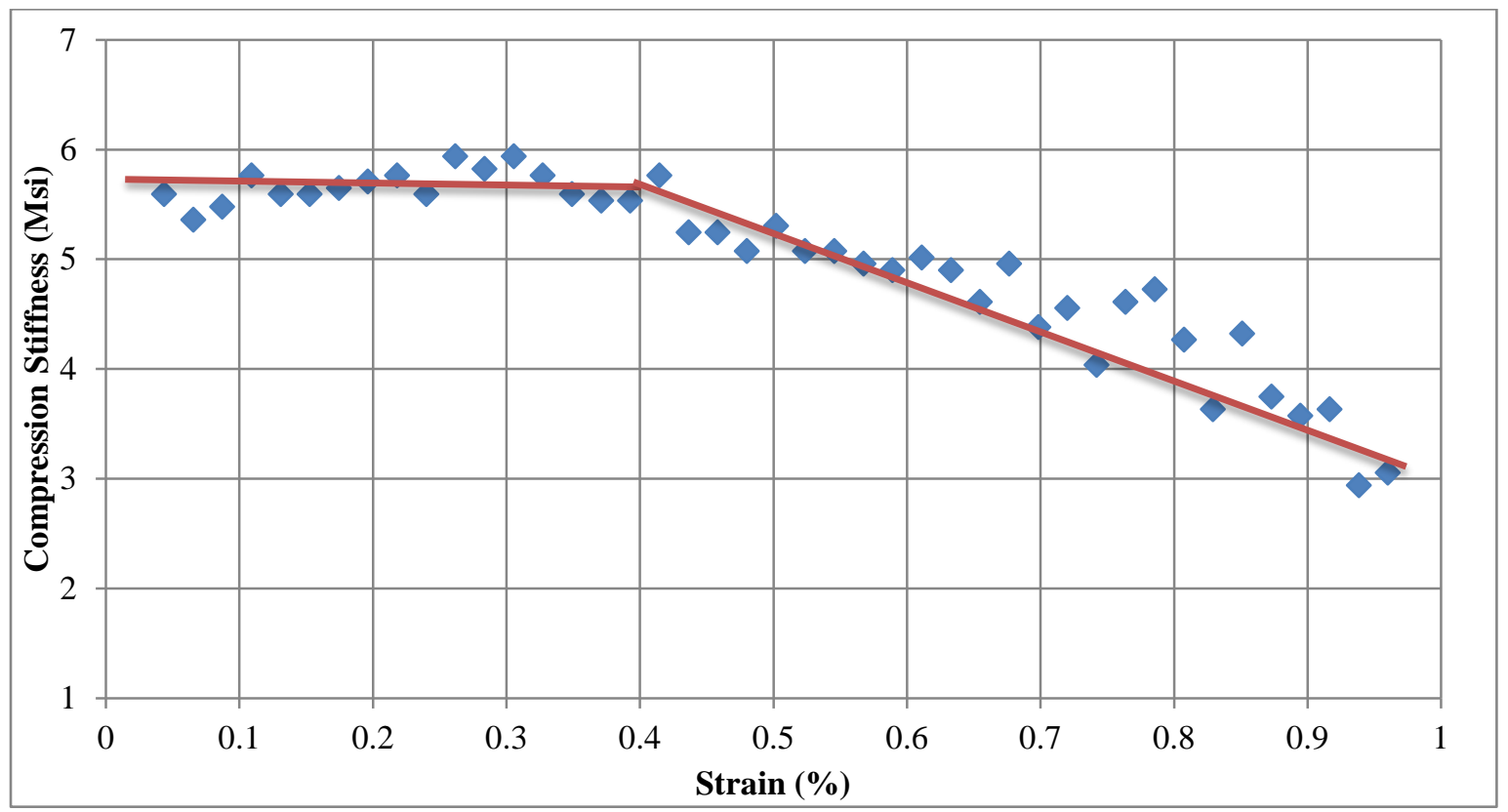

Figure 4-5 Change in Stiffness Curve from Four-Point Bend Sample 2 (Compression Face) - Section PU-16x0.5

As shown in Figure 4-5, the stiffness change also follows a two-part pattern. From 0-40\% strain the stiffness is fairly constant and then from $40-100 \%$, the stiffness takes on a linear decrease. The same sample was discussed earlier in section 3.3.2.2 and it was decided, based on circumferential strain on the side of the tube that nonlinearity began at $40 \%$ of the ultimate load. The same conclusion can be made here for $40 \%$ of ultimate strain. This matches closely with the 
sample 5 results in which $\sim 45 \%$ of ultimate strain was the bifurcation point. Although not shown here, sample 4 having a gage on the tension face, shows strikingly similar behavior as sample 5 (Figure 4-4). Sample 4 changes from a constant stiffness to a decreasing linear stiffness at around $40 \%$ of ultimate strain.

Section PU-12x0.5, with a D/t ratio of 24, exhibits similar behavior to the previously discussed sections. Two of the five sections had strain gages on the top in the longitudinal direction and the other three had strain gages on the bottom in the longitudinal direction. As with the section PU-16x0.5, the top strain gage shows a two part stiffness curve in which a constant stiffness characterizes the tube up to a certain strain, and then a decreasing linear change occurs. The tubes that had the longitudinal gage on the bottom (tension face) convey a linearly decreasing change throughout the entire loading. Evidence for this claim can be seen in Figure 4-6 and Figure 4-7, which show the compression strain gage and the tension strain gage, respectively for two different samples. 


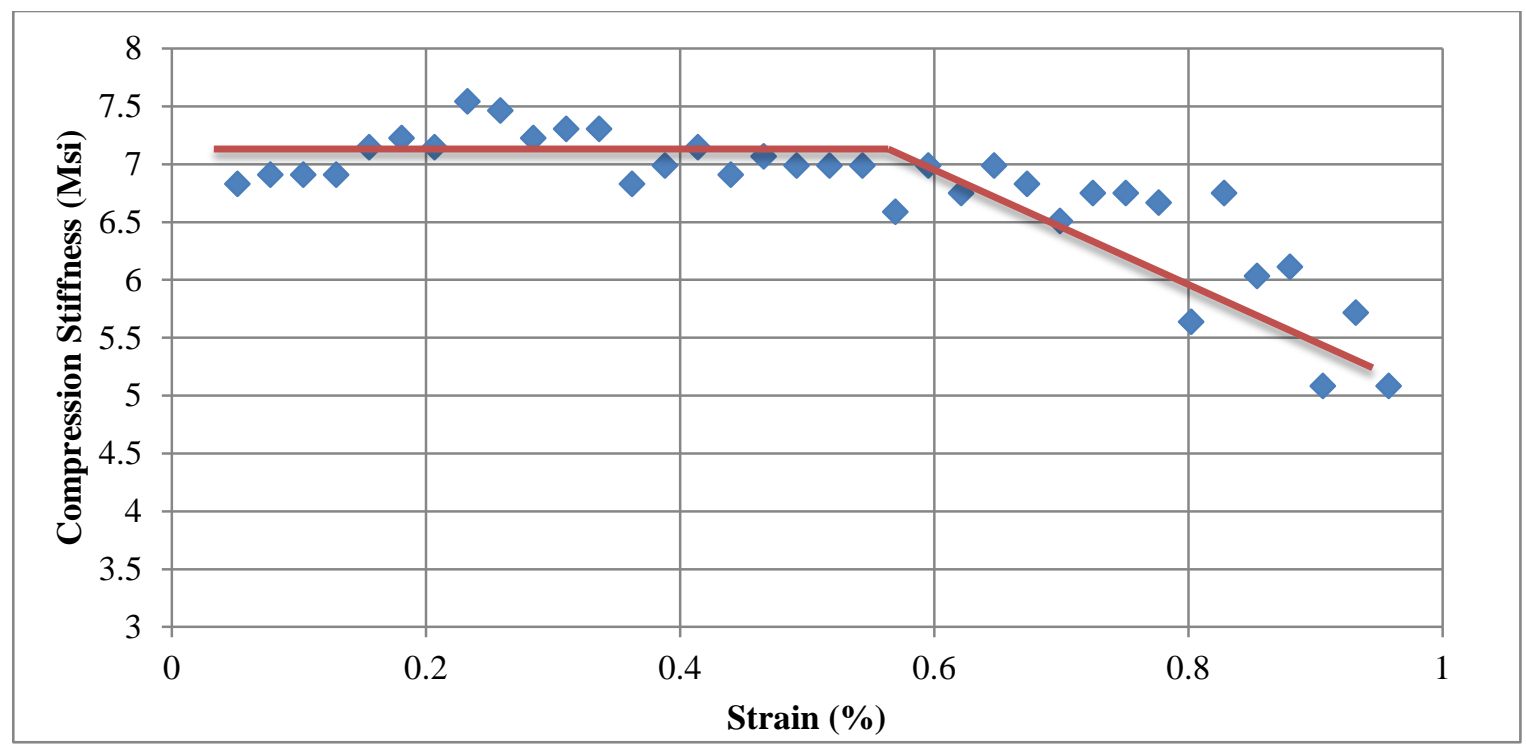

Figure 4-6 Change in Stiffness Curve from Four-Point Bend Sample 3 (Compression Face) - Section PU-12x0.5

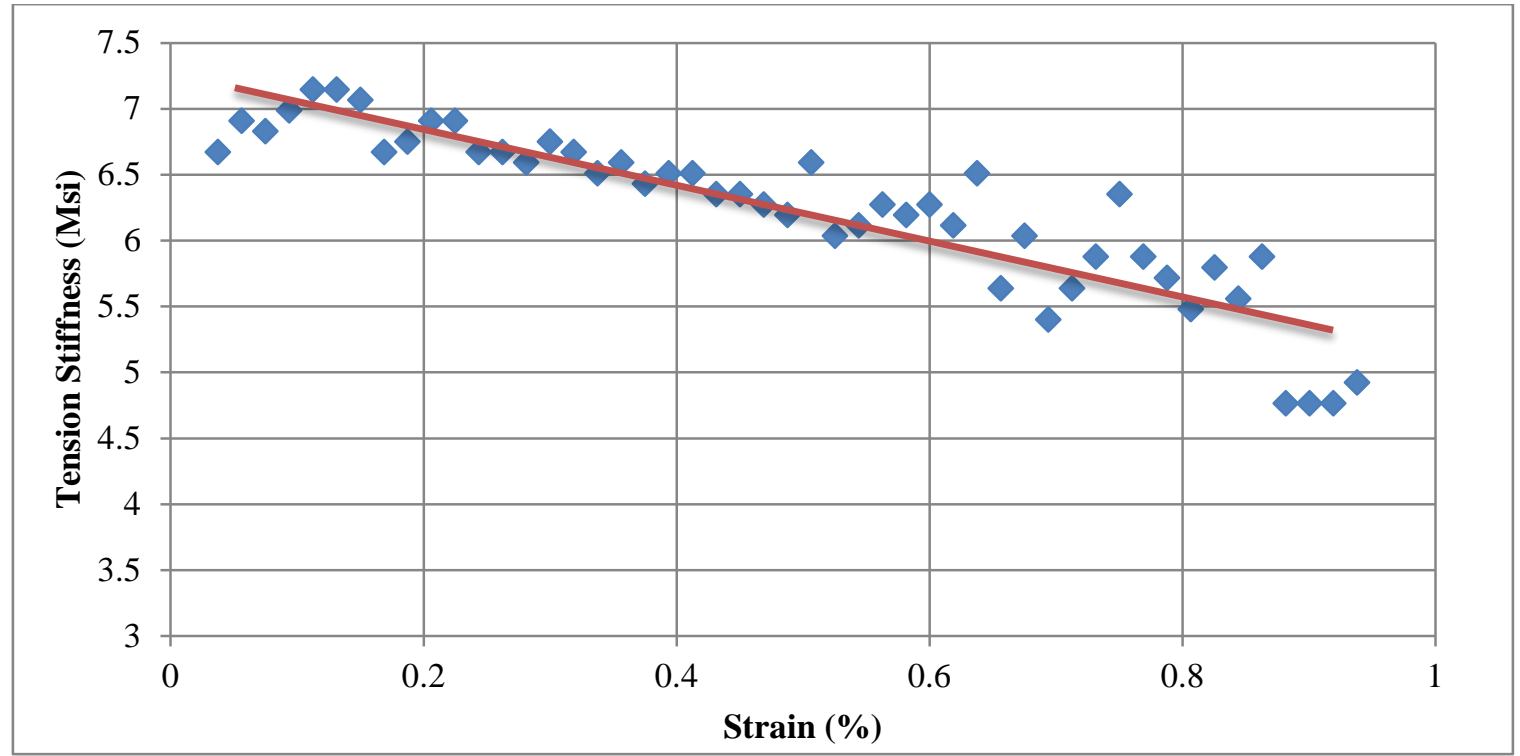

Figure 4-7 Change in Stiffness Curve from Four-Point Bend Sample 2 (Tension Face) - Section PU-12x0.5

Similar to previous sections, section PU-12x0.5 shows a point at which the stiffness begins changing. As seen in Figure 4-6, this point is roughly 57\% of the ultimate strain. Also, for the other sample with a compression face strain gage from section PU-12x0.5, the stiffness change 
occurs at approximately $50 \%$ of the ultimate strain. Both of these are higher than the $40-45 \%$ of ultimate strain at which the stiffness changed for section PU-16x0.5.

Section PU-12x0.375, having a D/t ratio of 32, showed the least amount of stiffness reduction throughout loading compared to the other specimens. All three specimens had the longitudinal strain gage located on the bottom of the tube; however, the post-fatigue sample had a strain at both top and bottom locations. It was decided earlier (section 3.8) that the 200 fatigue cycles had little to no effect on the stiffness and strength of the tube; therefore, this tube will be examined to determine how the stiffness changes during loading. Figure 4-8 and Figure 4-9 illustrate the change in stiffness as recorded from the top (compression face) and bottom (tension face), respectively, of sample 4 of section PU-12x0.375.

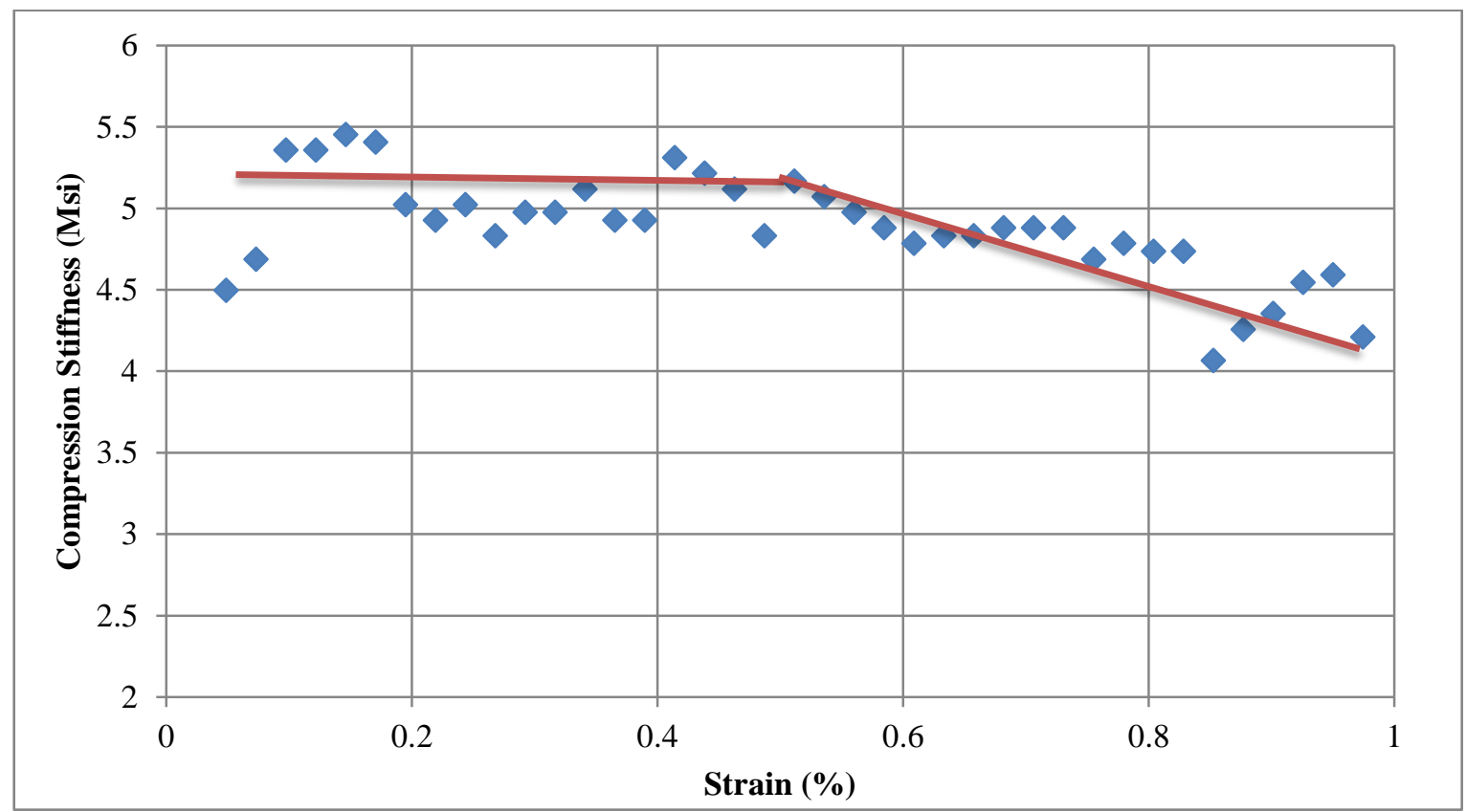

Figure 4-8 Change in Stiffness Curve from Four-Point Bend Sample 4 (Compression Face) - Section PU-12x0.375 


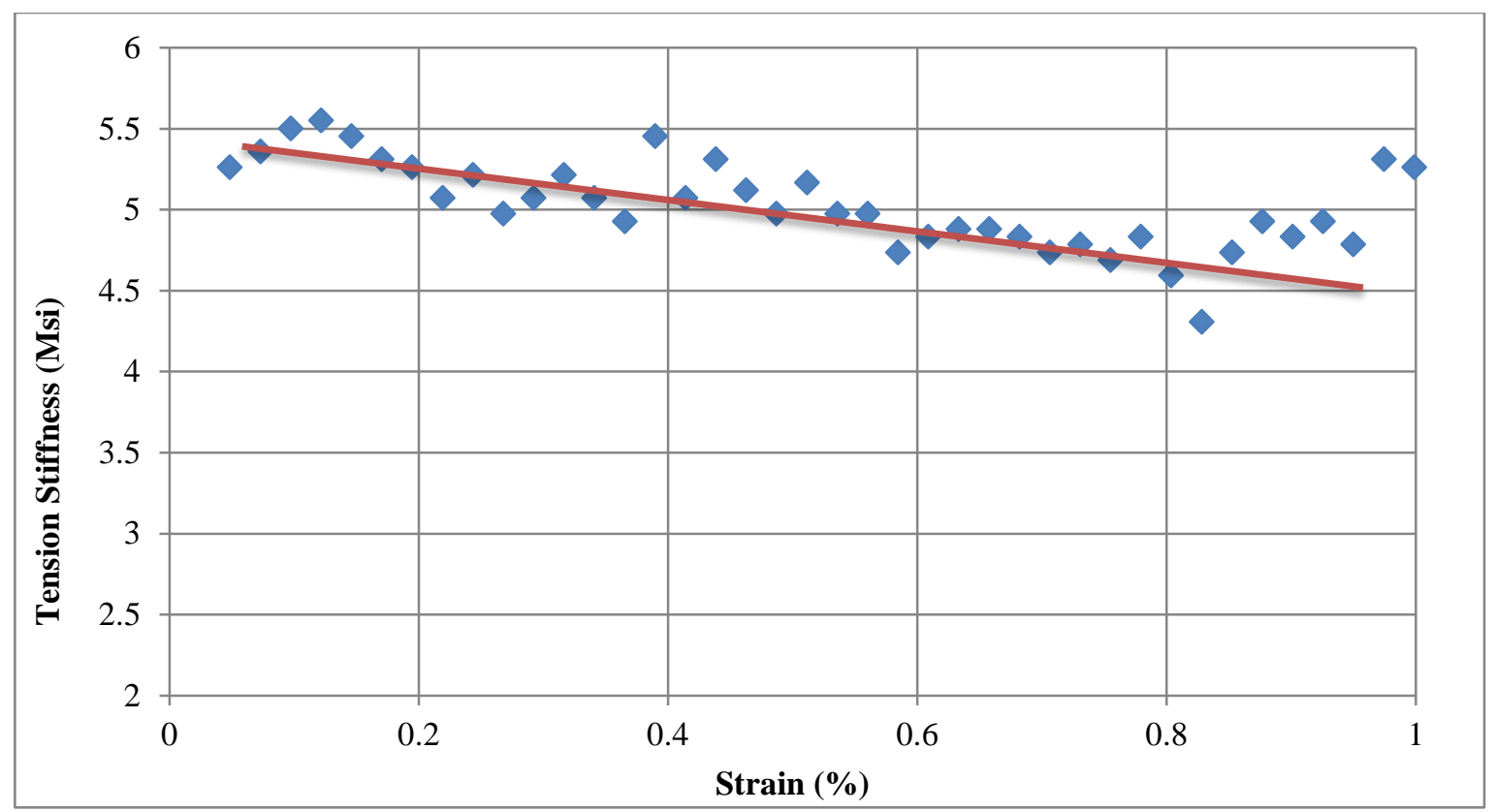

Figure 4-9 Change in Stiffness Curve from Four-Point Bend Sample 4 (Tension Face) - Section PU-12x0.375

Figure 4-8, showing the change in stiffness with respect to the compression face, shows vague correlation the results of the previously discussed sections. The change in stiffness occurs in two parts; although, the change is less dramatic than the other sections. This is probably attributed to a higher percent of non-unidirectional fibers. Section PU-12x0.375 contains the same $+45 / 90 /-45$ fiber mat as the other sections; therefore, since the wall thickness of section PU-12x0.375 is less than the other sections the non-unidirectional fiber mat plays a large role in resisting any cross sectional deformation. The change from constant stiffness to linear decreasing stiffness occurs at approximately 50\% of ultimate strain. Figure 4-9 illustrates that the tension face of the tube doesn't experience the same stiffness reduction behavior, but instead the stiffness drops somewhat linearly throughout the loading.

From the stiffness analysis of all four sections, a bilinear change was found on the compression face of the tubes. This bilinear change in stiffness did not occur clearly for VE- 
16x0.5; however, it occurred at approximately 40\% strain for PU-16x0.5, 50-55\% strain for PU12x0.5, and 50\% for PU-12x0.375. These results are summarized in Table 4-1 along with the D/t ratio for each section. This is shown in order to emphasize that a higher $\mathrm{D} / \mathrm{t}$ results in an earlier onset of nonlinearity during bending.

Table 4-1 Summary of Stiffness Change Points

\begin{tabular}{|c|c|c|c|}
\hline Section & D/t & $\begin{array}{c}\text { Stiffness Change } \\
\text { (\% of ultimate } \\
\text { strain) }\end{array}$ & $\begin{array}{c}\text { Stiffness Change } \\
\text { (\% of ultimate } \\
\text { stress) }\end{array}$ \\
\hline PU-16x0.5 & 32 & 40 & 44 \\
\hline VE-16x0.5 & 32 & N/A & N/A \\
\hline PU-12x0.5 & 24 & $50-55$ & $58-60$ \\
\hline PU-12x0.375 & 32 & 50 & 50 \\
\hline
\end{tabular}

\subsection{Bending Stiffness Replacement - Laminated Plate Approach}

A method to determine bending stiffness, EI, for a cylindrical section based on classical lamination theory (CLT) is explained below. This bending stiffness can be used as a replacement in designer friendly bending equations such as Euler-Bernoulli's equation. As it applies to the bilinear stiffness experienced by the tubes tested in four-point bending, this replacement stiffness will yield a comparable result to the initial constant stiffness before the bifurcation. Using the manufacturer-supplied fiber architecture and material properties, laminate properties can be found with reasonable accuracy by the rule of mixtures approach (Barbero, 2011). The raw material properties were given by the manufacturer; however, some had to be approximated using published data. The raw material properties used are shown in Table 4-2. 
Table 4-2 Raw Material Properties used in Tube Sections

\begin{tabular}{|c|c|c|c|c|c|c|c|c|}
\hline Material & $\begin{array}{c}\text { Elastic } \\
\text { Modulus }\end{array}$ & $\begin{array}{c}\text { Tensile } \\
\text { Strength }\end{array}$ & $\begin{array}{c}\text { \% } \\
\text { Elongation } \\
\text { to failure }\end{array}$ & $\begin{array}{c}\text { Poisson's } \\
\text { Ratio }\end{array}$ & Density & $\begin{array}{c}\text { Compression } \\
\text { Strength }\end{array}$ & $\begin{array}{c}\text { Shear } \\
\text { Strength }\end{array}$ & $\begin{array}{c}\text { Shear } \\
\text { Modulus }\end{array}$ \\
\cline { 2 - 9 } & $(\mathrm{psi})$ & $(\mathrm{psi})$ & $\%$ & & $\left(\mathrm{lb} / \mathrm{in}^{3}\right)$ & $(\mathrm{psi})$ & $(\mathrm{psi})$ & $(\mathrm{psi})$ \\
\hline E-glass & 11000000 & 325000 & $4.4^{*}$ & $0.22^{*}$ & 0.0919 & - & & $4508197^{*}$ \\
\hline VE & 464121 & 12473 & 5.5 & $0.38^{*}$ & - & $16984^{*}$ & $11995^{*}$ & $168160^{*}$ \\
\hline PUR & 420609 & 12038 & 9.4 & 0.41 & - & - & 8100 & \\
\hline
\end{tabular}

*This value was taken from Barbero (2011).

The modulus in the fiber direction and the main Poisson's ratio were found by Equations 4-1 and 4-2:

$$
\begin{aligned}
& E_{1}=V_{f} E_{f}+V_{m} E_{m} \\
& v_{12}=V_{f} v_{f}+V_{m} v_{m}
\end{aligned}
$$

where $E_{f}$ and $E_{m}$ are the Young's moduli, $V_{f}$ and $V_{m}$ are the volume fractions, and $v_{f}$ and $v_{m}$ are the Poisson's ratios for the fibers and matrix, respectively. The transverse modulus is better approximated using the Halpin-Tsai formula shown in Equation 4-3:

$$
\begin{gathered}
E_{2}=E_{m}\left[\frac{1+\zeta \eta V_{f}}{1-\eta V_{f}}\right] \\
\eta=\frac{E_{f} / E_{m}-1}{E_{f} / E_{m}+\zeta}
\end{gathered}
$$

where the value $\zeta=2$ is a good fit for the case of circular fibers (Barbero, 2011). The shear modulus is found by the cylindrical assemblage model as shown in Equation 4-4

$$
G_{12}=\frac{\left(1+V_{f}\right)+\left(1-V_{f}\right) G_{m} / G_{f}}{\left(1-V_{f}\right)+\left(1+V_{f}\right) G_{m} / G_{f}}
$$

where $G_{f}$ and $G_{m}$ are the shear moduli for the fibers and matrix, respectively. 
Once the moduli are obtained for each lamina and the $[\mathrm{ABD}]$ matrix is calculated for a laminated plate, then the stiffness replacement for a closed tubular section can be found by Equation 4-5, derived by Kollár (Kollár \& Springer, 2003):

$$
\widehat{E I}_{y y}=\int_{(S)}\left(\frac{1}{a_{11}} z^{2}+\frac{1}{d_{11}} \cos ^{2} \alpha\right) d \eta
$$

Equation 4-5 is valid for a symmetric and orthotropic layup and may be modified for cylindrical sections as shown in Equation 4-6:

$$
\widehat{E I}_{y y}=\widehat{E I}_{z z}=\pi\left(\frac{R^{3}}{a_{11}}+\frac{R}{d_{11}}\right)
$$

Once the replacement stiffnesses are obtained from Equation 4-6, they can be directly compared to moduli values calculated from experimental bending testing (see section 3.3.2). The comparison of the theoretical bending stiffness to the experimental bending stiffness is shown in Table 4-3 with the percent difference showing the theoretical values deviation from experiment. This method resulting in Equation 4-6 will hereafter be referred to as CLT for convenience.

Table 4-3 Bending Stiffness Comparison, CLT vs. Experiment

\begin{tabular}{|c|c|c|c|}
\hline \multirow{2}{*}{ Section } & \multicolumn{2}{|c|}{ Bending Stiffness, EI (Mlb-in ${ }^{2}$ ) } & \multirow{2}{*}{$\begin{array}{c}\text { Percent } \\
\text { Difference }\end{array}$} \\
\cline { 2 - 3 } & Experiment & CLT & -12.99 \\
\hline PU-16x0.5 & 4333 & 3770 & -6.47 \\
\hline VE-16x0.5 & 4077 & 3813 & -20.61 \\
\hline PU-12x0.5 & 1978 & 1570 & -3.04 \\
\hline PU-12x0.375 & 1218 & 1181 & \\
\hline
\end{tabular}

Also calculated using theoretical bending stiffness were center span deflections through Euler - Bernoulli's beam deflection equation at the center span for four-point bending:

$$
\Delta=\frac{P L^{3}}{28 E I}
$$


The deflections found from Equation 4-7 for each section were from 10-30 \% higher than the experimental values. This can be observed in the following load deflection curves (Figure 4-11 through Figure 4-14). It isn’t completely clear why the theoretical deflections are lower than the experimental deflections, but since the CLT and the FE results match closely, it is likely due to small discrepancies between the material properties and fiber architectures used in the theoretical calculations and the true characteristics of the sections.

\subsection{Failure Load Prediction}

As discussed in the Literature Review (CHAPTER 2), there are many equations available for determining the critical moment that causes collapse of a thin walled composite tube. However, for the tubes tested in the study, the failure mode from four-point bending resulted in crushing under axial compression resulting in local buckling. Therefore, the equations presented in the Literature Review in section 2.3 (Equations 2-3 through 2-14) are only valid whenever local buckling is the cause of failure.

In order to predict the failure load of the tubes in bending, the additional local buckling must be accounted for with the bending stress. Using the failure strain as the criteria for determining when the tubes will fail, the global bending strain is calculated as follows

$$
\frac{M c}{E I}=\varepsilon
$$

where $\mathrm{M}$ is the applied bending moment, $\mathrm{c}$ is the distance from the centroid to the outermost fiber of the tube, E is the Young's Modulus in the axial direction, and I is the moment of inertia of the tube. This is the commonly used Euler equation for bending stress; however, to account 
for additional load due to local buckling, an axial load compression effect will be added to the bending stress resulting in

$$
\frac{M c}{E I}+\frac{P}{A}=\varepsilon
$$

where $\mathrm{P}$ is the load either of the application points, and $\mathrm{A}$ is the area of the cross section in compression. By inspection, A will be no greater than half the cross sectional area; however, it can be adjusted to fit the properties of the tube. Substituting PL/3 for M to fit the case of fourpoint bending and rearranging to solve for $\mathrm{P}$ results in

$$
P=\frac{E \varepsilon}{\left[\frac{L}{3} \frac{C}{I}+\frac{1}{A}\right]}
$$

where L is the span length. Generally speaking, the top half of the cylinder is in compression; therefore, A will be taken as half of the cross sectional area of each tube. Using the average modulus and average maximum strain from the four-point bending experimental tests, the failure load, P, was calculated. The results of Equation 4-10 compared to the experimental failure load are shown in Table 4-4. Also included in Table 4-4 is the result of the equation ignoring the local compression effect (Equation 4-8).

Table 4-4 Failure Load Prediction Compared to Experiment

\begin{tabular}{|c|c|c|c|c|c|c|}
\hline \multicolumn{2}{|c|}{} & \multicolumn{2}{c|}{$\begin{array}{c}\text { Accounting for P/A } \\
\text { Effect }\end{array}$} & \multicolumn{2}{c|}{ Ignoring P/A } \\
\hline Section & $\begin{array}{c}\text { Max } \\
\text { Load } \\
(\mathbf{k i p s})\end{array}$ & $\begin{array}{c}\text { Avg Max } \\
\text { Strain } \\
(\boldsymbol{\mu \varepsilon})\end{array}$ & $\begin{array}{c}\mathbf{2 P} \text { (Eq 4-10) } \\
\text { (kips) }\end{array}$ & $\begin{array}{c}\text { \% } \\
\text { Difference }\end{array}$ & $\begin{array}{c}\mathbf{2 P} \\
\text { (Mc/I) } \\
\text { (kips) }\end{array}$ & $\begin{array}{c}\text { \% } \\
\text { Difference }\end{array}$ \\
\hline PU-16x0.5 & 101.63 & 11152 & 105.80 & $\mathbf{4 . 1 0}$ & 113.26 & 11.44 \\
\hline VE-16x0.5 & 83.06 & 8913 & 79.56 & $\mathbf{- 4 . 2 1}$ & 85.17 & 2.54 \\
\hline PU-12x0.5 & 90.93 & 12720 & 98.05 & $\mathbf{7 . 8 3}$ & 104.81 & 15.27 \\
\hline PU-12x0.375 & 52.98 & 10843 & 51.41 & $\mathbf{- 2 . 9 6}$ & 55.04 & 3.88 \\
\hline
\end{tabular}


As shown in Table 4-4, accounting for the local compression effect yields a more accurate result compared to experiment that ignoring this effect. Equation 4-10 produces better correlation in every section with exception of VE-16x0.5 which was noted earlier to not experience much, if any, local buckling effect.

\subsection{Finite element Analysis}

The four-point bending tests were modeled using finite element analysis to further characterize the local buckling behavior that occurs during loading.

Using the rule of mixture equations (Equations 4-1 through 4-3), the material properties were defined for each lamina. ANSYS software was used for the finite element modeling. A four-node element with six degrees of freedom at each node was used; using this element, any number of lamina can be defined for each section. The 16 in diameter tubes, PU-16x0.5 and VE16x0.5, were both discretized with 28 elements in the circumferential direction and 160 elements in the longitudinal direction. The 12 in diameter tubes, PU-12x0.5 and PU-12x0.375, were both discretized with 20 elements in the circumferential direction and 120 elements in the longitudinal direction. Figure 4-10 depicts a 16" diameter tube discretized with boundary conditions and external loads. The red arrows are the applied load which match the location of the experiment, and the light blue represent the boundary conditions. The tube was restricted in $\mathrm{Y}$ and $\mathrm{X}$ directions at the end and in the $\mathrm{Z}$ direction at center span. The $\mathrm{Y}$ and $\mathrm{X}$ restrictions mimic the experimental setup; however, the $\mathrm{Z}$ restraint was added in order make the model stable. 


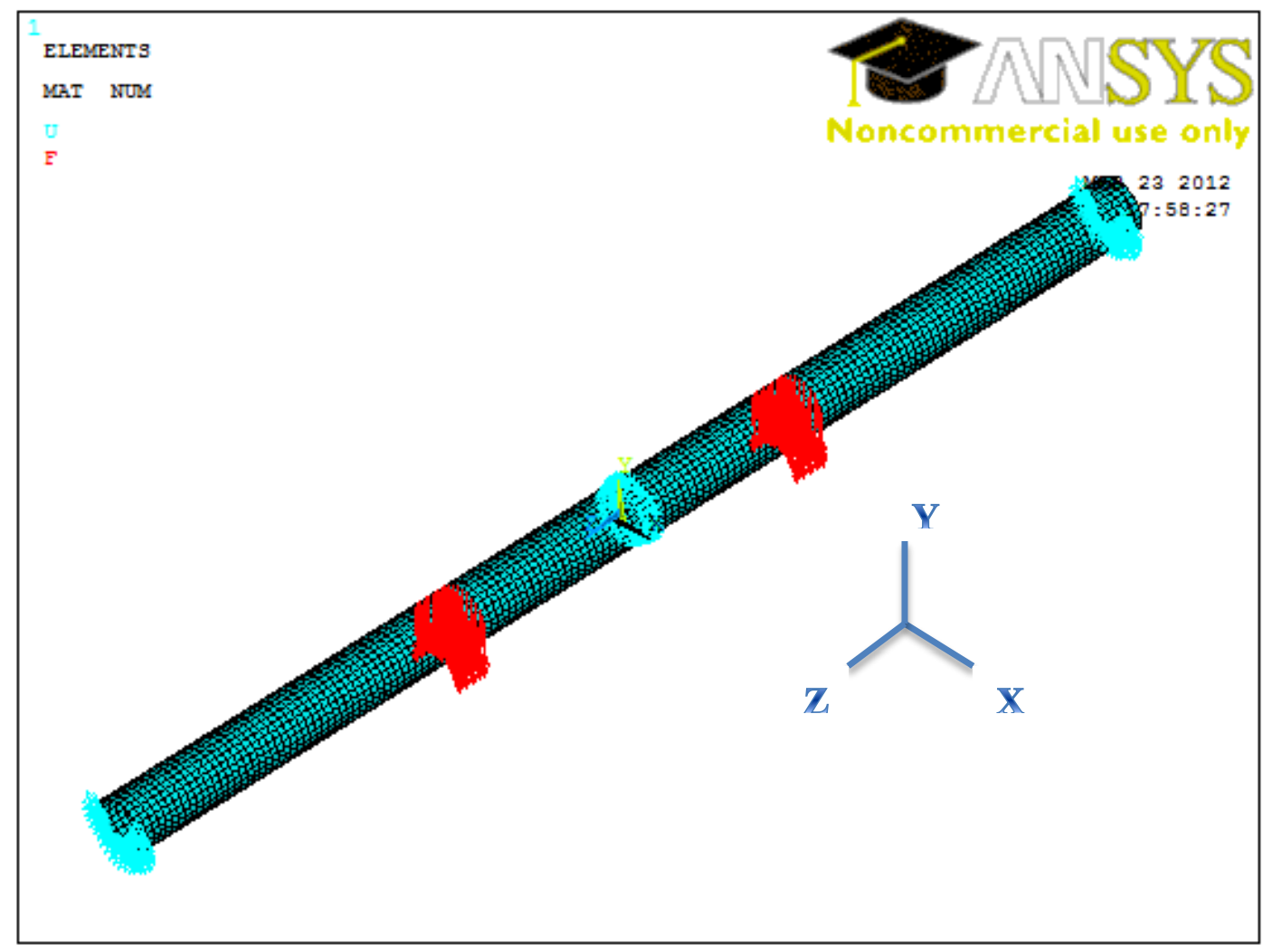

Figure 4-10 Discretized Tube Modeled in ANSYS with External Loads and Boundary Conditions

After running the model in a linear static mode, results were found to be nearly identical to those obtained by CLT. In order to account for the change in shape of the cross section that occurs during bending and the resulting stiffness reduction, a large displacement mode was used. This mode uses the Newton-Raphson method to converge on a solution. As the load is broken down into steps, ANSYS adjusts the stiffness matrix of each step to reflect any geometric changes in the cross section.

The maximum load reached in the experiment was set as the max load in the model, leaving the model to automatically choose time steps as it ramped up to the input maximum. The resulting loads vs. deflections plots from the finite element analysis are shown for each section in the following figures (Figure 4-11 through Figure 4-14). 


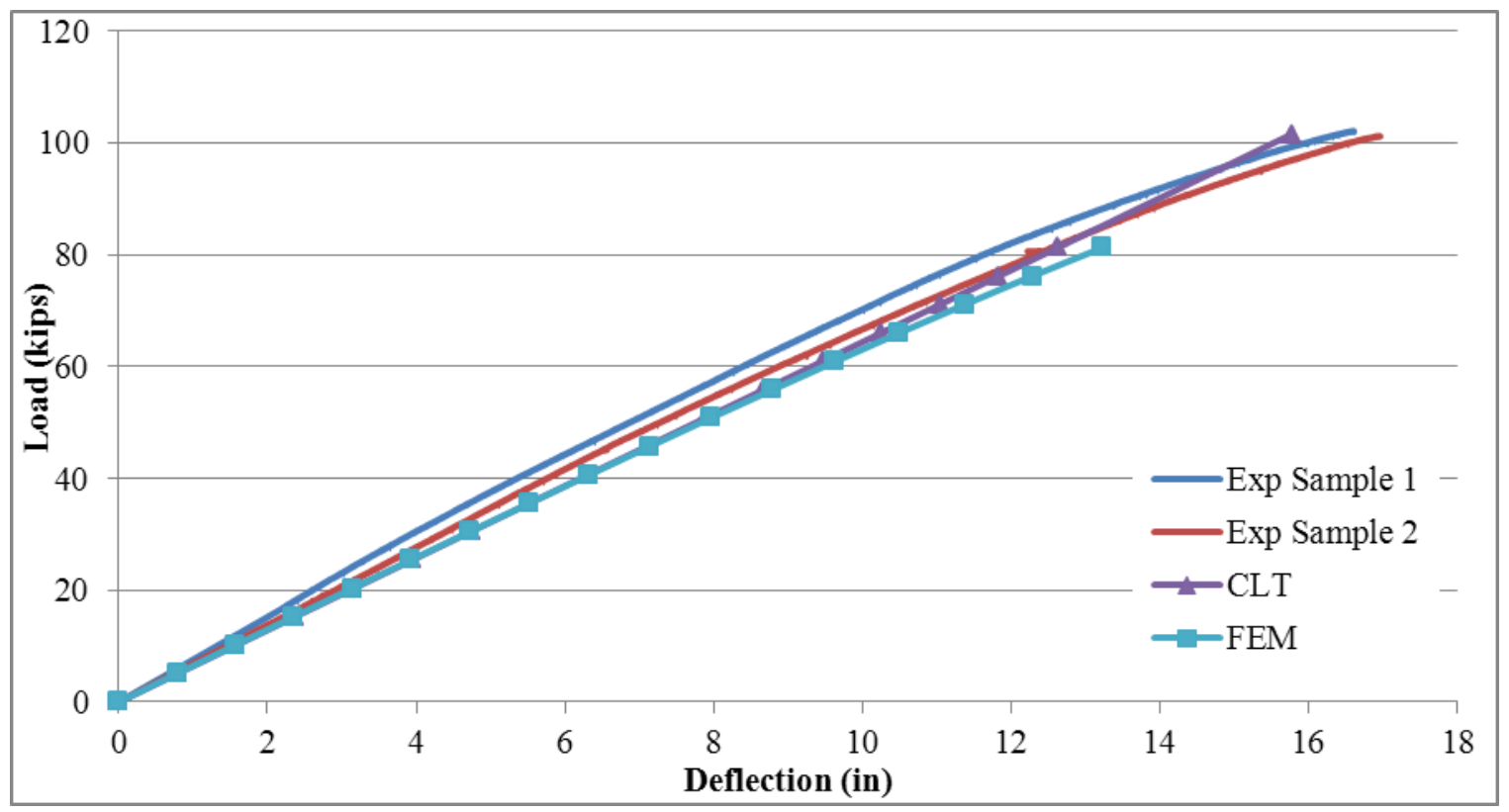

Figure 4-11 Load-Deflection Curve Comparison for Exp vs. FEM vs. CLT - Section PU-16x0.5

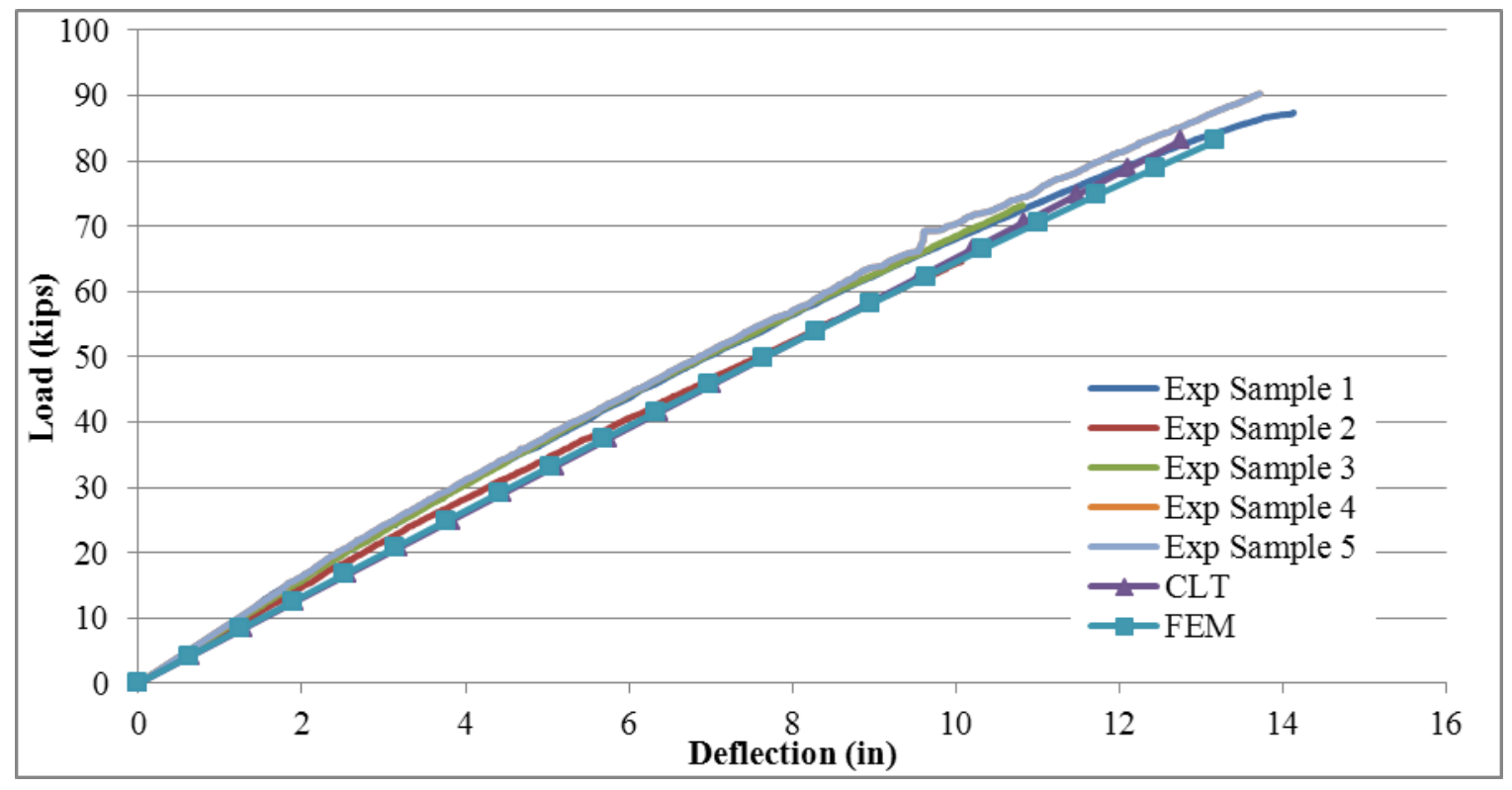

Figure 4-12 Load-Deflection Curve Comparison for Exp vs. FEM vs. CLT - Section VE-16x0.5 


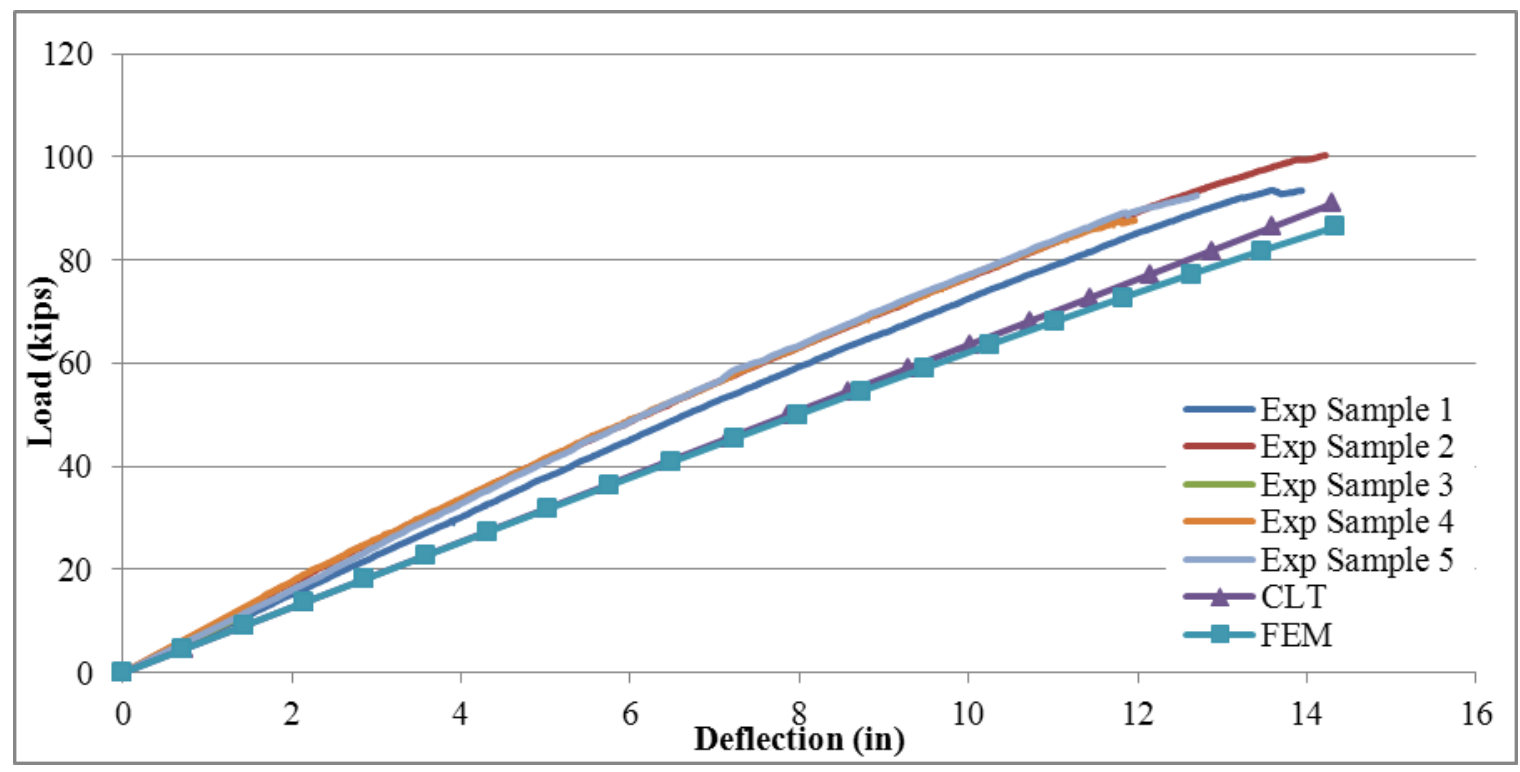

Figure 4-13 Load-Deflection Curve Comparison for Exp vs. FEM vs. CLT - Section PU-12x0.5

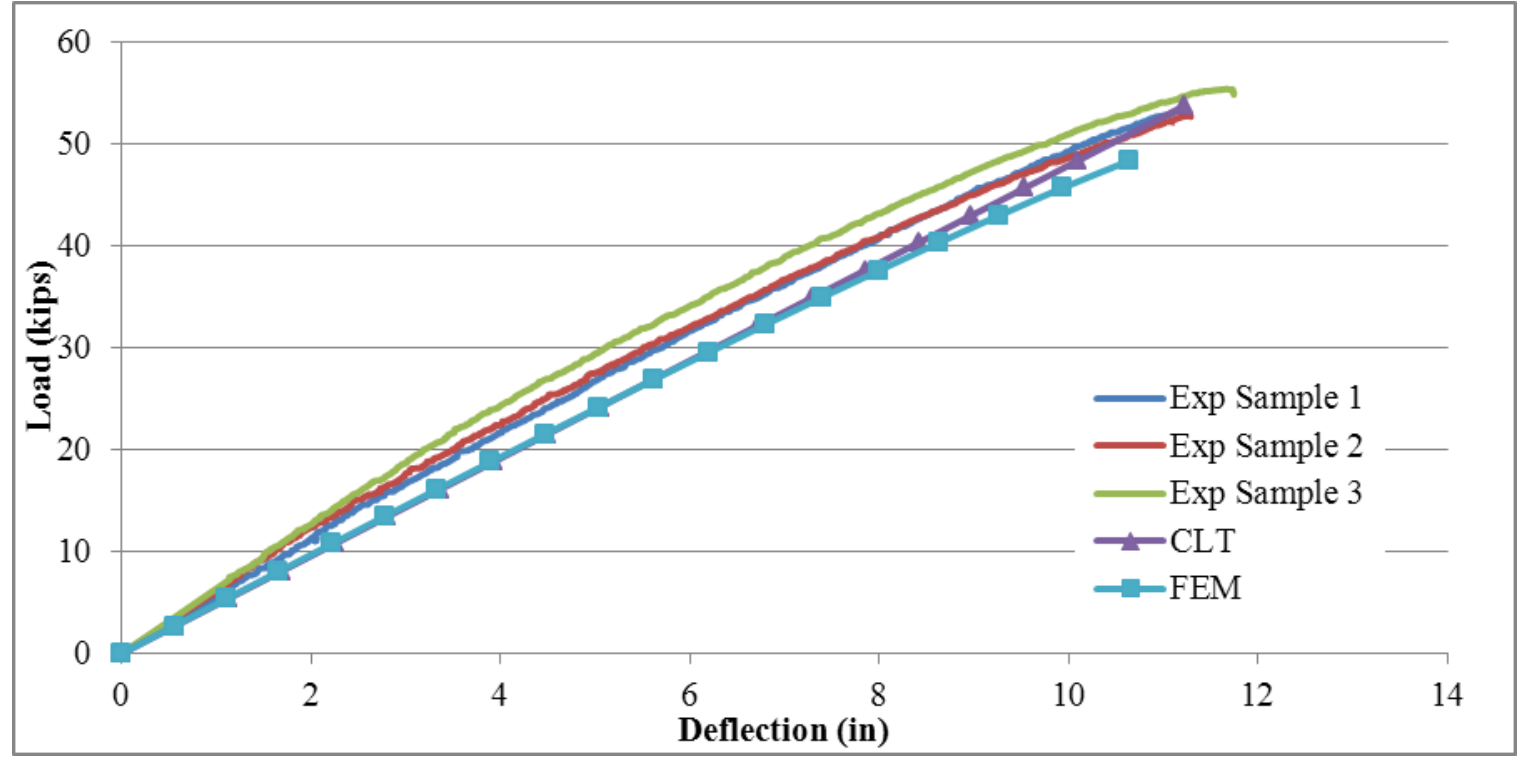

Figure 4-14 Load-Deflection Curve Comparison for Exp vs. FEM vs. CLT - Section PU-12x0.375

Each model produced results almost exact to that of the CLT prediction, and for each section with the exception of PU-12x0.5, the deflections were anywhere from $10 \%$ to $18 \%$ different than experiment. Section PU-12x0.5 was approximately $20 \%$ to $30 \%$ under predicting. 
It is not completely clear why the FEM was consistently underpredicting. Since the FEM matches so closely with the CLT theory deflection results, it is assumed that accurate material properties or layup architecture were not used.

In order to validate whether the finite element was able to capture the cross sectional deformation accurately, the reduction in vertical radius of the cross section is observed from the finite element model. A technique taken from Ibrahim et al. (2000) was applied to the previously developed FE models. By subtracting the bottom deflection from the top deflection at midspan, the change in vertical radius was found. The result of this is then compared to experimental results. Video footage was conducted on Sample 4 of PU-12x0.375 and the change in vertical radius was observed from the footage. The results of the finite model and experimentation are shown and compared in Figure 4-15. 


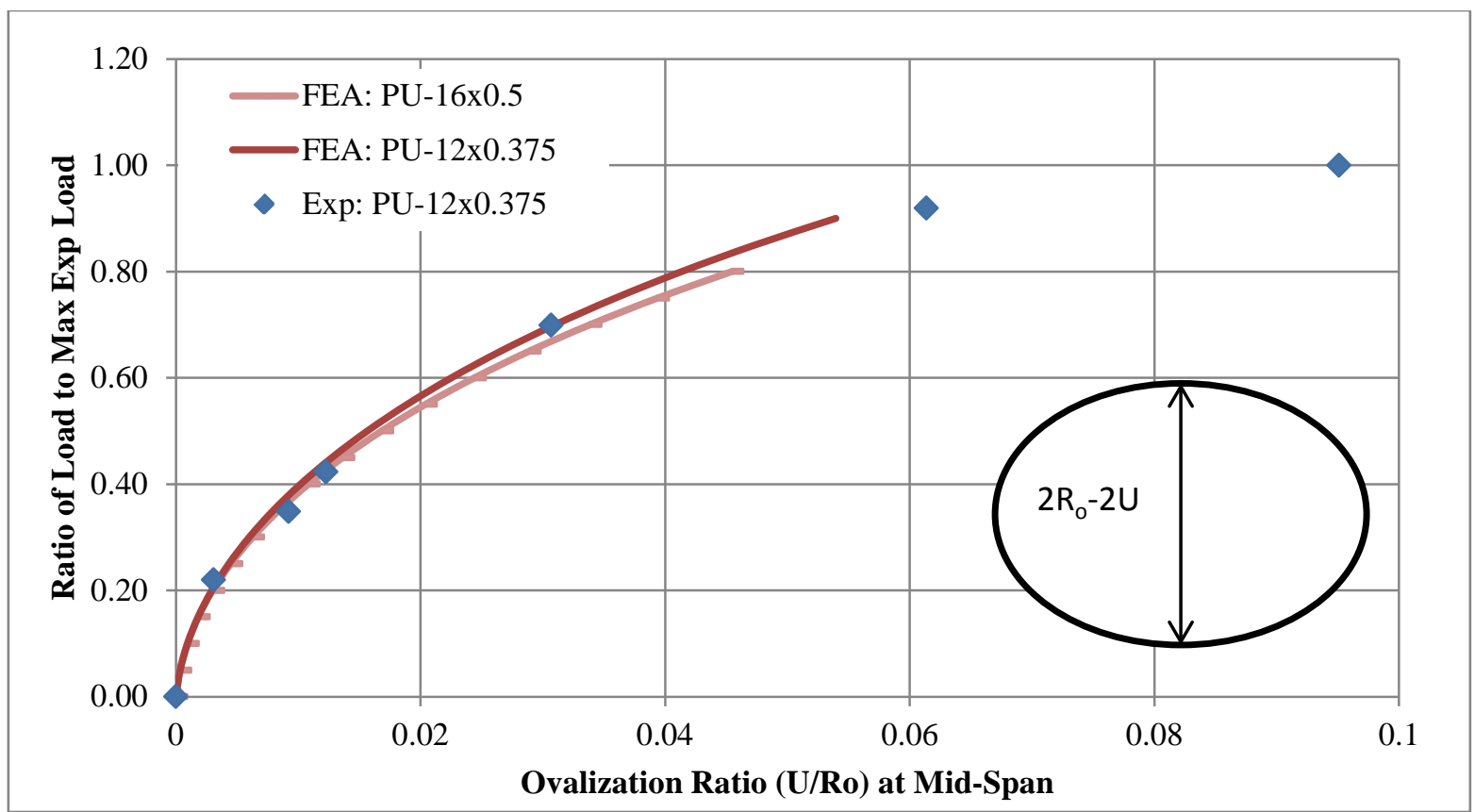

Figure 4-15 Ovalization Comparison of Finite Results vs. Experimental Results

Figure 4-15 depicts the resulting FE ovalization ratios and corresponding load ratios for sections PU-16x0.5 and PU-12x0.375, where $R_{o}$ is the initial radius of the cross section and $U$ is the radial deformation distance. Loading is not shown up to the max experimental load for the FE models because instability was reached in the model before that point. The finite model slightly provides a good approximation of ovalization.

\subsection{Conclusion}

From the four-point bending tests, sections PU-16x0.5, PU-12x0.5, and PU-12x0.375 were shown to have a bilinear stiffness behavior. The stiffness remains constant up to a certain strain/load and then began to decrease linearly. Section VE-16x0.5 showed a more stable stiffness and only decreased slightly throughout loading. The reason for this is due polyurethane's ductility and high strain to failure as shown in Table 4-2. PU-16x0.5 experienced a stiffness change at $40 \%$ strain for PU-16x0.5, 50-55\% strain for PU-12x0.5, and 50\% for PU- 
12x0.375. PU-12x0.5 experienced a stiffness change at a higher percentage due to its higher $\mathrm{D} / \mathrm{t}$ ratio. A good scientific reason for the stiffness changing and local buckling occurring at certain percentages of ultimate strain is unknown; however, the tests do show and describe this behavior and therefore it is likely caused by compression of the fibers as described.

A bending stiffness prediction was made based on classical lamination theory. The results showed an underprediction for each section. The difference was 13\% for PU-16x0.5, $6.5 \%$ for VE-16x0.5, $20.6 \%$ for PU-120x0.5, and 3\% for section PU-12x0.375. The varying differences are concluded to be somewhat due to inconsistencies from the material properties and fiber architecture used. Local effects could also yield higher experimental stiffnesses. Deflections were calculated using Euler's beam equation for bending and plotted in a load deflection curve. Finite element modeling was also used to attempt to capture any nonlinear behavior due to local buckling. The CLT and FEM results were very close until the later loading stages in which the finite element model loses stiffness as a result of its accounting for nonlinear behavior. For sections PU-16x0.5, VE-16x0.5, and PU-12x0375 the deflections estimated by CLT and FEM erred by approximately 10-18 \%. For section PU-12x0.5 the CLT and FEM deflections were underestimated by 20-30\%. Again, since both methods produced similar values, the error between their prediction and the experimental results most likely lies with assumptions regarding the material characteristics.

A method is proposed for predicting the failure load. This method attempts to take into account the local compression effect experience by the tubes in bending. Using the strain and modulus obtained from experiment, a prediction for each section is made. The failure load estimation has a percent difference compared to experimental results of $+4.1 \%$ for PU-16x0.5, 4.2\% for VE-16x0.5, $+7.8 \%$ for PU-12x0.5, and $-2.9 \%$. The results prove to be more accurate 
than when this effect is ignored. The only section where accounting for the local compression effect proves to be less accurate is VE-16x0.5. This section is the only section using a vinyl ester resin, and this section was shown to not experience as much of a contribution from local buckling/compression from experiment. Therefore, the model predicts well for the sections with a polyurethane resin system. Additional work should be completed to test this simple approach's ability to estimate the failure load of composite tubes in bending, particularly with varying tubes of different fiber-resin systems and fiber layup architectures. 


\section{CHAPTER 5 CONCLUSIONS AND RECOMMENDATIONS}

In this study, a review of published literature was conducted focusing on the following: 1) bending response of thin-walled cylindrical FRP and steel tubes; 2) plastic bending collapse of metals; 3) prebuckling response of cylindrical composite tubes; 4) bending stiffness predictions of composite tubes. A variety of mechanical tests were conducted on four different GFRP cylindrical tubular sections with varying cross section dimensions and resin systems. The GFRP tubes, manufactured through pultrusion under high pressure, were tested under bending, local crushing, and for special joining mechanisms. The test procedures and results are reported in Chapters 3 and 4, respectively. The polyurethane as well as vinyl ester matrix systems were tested for load to failure, strain to failure, stiffness, and energy absorption. Using the four-point bending experimental results, a prediction model is formulated for the failure load of the FRP tubes, including local compression effects. Good correlation is found with the proposed prediction technique and the experimental data. As narrated below, specific conclusions on bending and connection responses are drawn from the experimental and theoretical data.

\subsection{Mechanical Testing of Glass FRP Tubes}

\subsubsection{Four-Point Bending Response}

The primary failure mode of all sections under four-point bending was crushing in the compression side resulting from local buckling. VE-16x0.5 showed minimal local buckling and exhibited mostly compression crushing failure. The PU-12x0.5 specimens were found to have much higher stresses and strains to failure than the tubes with higher wall thickness ratios, indicating that the local buckling effects were more predominant in pipes with relatively thinner walls (refer to Section 3.3.2). This was evident in the diameter to wall thickness (D/t) ratio being 
24 for PU-12x0.5 versus 32 for all other samples. Also revealed by the four-point bending results, was a bilinear stiffness response. The bending stiffness for all polyurethane sections remained constant up to a certain strain level and then decreased approximately linearly. The percentage of ultimate strain at which this occurred was approximately $40 \%$ for PU-16x0.5, 5055\% for PU-12x0.5, and 50\% for PU-12x0.375 (see Table 4-1). The vinyl ester matrix did not exhibit such bilinear behavior.

The 200 cycle at $40 \%$ of ultimate stress fatigue test showed a negligible stiffness change for each section except PU-12x0.5 which showed a decrease of $12 \%$. This could be a cause for concern for designers and it is recommended another test be performed to ensure that fatigue is not a problem for this section. Section VE-12x0.5 failed at the load saddle during the postfatigue static test instead of the center span, this was likely not due to fatigue, but probably an unsymmetrical loading.

\subsubsection{Connection and Coupon Response}

The primary failure mode of connection test A was local crushing of the tube wall (refer to section 3.5.2). The bolt pushed its way through the wall slowly without abruptly rupturing. Connection test B showed sudden local cracking failure of each section (refer to section 3.6.2). The 6x6" washer under a point load yielded less local damage than the $4 \times 4$ " washer due to the load spread over a larger area.

Tensile coupon testing for section PU-16x0.5 and PU-12x0.5 yielded similar stresses to failure of 103 and $95 \mathrm{ksi}$, respectively. The primary mode of failure was fiber breakage at the grips resulting in delamination. Section PU-12x0.375 experienced similar results with stresses to failure of 107 ksi. PU-12x0.375 coupons had an average compression failure stress of $53 \mathrm{ksi}$ and 
an average bending failure stress of $105 \mathrm{ksi}$. The unusually low compression stress is likely due to damage to the coupons from cutting.

\subsubsection{Comparison of Polyurethane vs. Vinyl Ester}

From the four-point bending test, PU-16x0.5 compared to VE-16x0.5 had a 17\% higher load to failure, $20 \%$ higher strain to failure, $6 \%$ higher elastic modulus, and 38\% higher energy absorbed to failure. From the crush test, the PU-16x0.5 had a 32\% higher load to failure. Although vinyl ester has a higher modulus and tensile strength, polyurethane has a much higher percent elongation to failure (see Table 4-2). These test results show that polyurethane has a better bond with the glass fibers. Connection test A revealed that VE-16x0.5 had approximately a $25 \%$ lower load to failure. This connection test reveals the higher stiffness of the polyurethane resin as this test resulted in highly local failure, and therefore highly depends on the resin's properties. This could also reveal that the polyurethane is able to bond to the glass fibers as polyurethane is not inherently stiffer than vinyl ester in raw form (see Table 4-2).

\subsection{Theoretical Calculations}

\subsubsection{Theoretical vs. Experimental Data Comparison}

Classical prediction techniques involving lamination theory produced a single bending stiffness which can be quite useful for designers, but experiments showed that a bilinear stressstrain curve results from bending tests whenever sections with high D/t ratios reach high strains. This prediction of bending stiffness is about $3-20 \%$ below the experimental results. In these cases, other techniques must be used to account for the stiffness reduction. A finite element model can be used to incorporate non-linearity, but is not inherently more accurate than the classical lamination theory. Finite element modeling can also give insight into the change of 
shape of thin-walled cylindrical beams, and correlates fairly well in this regard with data obtained from experimentation.

A simple approach to predicting the failure load of composite tubes undergoing bending was presented. This approach accounted for the local buckling/compression effect of each section. The result of this designer friendly approach produced good correlation to experimental results with errors of $+4.1 \%$ for PU-16x0.5, $-4.2 \%$ for VE-16x0.5, $+7.8 \%$ for PU-12x0.5, and $-2.9 \%$. These errors were lower than the errors resulting from conventional bending stress calculations with the exception of the vinyl ester section. The results presented in this paper will be used in upcoming work aimed at equipping designers with equations that can handle stiffness changes due to the ovalization that occurs in the bending of cylindrical orthotropic tubes.

\subsection{Recommendations}

In order to reinforce the conclusions presented in this paper, further work comparing polyurethane to other resin systems should be done. It may be that the pultrusion process is what allows polyurethane to work better than vinyl ester with glass fibers. Scanning electron microscope investigation would be useful to obtain greater details of the bond between glass fibers and polyurethane of tested samples. Simple mechanical tests such as coupon testing with only unidirectional fibers will eliminate other variables and allow more insight into how well polyurethane bonds with glass fibers compared to vinyl ester.

The ability of classical lamination theory had some difficulty predicting the stiffness of the composite tubes. This standard approach typically has better results (Chan \& Demirhan, 2000), but the uncertainty of raw material properties and fiber volume fraction are possible reasons for 
poorer estimation. The local effect probably has an effect on stiffness; hence more work needs to be performed on samples made of pultrusion using high pressure resin infusion in order to confirm the ability of laminate plate theory and predict the bending stiffness. The future work would ideally consist of simple varying fiber layups (more or less off-axis fibers) and varying D/t ratio to pinpoint the primary contributor of local compression effects.

Even though, the proposed failure load prediction expression agreed well with experimental results accounting for the local compression/buckling effects, it would be ideal to apply the same approach to other composite tubes with varying $\mathrm{D} / \mathrm{t}$ ratios and fiber-resin systems. Accounting for the local compression was shown to be better than ignoring it for all sections except vinyl ester. This recommendation shows that special care needs to be taken when using the ductile polyurethane resin. Additional work should focus on modifying the failure load prediction based on material properties of the section such as fiber volume fraction, elastic moduli, Poisson's ratio, etc. This would increase the versatility of the model by being able to adjust for any FRP composite section. 


\section{REFERENCES}

Barbero, E. J. (2011). Introduction to Composite Materials Design. Boca Raton: Taylor and Francis Group.

Brazier, L. G. (1927). On the Flexure of Thin Cylindrical Shells and Other "Thin" Sections. Proceedings of the Royal Society, 104-114.

Chan, W. S., \& Demirhan, K. C. (2000). A Simple Closed-Form Solution of Bending Stiffness for Laminated Composite Tubes. Journal of Reinforced Plastics and Composites, 19, 278-291.

Cheng, S., \& Ho, B. P. (1963, April). Stability of Heterogenous Aeolotropic Cylindrical Shells under Combined Loading. AIAA Journal, 1(4), 892-898.

Elchalakani, M., Zhao, X. L., \& Grzebieta, R. H. (2002). Plastic Mechanism Analysis of Circular Tubes under Pure Bending. International Journal of Mechanical Sciences, 44, 11171143.

Fuchs, H. P., \& Hyer, M. W. (1996). The Nonlinear Prebuckling Response of Short Thin-Walled Laminated Composite Cylinders in Bending. Composite Structures, 34, 309-342.

Ibrahim, S., \& Polyzois, D. (1999). Ovalization analysis of fiber-reinforced plastic poles. Composite Structures, 45, 7-12.

Ibrahim, S., Polyzois, D., \& Hassan, S. K. (2000). Development of Glass Fiber Reinforced Plastic Poles for Transmission and Distribution Lines. Canadaian Journal of Civil Engineering, 27(5), 850-858. 
Jones, M. R. (1969). Buckling of Circular Cylindrical Shells with Different Moduli in Tension and Compression. USAF, Air Force Report: No SAMSO-TR-70-55.

Kedward, K. T. (1978). Nonlinear collapse of thin-walled composite cylinders under flexural loading. International Conference on Composite Materials, (pp. 353-365). Toronto.

Kollár, L. P., \& Springer, G. S. (2003). Mechanics of Composite Structures. Cambridge: Cambridge University Press.

Liang, R., \& GangaRao, H. V. (2004). Applications of Fiber Reinforced Polymer Composites. In R. C. Creese, \& H. GangaRao (Ed.), Polymer Composites for Infrastructure Renewal and Economic Development (pp. 173-187). Morgantown: DEStech Publications.

Masmoudi, R., Mohamed, H., \& Metiche, S. (2008). Finite Element Modeling for Deflection and Bending Responses of GFRP Poles. Journal of Reinforced Plastics and Composites, 27(6), 639-658.

Oswald, T. A., Baur, E., Brinkmann, S., Oberbach, K., \& Schmachtenberg, E. (2006). International Plastics Handbook (4th ed.). Cincinatti, Ohio: Hanser Gardner.

Poonaya, S., Teeboonma, R., \& Thinvongpituk, C. (2009). Plastic Collapse Analysis of ThinWalled Circular Tubes Subjectd to Bending. Thin-Walled Structures, 47, 637-645.

Seide, P., \& Weingarten, V. (1964). On the Buckling of Circular Cylindrical Shells under Pure Bending. Jounral of Applied Mechanics, 28(1), 112-116.

Shadmehri, F., Derisi, B., \& Hoa, S. V. (2011). On Bending Stiffness of Composite Tubes. Composite Structures, 93, 2173-2179. 
Silvestre, N. (2009). Non-classical effects in FRP composite tubes. Composites: Part B, 40, 681697.

Tennyson, R. C. (1975). Buckling of Laminated Cylinders: A Review. Composites, 6(1), 17-24.

Tennyson, R. C., Ghan, K., \& Muggeridge, D. B. (1971). The Effect of Axisymmetric Shape Imperfections on the Buckling of Laminated Anisotropic Circular Cylinders. CASI Transactions, 4, 131-139.

Ueda, S. (1985, March). Moment-Rotation Relationship Considering Flattening of Pipe Due to Pipe Whip Loading. Nuclear Engineering and Design, 85(2), 251-259. 